Aus dem Institut für Pharmakologie und Toxikologie

(Prof. Dr. med. W.-H. Zimmermann)

der Medizinischen Fakultät der Universität Göttingen

\title{
Über die Differenzierung und
}

\section{Charakterisierung von Kardiomyozyten aus induzierten pluripotenten Stammzellen aus Rhesusmakaken in 2D- und 3D-Kulturen}

\author{
INAUGURAL-DISSERTATION \\ zur Erlangung des Doktorgrades \\ der Medizinischen Fakultät der \\ Georg-August-Universität Göttingen
}

vorgelegt von

Arne Benjamin Krahn

aus

Hessisch Lichtenau

Göttingen 2020 
Dekan:

Referent:

Ko-Referent/in:

Drittreferent/in:
Prof. Dr. med. W. Brück

Prof. Dr. med. W.-H. Zimmermann

PD Dr. med. K. Streckfuß-Bömeke

Prof. Dr. med. R. Dressel (Promotor)

Datum der mündlichen Prüfung: 16.11.2021 
Hiermit erkläre ich, die Dissertation mit dem Titel "Über die Differenzierung und Charakterisierung von Kardiomyozyten aus induzierten pluripotenten Stammzellen aus Rhesusmakaken in 2D- und 3D-Kulturen" eigenständig angefertigt und keine anderen als die von mir angegebenen Quellen und Hilfsmittel verwendet zu haben.

Göttingen, den

(Unterschrift) 


\section{$\underline{\text { Inhaltsverzeichnis }}$}

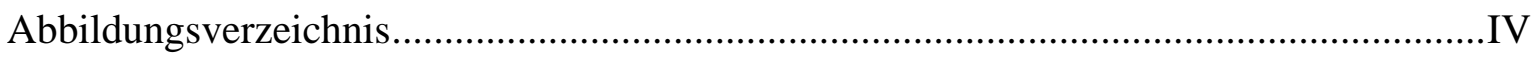

Tabellenverzeichnis ................................................................................................

Abkürzungsverzeichnis........................................................................................... VIII

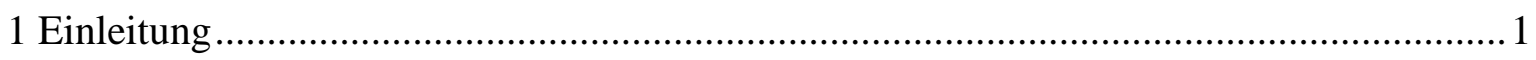

1.1 Stellenwert der Herz-Kreislauferkrankungen ................................................ 1

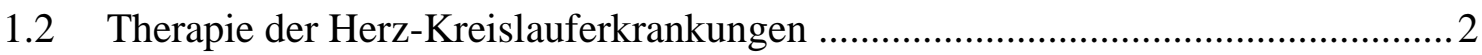

1.3 Tissue Engineering als potenzielle Therapie von Herz-Kreislauferkrankungen......... 3

1.4 Zielsetzung der vorliegenden Arbeit ..................................................................

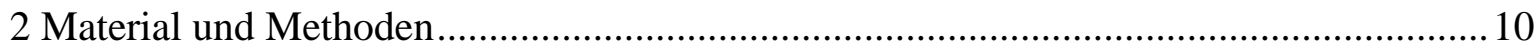

2.1 Kulturmedien, Lösungen und Puffer................................................................. 10

2.2 Immunfluoreszenzfärbungen zur Testung der Antikörperspezifität an Gewebe des

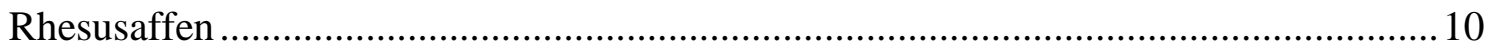

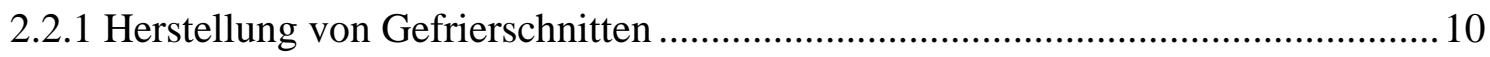

2.2.2 Immunfluoreszenzfärbung von Gefrierschnitten ............................................ 10

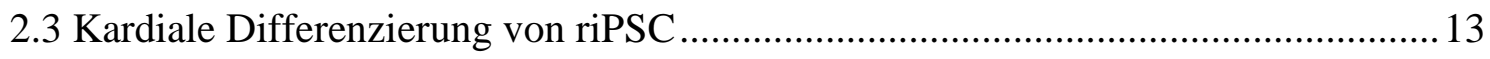

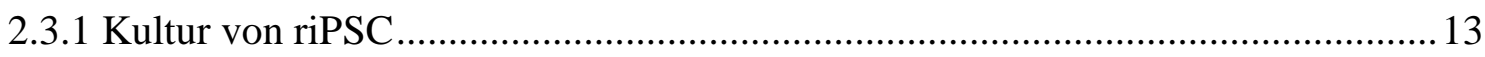

2.3.2 Differenzierung von riPSC zu Kardiomyozyten ............................................ 15

2.3.3 Durchflusszytometrie zur Analyse von riPSC und differenzierten Kardiomyozyten

2.4 Morphologische und funktionelle Charakterisierung differenzierter Kardiomyozyten

2.4.1 Immunfluoreszenzfärbung fixierter Kardiomyozyten zur Analyse der

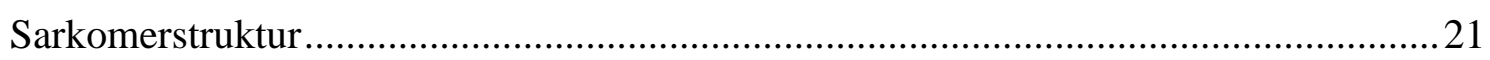

2.4.2 Aufzeichnung zytosolischer Kalziumkonzentration in Kardiomyozyten ..............21

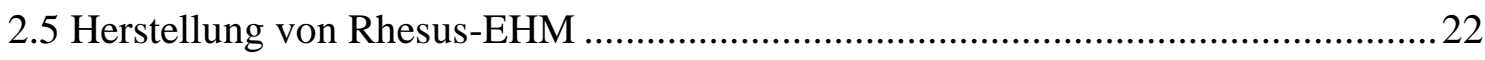

2.5.1 Herstellung von Silikon-Gussformen und Silikonhaltern ................................. 22

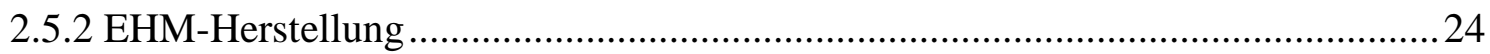


2.6.1 Dissoziierung von EHM für Einzelzellanalysen ...........................................28

2.6.2 Bestimmung des Anteils von Kardiomyozyten in EHM....................................28

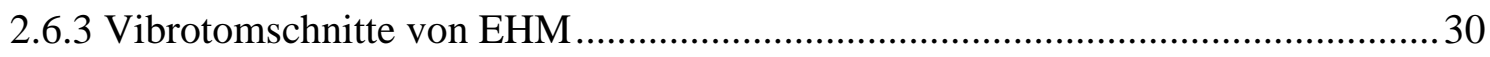

2.6.4 Immunfluoreszenzfärbung von Vibrotomschnitten und kompletten EHM zur

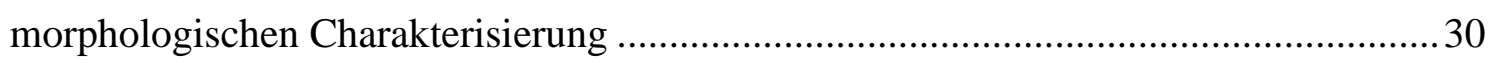

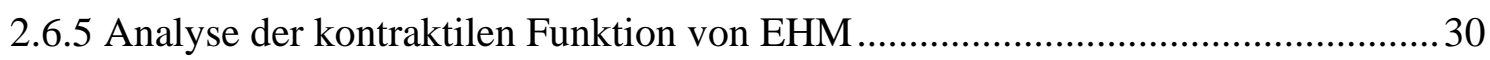

2.6.6 Elektrophysiologische Analysen von EHM zur Untersuchung von

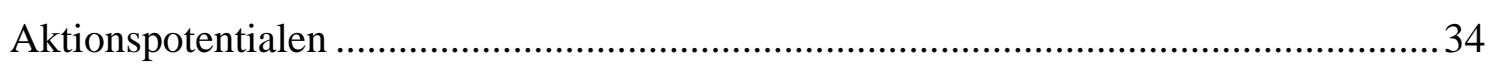

2.7 Messung der Sarkomerlänge in Herzmuskelzellen ............................................... 35

2.8 RNA-Präparation aus schockgefrorenen EHM ................................................ 35

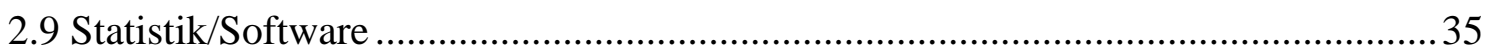

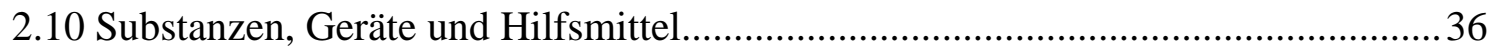

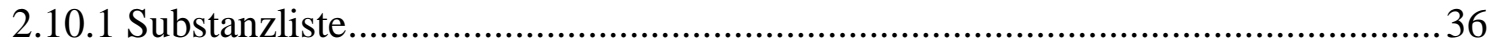

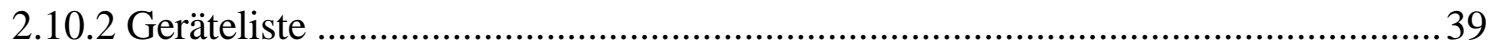

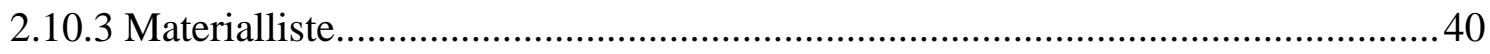

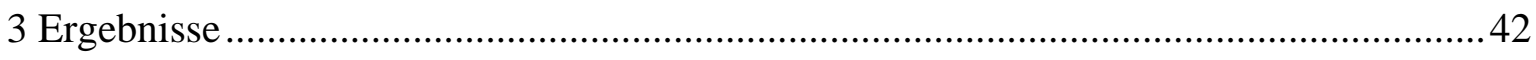

3.1 Testung der Antikörperspezifität an Gewebe aus Rhesusaffen...............................42

3.2 Differenzierung von riPSC zu Kardiomyozyten ............................................. 48

3.2.1 Output und Pluripotenz der riPSC-Kultur................................................. 48

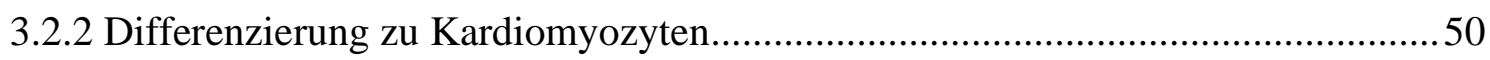

3.3 Morphologische Charakterisierung der differenzierten Kardiomyozyten mittels

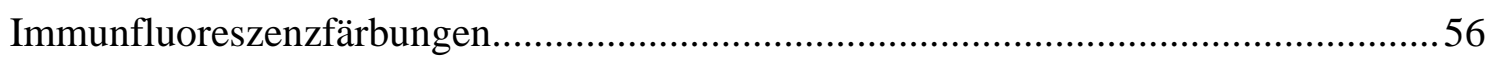

3.4 Funktionelle Charakterisierung der differenzierten Kardiomyozyten mittels

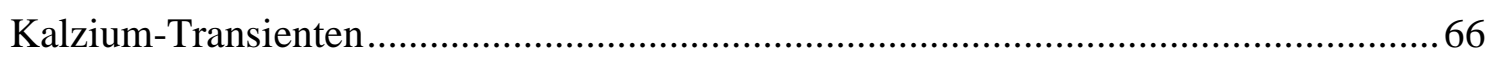

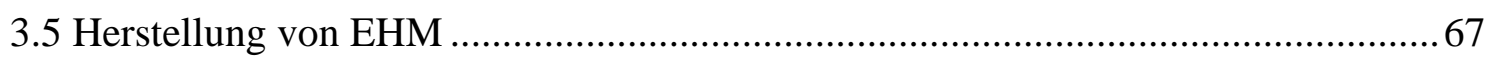

3.6 Morphologische und funktionelle Charakterisierung der EHM ............................6 68

3.6.1 Dissoziierung von EHM und Bestimmung des Kardiomyozytenanteils ...............68

3.6.2 Kontraktionsanalysen zur funktionellen Charakterisierung der EHM..................73 
3.6.3 Elektrophysiologische Charakterisierung mittels Aktionspotentialmessungen in EHM 80

3.6.4 Immunfluoreszenzfärbungen von EHM zur Analyse der dreidimensionalen

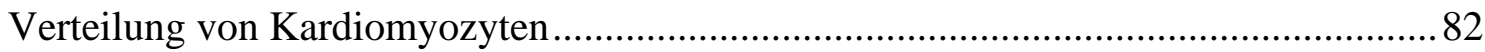

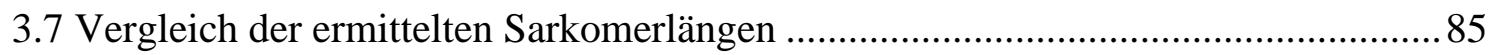

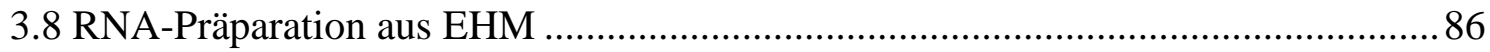

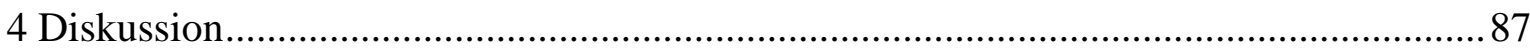

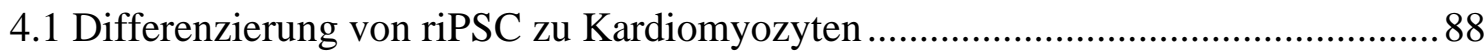

4.2 Herstellung und morphologische Charakterisierung von EHM .............................92

4.3 Funktionelle Charakterisierung von EHM mittels Kontraktionsanalysen ................94

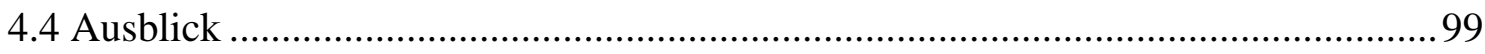

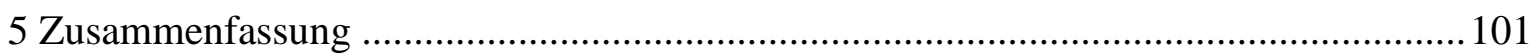

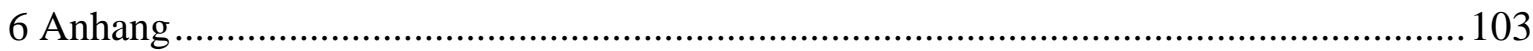

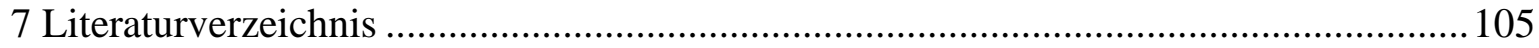




\section{Abbildungsverzeichnis}

$\begin{array}{lll}\text { Abbildung } 1 & \text { Schematische Planung der Arbeit } & 9\end{array}$

$\begin{array}{lll}\text { Abbildung } 2 & \text { Schema des Differenzierungsprotokolls } & 18\end{array}$

Abbildung 3 Setup zur Generierung von EHM 24

Abbildung 4 Zellzählung mittels Stromausschlussverfahren 29

Abbildung $5 \quad$ Setup zur Kontraktionskraftmessung 33

Abbildung $6 \quad$ Schematische Darstellung einer Kontraktionsamplitude 34

Abbildung 7 Immunfluoreszenzfärbung von Herzmuskelgewebe des Rhesus- 43

affen, Verdünnungsreihe des Anti-alpha-Aktinin-Antikörpers

Abbildung 8 Immunfluoreszenzfärbung von Herzmuskelgewebe des Rhesus- 44

affen, Verdünnungsreihe des Anti-alpha-Aktinin-Antikörpers in

Detailaufnahme

Abbildung 9 Negativkontrolle der Immunfluoreszenzfärbung von Herzmuskel- 45 gewebe des Rhesusaffen

Abbildung 10 Immunfluoreszenzfärbung von Herzmuskelgewebe des Rhesus- 46 affen zur Darstellung von Connexin43

Abbildung 11 Immunfluoreszenzfärbung von Skelettmuskelgewebe des Rhesus- 47 affen

Abbildung 12 Vorgehen bei der Auswertung von Ergebnissen der Durchfluss- 49 zytometrie

Abbildung 13 Pluripotenzfaktorenanalyse von riPSC mittels Durchfluss- 50 zytometrie

Abbildung 14 Entwicklung der Zellkultur im Verlauf der Differenzierung 55

Abbildung 15 Immunfluoreszenzfärbung von aus riPSC differenzierten Kardio- 59 myozyten zur Darstellung von $\alpha$-Aktinin (1)

Abbildung 16 Immunfluoreszenzfärbung von aus riPSC differenzierten Kardio- 60 myozyten zur Darstellung von $\alpha$-Aktinin (2)

Abbildung 17 Immunfluoreszenzfärbung von aus riPSC differenzierten Kardio- 61 myozyten zur Darstellung von Connexin43

Abbildung 18 Immunfluoreszenzfärbung von aus riPSC differenzierten Kardio- 62 myozyten zur Darstellung von Myosin 
Abbildung 19 Immunfluoreszenzfärbung von aus riPSC differenzierten Kardio- 63 myozyten zur Darstellung von Tropomyosin

Abbildung 20 Immunfluoreszenzfärbung von aus riPSC differenzierten Kardio- 64 myozyten zu Darstellung von Troponin I

Abbildung 21 Immunfluoreszenzfärbung von aus riPSC differenzierten Kardio- 65 myozyten zur Darstellung von NKX2.5

Abbildung 22 Kalzium-Transienten von aus riPSC differenzierten Kardio- 67 myozyten

Abbildung 23 Frequenzentwicklung in riPSC-EHM 68

Abbildung 24 Beziehung zwischen extrazellulärer Kalziumkonzentration und 75 entwickelter Kraft

Abbildung $25 \quad$ Beziehung zwischen Stimulationsfrequenz und entwickelter Kraft 78

Abbildung 26 Kraftentwicklung unter pharmakologischer Intervention mittels 80 Isoprenalin und Carbachol

Abbildung 27 Aktionspotentialmessungen an Kardiomyozyten aus EHM 81

Abbildung 28 Immunfluoreszenzfärbung von Vibrotomschnitten an EHM 83

Abbildung 29 Immunfluoreszenzfärbung von Vibrotomschnitten an EHM, 84 Vergrößerungsaufnahme aus Abbildung 28

Abbildung 30 Detailaufnahme der Sarkomerstruktur mittels Immunfluoreszenz- 85 färbung von Vibrotomschnitten an EHM 


\section{Tabellenverzeichnis}

Tabelle 1 Zusammensetzung des Blockpuffers 11

Tabelle 2 Primäre Antikörper für die Immunfluoreszenzfärbung 12

Tabelle 3 Sekundäre Antikörper für die Immunfluoreszenzfärbung 13

$\begin{array}{lll}\text { Tabelle } 4 \text { Zusammensetzung des HFF-Mediums } & 14\end{array}$

Tabelle 5 Zusammensetzung des hES-Mediums 14

$\begin{array}{lllllll}\text { Tabelle } 6 & \text { Zusammensetzung } & \text { der } & \text { Zellkulturmedien } & \text { zur } & \text { kardialen } & 17\end{array}$ Differenzierung

$\begin{array}{lll}\text { Tabelle } 7 & \text { Zusammensetzung des Selektionsmediums } & 18\end{array}$

Tabelle 8 Zusammensetzung der Verdaulösung 19

Tabelle 9 Liste der bei der Immunfluoreszenzmarkierung verwendeten 20 primären Antikörper

Tabelle 10 Zusammensetzung der Tyrode-Lösung zur Messung der Kalzium- 22 Transienten

Tabelle 11 Zusammensetzung der Kulturmedien zur EHM-Herstellung 26

Tabelle 12 Zusammensetzung des Master-Mix 27

Tabelle 13 Mischungsverhältnis der EHM-Rekonstitutionsmischung 27

Tabelle 14 Zusammensetzung der Kollagenase-Lösung 28

Tabelle 15 Zusammensetzung der Tyrode-Lösung für die Kontraktionskraft- 32 messung

Tabelle $16 \quad$ Liste der verwendeten Substanzen 36

Tabelle 17 Liste der verwendeten Geräte 39

Tabelle 18 Liste der verwendeten Materialien 40

Tabelle 19 Ergebnisse der Verdünnungsreihe des primären Antikörpers Anti- $\alpha-\quad 42$ Aktinin

Tabelle 20 Ergebnisse der Analyse von Pluripotenzmarkern mittels Durchfluss- 50 zytometrie an riPSC

Tabelle 21 Spezifität der Immunfluoreszenzfärbung von aus riPSC 58 differenzierten Kardiomyozyten

$\begin{array}{lll}\text { Tabelle } 22 \text { Ergebnisse der EHM-Dissoziierung (Input) } & 70\end{array}$

$\begin{array}{lll}\text { Tabelle } 23 & \text { Ergebnisse der EHM-Dissoziierung (Output) } & 71\end{array}$

Tabelle 24 Beziehung zwischen Vordehnung und Kraftentwicklung der EHM 74 
Tabelle 25 Beziehung zwischen extrazellulärer Kalziumkonzentration und 74 entwickelter Kraft

Tabelle 26 Durchschnittliche Kardiomyozytenzahl pro EHM und 76 durchschnittliche, maximale Kraft pro Kardiomyozyt

Tabelle 27 Kraftentwicklung unter pharmakologischer Intervention mittels 79 Isoprenalin und Carbachol

Tabelle 28 Übersicht der Aktionspotentialparameter an Kardiomyozyten aus 82 EHM

Tabelle 29 Analyse der Sarkomerlänge 86

Tabelle 30 Ergebnisse der RNA-Präparation der EHM $(n=6) \quad 86$

Tabelle 31 Vergleich der maximalen Kontraktionskraft pro EHM und pro aus 98 EHM isoliertem Kardiomyozyt

Tabelle A1 Daten zur Beziehung zwischen extrazellulärer 103 Kalziumkonzentration und entwickelter Kontraktionskraft

$\begin{array}{lll}\text { Tabelle A2 Ergebnisse der erfolgreichen Differenzierungsrunden } & 104\end{array}$ 


\section{Abkürzungsverzeichnis}

APD 20/50/90

BMP-2/4

CHIR99021

c-MYC

CPC

DNA

Diff.

DPBS

$\mathrm{dV} / \mathrm{dt}$

EC50

EHM

ESC

FACS

FBS

FGF-2

HEPES

hESC

hiPSC

HFF

IGF-1

iPSC

Klf-4

$\mathrm{L}_{0}$

Lmax

LIN-28

$\mathrm{N}$

Nkx2.5

Oct-4

PSC

$\mathrm{RhFF}$

riPSC

RNA
Aktionspotentialdauer bei 20/50/90-prozentiger Repolarisation bone morphogenetic protein-2/4

glycogen synthase kinase-3 inhibitor

cellular myelocytomatosis oncogene

cardiac progenitor cell

deoxyribonucleic acid

Differenzierung

Dulbecco's phosphate-buffered saline

Spannungsänderung/Zeit

mittlere effektive Wirkkonzentration

engineered heart muscle

embryonic stem cell

fluorescence-activated cell sorting

fetal bovine serum

fibroblast growth factor-2

2-(4-(2-Hydroxyethyl)-1-piperazinyl)-ethansulfonsäure

human embryonic stem cell

human induced pluripotent stem cell

human foreskin fibroblast

insulin-like growth factor 1

induced pluripotent stem cell

Krüppel-like factor 4

EHM ohne Vorspannung

EHM mit maximaler Vorspannung

lineage protein 28

Normal

homeobox protein $N k x 2.5$

octamer-binding transcription factor 4

parthenogenetic stem cell

rhesus foreskin fibroblast

rhesus induced pluripotent stem cell

ribonucleic acid 
ROCK

RT

SIRPA

SOX2

SSEA-1

$\mathrm{T} 1$

$\mathrm{T} 2$

TGF-beta 1

TRA-1-60

TT

VEGF-A

VCAM1 rho-associated protein kinase

resting tension

signal regulatory protein alpha

sex determining region $Y$-box 2

stage-specific embryonic antigen 1

Anspannungszeit

Relaxationszeit

transforming growth factor beta 1

tumor rejection antigen 1-60

twitch tension

vascular endothelial growth factor

vascular cell adhesion protein 1 


\section{Einleitung}

\subsection{Stellenwert der Herz-Kreislauferkrankungen}

Die außerordentliche Bedeutung des Verständnisses und der Behandlung von HerzKreislauferkrankungen zeigt sich anhand aktueller Zahlen zu Mortalität und Morbidität in den Industriestaaten, im Nachfolgenden bezogen auf die Bundesrepublik Deutschland. Erkrankungen dieses Formenkreises nahmen in der Todesursachenstatistik 2015 den ersten Platz mit 356.616 von insgesamt 925.200 Todesfällen ein, noch vor Neubildungen mit 233.752 Todesfällen (Destatis 2017c). Sie sind somit für rund 40\% aller Todesfälle in Deutschland verantwortlich. Im Einzelnen sind die chronische ischämische Herzkrankheit (8\% aller Fälle), der akute Myokardinfarkt (5\%) und die Herzinsuffizienz (5\%) die Haupttodesursachen aus dem Formenkreis Herz-Kreislauferkrankungen (Meinertz et al. 2018). Betrachtet man die Sterbeziffern für das Jahr 2015, also Verstorbene pro 100.000 Einwohner, ergibt sich für die ischämischen Herzkrankheiten ein Wert von 156 (darunter subsummiert werden u. a. die chronische ischämische Herzkrankheit mit 92, gefolgt vom akuten Myokardinfarkt mit 60) und für die Herzinsuffizienz ein Wert von 58. Im Bereich der koronaren Herzkrankheit kam es zwischen 1990 und 2015 zu einer Reduktion der altersstandardisierten Sterbeziffer von 216 auf 144, mutmaßlich bedingt durch Risikoreduktion sowie optimierte Therapie- und Diagnoseverfahren. Auch bei der Herzinsuffizienz zeigt sich ein Abfall der Sterbeziffer in diesem Zeitraum von 123 auf 52, hierunter subsummiert sind jedoch chronische und akute Herzinsuffizienz. Der Mortalitätsrückgang ist hierbei mutmaßlich insbesondere auf eine verbesserte Versorgung der akuten Dekompensation zurückzuführen. Trotz der therapeutischen Erfolge bleibt die durchschnittliche 5-Jahres-Letalität nach Diagnosestellung mit 50\% weiter sehr hoch (Herold 2018; Meinertz et al. 2018). Auch bei Betrachtung der Morbidität wird die Bedeutung dieser Erkrankungsentitäten ersichtlich. Insgesamt kam es 2016 zu 1,7 Mio. stationären Aufnahmen aufgrund von Herzerkrankungen, was einer stationären Morbiditätsziffer von 2076 entspricht (also stationäre Aufnahmen pro 100.000 Einwohner), wobei auch hier die ischämischen Herzkrankheiten mit einer Morbiditätsziffer von 803 und die Herzinsuffizienz mit 555 dominieren (Meinertz et al. 2018). In Bezug auf die Gesamtzahl stationärer Aufnahmen von etwa 20 Millionen verursachten Herzkreislauferkrankungen 2016 mit 2,9 Mio. ebenfalls den größten Anteil (Destatis 2017a). Verfolgt man die Entwicklung der Morbidität dieser Erkrankungen von 1995 bis 2016, ergibt sich 
ein entgegengesetztes Bild. Während die stationäre Morbidität der ischämischen Herzkrankheiten in diesem Zeitraum um 17,9\% abnahm, stieg die der Herzinsuffizienz um 101,5\%. Letzterer Anstieg wird einem allgemeinen Anstieg der Lebenserwartung und dem damit verbundenen längeren Leben mit der zugrundeliegenden kardialen Erkrankung sowie verbesserten Therapien bei ischämischer Herzerkrankung zugeschrieben (Meinertz et al. 2018). Auch volkswirtschaftlich sind die Herzkreislauf-erkrankungen von immenser Bedeutung, so verursachten sie 2015 Krankheitskosten in Höhe von 46 Mrd. Euro und somit $14 \%$ der gesamten Gesundheitskosten in Deutschland. 22 Mrd. Euro entfielen dabei allein auf (teil-)stationäre Versorgung. Damit verursachen sie die höchsten Kosten im deutschen Gesundheitswesen (Destatis 2017b). Zusammenfassend kann festgestellt werden, dass Herzkreislauferkrankungen und insbesondere Herzerkrankungen nicht nur die häufigste Todesursache darstellen, sondern auch die häufigste Ursache stationärer Aufnahmen und verantwortlich für den größten Anteil der Gesundheitskosten aller Krankheitsgruppen in Deutschland sind. Hierbei wird ersichtlich, dass eine Verbesserung der Therapieoptionen, insbesondere der Herzinsuffizienz, unbedingt erforderlich ist.

\subsection{Therapie der Herz-Kreislauferkrankungen}

Durch die terminale Differenzierung der Kardiomyozyten ist jeder Zelluntergang irreversibel und führt dadurch $\mathrm{zu}$ einer Schwächung des Herzmuskels. Ursache ischämischer Herzkrankheiten ist die atherosklerotische Plaque, die nach Ruptur oder Erosion $\mathrm{zu}$ thromboembolischen Ereignissen und durch Verlegung koronarer Äste zum Myokardinfarkt führt. Erfolgt innerhalb von zwei bis vier Stunden keine Wiedereröffnung des verschlossenen Gefäßes, kommt es zum irreversiblen Myokarduntergang (Brandt et al. 2013). Pathophysiologisch liegt eine ischämiebedingte Koagulationsnekrose vor, deren Abräumung durch Entzündungszellen nach 6 bis 24 Stunden beginnt und die ab dem dritten Tag zunehmend durch Granulationsgewebe und kollagene Fasern ersetzt wird. Nach sechs Wochen ist der fibrotische Umbau abgeschlossen (Baba et al. 2012). Auf dem Boden eines Herzinfarktes kann sich eine ischämische Kardiomyopathie und damit langfristig eine meist linksventrikuläre Herzinsuffizienz mit eventuell konsekutiver Globalherzinsuffizienz entwickeln. Weitere Ursachen einer Herzinsuffizienz, insbesondere mit globaler Einschränkung der Kontraktilität, sind der Verlust von kontraktilem Gewebe durch Myokarditis oder toxische Einflüsse (bspw. Alkohol). Bei der Therapie des Herzinfarktes steht, neben anderen Maßnahmen wie der Antikoagulation, die Rekanalisierung des verschlossenen Koronarastes im Mittelpunkt. Therapie der ersten 
Wahl ist die perkutane Koronarintervention innerhalb von 90 Minuten (Brandt et al. 2013). Die medikamentöse Standardtherapie der linksventrikulären Herzinsuffizienz besteht aus Hemmern des Renin-Angiotensin-Systems, Betarezeptorenblockern, Diuretika (Thiazide, Schleifendiuretika) sowie Mineralokortikoidrezeptor-Inhibitoren und setzt an den Punkten Nachlastsenkung, Schutz vor beta-adrenerger Überstimulation und Volumenreduktion zur Vorlastsenkung an. Rein symptomatisch werden Herzglykoside eingesetzt, die einen negativ chronotropen sowie positiv inotropen Effekt erzielen. Einzig kausale Therapie ist bislang die Herztransplantation, die bei schwerer Herzinsuffizienz und bereits maximal eskalierter medikamentöser Therapie indiziert ist und gute Resultate mit einer 5-JahresÜberlebensrate von $70 \%$ bis $80 \%$ zeigt, jedoch durch den Mangel an Spenderorganen limitiert ist (Brandt et al. 2013). So standen 2018 in Deutschland einer bereits sehr restriktiven Abfrage von 719 Spenderorganen lediglich 318 Transplantate gegenüber (Eurotransplant International Foundation 2018). So genannte Kunstherzen, wie das left ventricular assist device, können im Notfall durch mechanische Unterstützung der Pumpfunktion des Herzens die Zeit bis zur Transplantation überbrücken (Brandt et al. 2013), gehen aber mit erheblichen Nebenwirkungen (u. a. Schlaganfall, Blutungen, Infektionen) einher.

\subsection{Tissue Engineering als potenzielle Therapie von Herz-Kreislauferkrankungen}

Um den Engpass an therapeutischen Optionen zu überkommen, wird seit etwa 20 Jahren an der Entwicklung zellbasierter Verfahren zur Remuskularisierung des Herzens gearbeitet (Karikkineth und Zimmermann 2013). Hierzu zählt auch das kardiale tissue engineering als Methode für die Herstellung von Herzgewebe im Labor für eine Anwendung als Gewebeersatz. Dieses strebt die Generierung von funktionellem Herzgewebe in vitro, eine nachfolgende Qualitätskontrolle insbesondere in Bezug auf kontraktile Parameter ex vivo sowie eine Implantation in vivo an. Ziel ist dabei eine Verbesserung der Kontraktionskraft bei manifester Herzinsuffizienz (Zimmermann 2009). Über tissue engineering hergestellte Herzgewebe müssen multiple Anforderungen erfüllen: Primär müssen künstliche Herzgewebe kontraktile Eigenschaften des natürlichen Herzmuskels zeigen. Des Weiteren müssen künstliche Herzgewebe funktionell integrierbar sein, um die Kontraktionskraft des Empfängerherzens zu stärken. Zuletzt ist zu bedenken, dass sie v. a. bei Anwendung in pädiatrischen Patienten mit dem Empfängergewebe mitwachsen und lebenslang funktionell bleiben müssen (Taylor et al. 2014). Die Herstellung künstlicher Herzgewebe benötigt typischerweise zwei Hauptkomponenten: (1) ein Matrix-Grundgerüst im Sinne der kar- 
dialen extrazellulären Matrix, häufig auch als scaffold bezeichnet, und (2) Zellen, um die kontraktile Funktion des Herzgewebes zu unterhalten.

Das scaffold kann synthetischen oder organischen Ursprungs sein, dabei reichen die eingesetzten Materialien von Kollagen und Fibrin bis hin zu von Zellen befreiter nativer extrazellulärer Matrix (Zimmermann 2009). Geeignete Materialien müssen folgende Kriterien erfüllen: (1) mechanische Stabilität bei gleichzeitiger Flexibilität und Dehnbarkeit, (2) Bereitstellung eines Mikromilieus, das $\mathrm{zu}$ Zelldifferenzierung und -reifung anregt und dabei freie Diffusion zulässt, um den hohen Nährstoff- und Sauerstoffbedarf von Herzgewebe zu decken und (3) Unterstützung einer parallelen Ausrichtung der Kardiomyozyten im 3D-Design, zwecks gerichteter Kontraktilität. Zudem sollten sie (4) ungiftig, biodegradierbar und resorbierbar sowie biokompatibel sein. Ein Ziel ist dabei der Ersatz des scaffolds durch endogene extrazelluläre Matrix nach Integration in das Empfängergewebe (Zimmermann und Eschenhagen 2003; Taylor et al. 2014).

Für die Besiedlung von scaffolds werden heute im Wesentlichen folgende Zelltypen diskutiert: (1) kardiale Progenitorzellen (CPC), (2) Herzmuskelzellen aus embryonalen Stammzellen (ESC), (3) Herzmuskelzellen aus induzierten pluripotenten Stammzellen (iPSC) oder (4) Herzmuskelzellen aus parthenogenetischen Stammzellen (PSC). Pluripotente Stammzellen (2-4) bieten den Vorteil einer nahezu unbegrenzten Vermehrbarkeit. iPSC sind durch künstliche Reprogrammierung von differenzierten somatischen Zellen hergestellte pluripotente Stammzellen. Takahashi und Yamanaka generierten erstmals in 2006 iPSC durch retrovirale Transduktion der Pluripotenzfaktoren Oct-3/4, SOX2, c-MYC und Klf-4 in Fibroblasten der Maus. In der Folge konnte die Adaptation der Technik der iPSC-Generierung auf humane (Takahashi et al. 2007) und nichthumane Primatenzellen gezeigt werden (Liu et al. 2008; Zhong et al. 2010; OkaharaNarita et al. 2012; Wunderlich et al. 2014). iPSC bieten grundsätzlich die Möglichkeit einer autologen Anwendung, die aber aufgrund des langen Prozesses der Stammzellgewinnung und Charakterisierung nicht für den Einsatz in schwer kranken Patienten mit einer stark eingeschränkten Lebenserwartung geeignet ist. Die allogene Transplantation von Zellen und künstlichen Geweben erscheint daher aus heutiger Sicht bei Patienten mit Herzmuskelschwäche der einzig sinnvoll gangbare Weg. 
Bei der Differenzierung pluripotenter Stammzellen $\mathrm{zu}$ Kardiomyozyten können grundsätzlich zwei Verfahren unterschieden werden, die spontane und die gerichtete Differenzierung. Um eine spontane Differenzierung zu erzielen, kann FBS enthaltendes Medium unter Ko-Kultur von zum Beispiel inaktivierten murinen embryonalen Fibroblasten verwendet werden. Bei diesem Verfahren werden jedoch nur geringe und für die Verwendung im Rahmen des tissue engineering ungenügende Anteile von 10-25\% Herzmuskelzellen erreicht (Kehat et al. 2001; Zimmermann et al. 2015). Um die benötigte höhere Kardiomyozytenausbeute zu erlangen, ist hingegen eine gerichtete Differenzierung unabdingbar. Dabei wird die natürliche Kardiogenese mittels Verwendung verschiedener Wachstumsfaktoren beziehungsweise small molecules wie Activin A, FGF-2, BMP-4, VEGF-A und dickkopf-related-protein 1 (DKK1) nachgeahmt. Auf diese Weise können Anteile kardialer Zellen von über 50\% erreicht werden. Diese Zellpopulationen können dann im Folgenden durch verschiedene Selektionsverfahren, u.a. der metabolischen Selektion, noch weiter aufgereinigt werden (Zimmermann et al. 2015). Die auch in dieser Arbeit verwendete metabolische Selektion nutzt die Tatsache, dass Laktat vornehmlich von Kardiomyozyten verstoffwechselt werden kann. Insbesondere fetale Herzmuskelzellen nutzen dieses als Hauptenergiequelle, wohingegen nichtkardiale Zellen, darunter auch undifferenzierte Stammzellen, auf andere Energieträger angewiesen sind. Aus diesem Grund kann ein laktathaltiges, glukosefreies Medium zur kardialen Selektion genutzt werden (Tohyama et al. 2013).

Der Wnt/ß-catenin-Signalweg gilt als zentraler Regulator der Kardiogenese. Paige et al. (2010) zeigten, dass seine Aktivierung zur frühen Mesoderminduktion führt. Dabei induzieren Activin A und BMP-4 die Expression von Wnt-Liganden. CHIR 99021, ein potenter Aktivator des Wnt-Signalweges mittels Suppression von GSK-3, potenziert diesen Effekt. Lian et al. (2012) wiesen dessen Potential zur Induktion kardialer, Is11- und NKX2.5-positiver Progenitorzellen nach. Eine frühe Wnt-Inhibition hingegen, ebenso wie eine späte Wnt-Aktivierung, verhindert die kardiale Differenzierung. Aus diesem Grund ist eine biphasische Wnt-Modulation nötig, bestehend aus früher Aktivierung und späterer Suppression. Die Zugabe von IWP-4 an Tag drei der Differenzierung, einem effektiven Wnt-Inhibitor, der Sekretion und Aktivität von Wnt blockiert, erhöhte drastisch die Effizienz einer kardialen Differenzierung. Dabei ist der Wechsel von Aktivierung zu Inhibition nur innerhalb eines schmalen Zeitfensters effektiv (Paige et al. 2010). 
Zur Züchtung kardialen Gewebes im Rahmen des tissue engineering gibt es derzeit generell vier verschiedene Ansätze:

Bei der ersten Methode wird die Besiedelung von vorgeformten Matrizes mit Zellen in Form eines Patches zur Ersetzung infarzierten Gewebes angestrebt. Diese Matrizes bestehen beispielsweise aus Polyglykolsäure (Bursac et al. 1999), Gelatine (Li et al. 1999), Alginat (Leor et al. 2000) oder Kollagen (Bursac et al. 1999; Kofidis et al. 2002). Bereits 1999 konnte gezeigt werden, dass sich gezüchtete Transplantate in natives Gewebe integrieren können und kontraktile Funktionen zeigen ( $\mathrm{Li}$ et al. 1999). Erstmalig implantierten Yanagawa et al. (2014) einen azellulären Patch beim Menschen, der aus von Zellen befreiter intestinaler Submukosa des Schweins bestand, auf ein ventrikuläres Aneurysma und erreichten eine Integration und sogar eine Verbesserung der kontraktilen Funktion des Empfängermyokards. Auch ein rein zellulärer Patch wurde bereits von Noguchi et al. (2016) vorgestellt, dieser wurde durch die Verschmelzung vieler kleiner kugelförmiger Zellverbände aus neonatalen Kardiomyozyten der Ratte, humanen Fibroblasten und Endothelzellen gebildet und entwickelte synchronisierte Kontraktionen.

Ein weiterer Ansatz ist die Fusion übereinandergelegter Monolayer aus Kardiomyozyten. Shimizu et al. (2002) stellten diesen Ansatz erstmalig vor und konnten zeigen, dass es zu einer elektrischen Kopplung zwischen den einzelnen Schichten und spontanen synchronisierten Kontraktionen kam, sowohl in vitro als auch in vivo.

Das nächste Prinzip strebt die Züchtung eines kompletten Organs an, dies ist jedoch bisher nur durch zelluläre Aussaat auf Organgerüste möglich und stellt damit eigentlich eine Erweiterung des ersten Ansatzes dar. Ott et al. (2008) zeigten die Machbarkeit eines solchen Ansatzes, indem sie Rattenherzen durch Perfusion mit verschiedenen Detergenzien von Zellen befreiten und das Organgerüst mit neonatalen Rattenkardiomyozyten erneut besiedelten und die Wiederherstellung einer kontraktilen Funktion nachwiesen. In der Folge gelang Lu et al. (2013) die Besiedelung dezellularisierter Mausherzen mit aus humanen iPSC differenzierten kardialen Progenitorzellen, die ebenfalls Kontraktilität und eine Reaktion auf pharmakologische Stimuli zeigten. Letztere blieben jedoch auf einem sehr niedrigen Niveau, was vermutlich einer mangelnden elektrischen Kopplung und dem Fehlen eines Reizleitungssystem geschuldet war. 
Des Weiteren ist es möglich, Zellen in initial flüssigem Kollagen Typ 1 und Komponenten der extrazellulären Matrix, welche hier als Trägersubstanzen dienen, aufzunehmen und nach Aushärtung dreidimensionale Gewebe zu erhalten. Eschenhagen et al. (1997) zeigten die Machbarkeit eines solchen Ansatzes unter Verwendung embryonaler Kardiomyozyten des Huhnes und zeigten an ihren mattenförmigen Geweben synchronisierte spontane Kontraktionen. Parallel konnte die Funktionstüchtigkeit dieses Modells, unter kontinuierlicher Optimierung, auch für neonatale Rattenkardiomyozyten nachgewiesen werden (Zimmermann et al. 2000; Zimmermann et al. 2002b). In der Folge wurde das Prinzip auf Herzmuskelzellen aus humanen ESC (Soong et al. 2012), humanen iPSC (Streckfuss-Bömeke et al. 2013) oder murinen PSC (Didié et al. 2013) übertragen. Es wurde gezeigt, dass diese - engineered heart muscles (EHM) genannten - Gewebe ebenso in Ringform erzeugt werden können, wie ursprünglich für ein Rattenmodell berichtet (Zimmermann et al. 2000). Nach EHM-Implantation im Rattenmodell konnte eine elektrische Kopplung zwischen Implantat und Empfänger sowie eine Verbesserung der systolischen und diastolischen Funktion infarzierter Rattenherzen nachgewiesen werden (Zimmermann et al. 2006). EHM versprechen eine breite Anwendbarkeit im Bereich der Gewebeersatztherapie, bei In-vitro-Studien zur kardialen Funktion und im Rahmen der Arzneimitteltestung. Vor einem klinischen Einsatz gilt es jedoch, etwaige Nebenwirkungen, insbesondere eine potentielle Tumorigenität der Stammzellen und eine mögliche Arrhythmogenität des implantierten Gewebes - durch mögliche ReentryMechanismen oder eine dem EHM intrinsische Schrittmacheraktivität - zu evaluieren (Karikkineth und Zimmermann 2013). Um Sicherheit und Effektivität zu prüfen, müssen EHM in einem Großtiermodell, welches eine dem Menschen vergleichbare Physiologie und Immunologie aufweist, als Allotransplantat getestet werden. Ein solches stellt der Rhesusaffe (Macaca mulatta) dar. In anderen Großtieren (u. a. Schwein, Hund und Schaf) besteht heute keine Möglichkeit, pluripotente Stammzellen für die Herzmuskelgenerierung zu gewinnen.

\subsection{Zielsetzung der vorliegenden Arbeit}

Die vorliegende Arbeit strebt aus diesem Grund die Adaption der Techniken der EHMGenerierung auf aus Stammzellen differenzierte Kardiomyozyten des Rhesusaffen und damit die Entwicklung eines Großtiermodells des kardialen tissue engineerings an und versucht folgende, ihr zugrundeliegende Hypothesen zu überprüfen: 
Induzierte pluripotente Stammzellen des Rhesusaffen (Macaca mulatta - riPSC) können in vitro zu Kardiomyozyten mit morphologischen und funktionellen Eigenschaften von nativen Kardiomyozyten differenziert werden.

\section{Aus riPSC differenzierte Kardiomyozyten können zur Herstellung von engineered heart muscles (EHM) verwendet werden}

Die Arbeit folgte dabei den nachfolgenden Schritten: Zuerst wurden Protokolle für die Immunfluoreszenzfärbung von Muskelproteinen in nativem Gewebe des Rhesusaffen getestet. Anschließend erfolgte eine Differenzierung von riPSC zu Kardiomyozyten nach Alginateinschluss und auf Basis definierter pharmakologischer Stimuli mit einer anschließenden Aufreinigung der Kardiomyozyten durch eine metabolische Selektion. Die Reinheit der Kardiomyozyten wurde durch Analysen mittels Durchflusszytometrie auf Basis zellspezifischer Immunfluoreszenzfärbungen quantifiziert. Daraufhin erfolgte eine morphologische Charakterisierung der Kardiomyozyten durch Immunfluoreszenzmarkierung kardiomyozytenspezifischer sarkomerischer Proteine und Interzellularkontakte sowie eine funktionelle Charakterisierung durch Messung von intrazellulären Kalziumkonzentrationen während des Kontraktionszyklus (sogenannte Kalziumtransienten) mittels kalziumsensitiver Farbstoffe. Daraufhin wurden EHM mittels aus riPSC differenzierten Kardiomyozyten hergestellt und deren kontraktile Funktion mittels Kontraktionskraftmessungen evaluiert. Anschließend erfolgte eine funktionelle Charakterisierung der EHM mittels Ableitung von Aktionspotenzialen und eine Analyse der Morphologie der EHM durch Immunfluoreszenzfärbungen an Vibrotomschnitten. Zuletzt wurde die Menge der in den EHM gebildeten RNA ermittelt. 
Induzierte pluripotente Stammzellen des Rhesusaffen

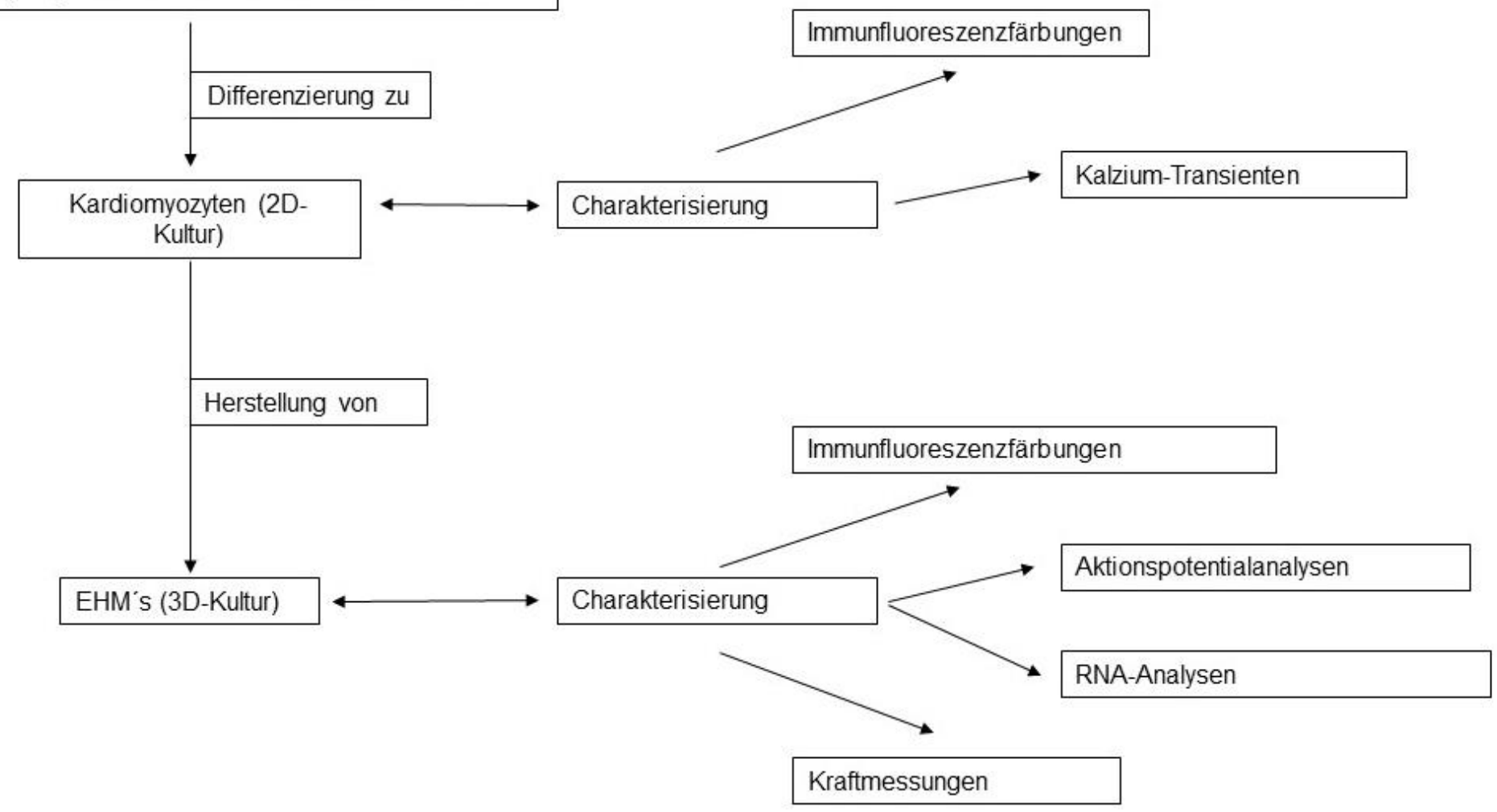

\section{Abbildung 1: Schematische Planung der Arbeit.}




\section{Material und Methoden}

\section{$\underline{2.1 \text { Kulturmedien, Lösungen und Puffer }}$}

Die im Rahmen dieser Arbeit verwendeten Kulturmedien, Lösungen und Puffer wurden nach den im Text aufgeführten Protokollen hergestellt. Diese werden jeweils bei erstmaliger Erwähnung eingeführt.

2.2 Immunfluoreszenzfärbungen zur Testung der Antikörperspezifität an Gewebe des Rhesusaffen

\subsubsection{Herstellung von Gefrierschnitten}

Herzmuskel- und Skelettmuskelgewebe des Rhesusaffen (Bereitstellung durch Prof. R. Behr, Deutsches Primatenzentrum) wurden in 4\%-Formaldehyd fixiert und über Nacht bei $4^{\circ} \mathrm{C}$ in 30-prozentiger Saccharose-Lösung auf Basis von DPBS gefriergeschützt. Am nächsten Tag wurden die Muskelpräparate in Förmchen gegeben und auf einer mit flüssigem Stickstoff gekühlten Platte in Tissue Tek O.C.T. TM compound eingebettet. Nach Aushärtung wurden sie mit einem Kryotom der Firma Leica mit $10 \mu \mathrm{m}$ Schnittdicke bei einer Kammertemperatur von $-22^{\circ} \mathrm{C}$ und einer Objekttemperatur von $-20^{\circ} \mathrm{C}$ geschnitten und auf Objektträger gezogen. Anschließend wurden sie bis zur weiteren Verwendung bei $-20^{\circ} \mathrm{C}$ aufbewahrt.

\subsubsection{Immunfluoreszenzfärbung von Gefrierschnitten}

Die Gewebeschnitte auf den Objektträgern wurden für 15 Minuten bei Raumtemperatur inkubiert und anschließend mit DPBS rehydriert. Nach 30 Minuten in Blockpuffer wurden die Schnitte mit Parafilmstreifen abgedeckt. Anschließend wurden $125 \mu 1$ einer vorbereiteten Antikörper-Lösung, bestehend aus Blockpuffer und dem jeweiligen primären Antikörper in entsprechender Verdünnung, hinzugegeben. Als primäre Antikörper wurden Anti- $\alpha$-Aktinin in einer Verdünnung von 1:250, 1:500 und 1:1000 sowie Anti-Connexin-43 in einer Verdünnung von 1:250 verwendet (siehe Tabelle 2). 
Tabelle 1: Zusammensetzung des Blockpuffers.

\begin{tabular}{|l|c|}
\hline Blockpuffer & \\
\hline DPBS (ohne Ca2+/Mg2+) & $500 \mathrm{ml}$ \\
\hline FCS & $25 \mathrm{ml}$ \\
\hline BSA (bovines Serumalbumin) & $5 \mathrm{ml}$ \\
\hline TritonX-100 & $2,5 \mathrm{ml}$ \\
\hline
\end{tabular}

Zur Markierung von Zellkernen (DNA) wurde Hoechst-Lösung des Herstellers BD Biosciences in einer Verdünnung von 1:1.000 verwendet und zusammen mit den sekundären Antikörpern hinzugegeben. Der enthaltene Farbstoff Bisbenzimidazol bindet spezifisch doppelsträngige DNA (Müller und Gautier 1975).

Nun folgte eine Inkubation bei $4^{\circ} \mathrm{C}$ über Nacht, unter erneuter Verwendung von Parafilmstreifen in einer feuchten Kammer, um das Austrocknen der Präparate zu verhindern. Am folgenden Tag wurden die Schnitte einmal mit Blockpuffer gespült und dann dreimal für jeweils 15 Minuten mit selbigem bei Raumtemperatur inkubiert. Daraufhin folgte eine einstündige Inkubation mit einer Antikörperlösung aus Blockpuffer und Anti-Maus-IgG Alexa Fluor 488 als sekundärem Antikörper (siehe Antikörper und Verdünnung in Tabelle 3) bei Raumtemperatur im Dunkeln. Zusammen mit den sekundären Antikörpern wurde mit Alexa Fluor 546 konjugiertes Phalloidin (Thermo Fisher Scientific) in einer Verdünnung von 1:60 verwendet. Phalloidin bindet filamentäres Aktin und erlaubt eine Zelltypidentifikation anhand der visualisierten Aktin-Organisation. Nach erneutem Spülen und Inkubation (3 min) mit Blockpuffer sowie einmaligem Spülen mit DPBS wurden die Gewebeschnitte in Fluoromount-G zur Fluoreszenzprotektion eingebettet. Die mikroskopische Analyse der Präparate erfolgte mit einem LSM 710/NLO Mikroskop (Zeiss). 
Tabelle 2: Primäre Antikörper für die Immunfluoreszenzfärbung.

\begin{tabular}{|c|c|c|c|c|c|c|c|}
\hline Antikörper & Anti- $\alpha$-Aktinin & $\begin{array}{c}\text { Anti- } \\
\text { Connexin-43 }\end{array}$ & Anti-GATA4 & $\begin{array}{l}\text { Anti-MF20 } \\
\text { (Myosin) }\end{array}$ & Anti-NKX2.5 & $\begin{array}{c}\text { Anti-kardiales } \\
\text { Troponin I }\end{array}$ & $\begin{array}{c}\text { Anti- } \\
\text { sarkomerisches } \\
\text { Tropomyosin }\end{array}$ \\
\hline Spezies & Maus & Maus & Hase & Maus & Hase & Hase & Maus \\
\hline Antikörperklasse & IgG1 & IgG1 & $\operatorname{IgG}$ & $\operatorname{IgG} 2 b$ & IgG & IgG & IgG1 \\
\hline Verdünnung & $1: 250$ & $1: 250$ & $1: 500$ & $1: 200$ & $1: 500$ & $1: 200$ & $1: 50$ \\
\hline Klon & EA-53 & $\begin{array}{c}\text { 2/Connexin- } \\
43\end{array}$ & Polyklonal & Monoklonal & Polyklonal & Polyklonal & $\mathrm{C} 1$ \\
\hline Firma & Sigma-Aldrich & $\begin{array}{c}\text { BD } \\
\text { Pharmingen }\end{array}$ & Abcam & $\begin{array}{l}\text { Developmental } \\
\text { Studies } \\
\text { Hybridoma Bank }\end{array}$ & abcam & $\begin{array}{c}\text { Santa Cruz } \\
\text { Biotechnology, } \\
\text { Inc. }\end{array}$ & Sigma Aldrich \\
\hline Artikelnummer & A7811 & 610062 & $a b 84593$ & AB-2147781 & ab35842 & sc-15368 & T9238 \\
\hline
\end{tabular}


Tabelle 3: Sekundäre Antikörper für die Immunfluoreszenzfärbung.

\begin{tabular}{|c|c|c|c|}
\hline Antikörper & $\begin{array}{c}\text { Anti-Maus-IgG } \\
\text { Alexa Fluor 488 }\end{array}$ & $\begin{array}{c}\text { Anti-Hase-IgG } \\
\text { Alexa Fluor 488 }\end{array}$ & $\begin{array}{c}\text { Anti-Hase-IgG } \\
\text { Alexa Fluor 546 }\end{array}$ \\
\hline Spezies & Ziege & Ziege & Ziege \\
\hline Antikörperklasse & IgG (Polyklonal) & IgG (Polyklonal) & IgG (Polyklonal) \\
\hline Verdünnung & $1: 1000$ & $1: 1000$ & $1: 1000$ \\
\hline Firma & $\begin{array}{c}\text { Thermo Fischer } \\
\text { Scientific } \\
\text { Invitrogen }\end{array}$ & $\begin{array}{c}\text { Thermo Fischer } \\
\text { Scientific Invitrogen }\end{array}$ & $\begin{array}{c}\text { Thermo Fischer } \\
\text { Scientific } \\
\text { Invitrogen }\end{array}$ \\
\hline Label & Alexa Fluor 488 & Alexa Fluor 488 & Alexa Fluor 546 \\
\hline Artikelnummer & A11001 & A11034 & A11010 \\
\hline
\end{tabular}

\section{$\underline{2.3 \text { Kardiale Differenzierung von riPSC }}$}

\subsubsection{Kultur von riPSC}

In dieser Arbeit wurde die von Dr. M. Tiburcy etablierte und freundlicherweise bereitgestellte riPSC-Zelllinie C1 (riPSC-C1) verwendet. Diese wurde mittels retroviraler Transduktion von Hautfibroblasten aus dem Rhesusaffen unter Verwendung von Oct-4, cMYC, Klf-4, SOX2, Nanog und LIN-28 hergestellt. riPSC-C1, in der Folge vereinfachend riPSC bezeichnet, wurden zum Erhalt der Pluripotenz auf humanen Vorhautfibroblasten (HFF-1; ATCC ${ }^{\circledR}$ SCRC-1041 ${ }^{\mathrm{TM}}$ ) kultiviert.

\subsubsection{Kultur humaner Vorhautfibroblasten}

Post-mitotische HFF-1 (durch gamma-Strahlung - 30 Gy) wurden in 9 ml HFF-Medium aufgenommen und anschließend bei 300 x g für fünf Minuten zentrifugiert. Der Überstand wurde abgenommen und das Zellpellet in $13 \mathrm{ml}$ HFF-Medium resuspendiert. Drei Millionen post-mitotische HFF-1 wurden pro T75-Kulturflasche ausplatiert. Nach ein bis zwei Tagen wurden diese Fibroblasten als Feeder-Zellen zur Unterstützung der riPSCKultur genutzt. 
Tabelle 4: Zusammensetzung des HFF-Mediums.

\begin{tabular}{|l|c|c|}
\hline HFF-Medium \\
\hline DMEM & & $500 \mathrm{ml}$ \\
\hline Penicillin/Streptomycin $\quad$ (Pen/Strep; $10.000 \quad \mathrm{U} / \mathrm{ml} /$ & $5,9 \mathrm{ml}(100 \mathrm{U} / \mathrm{ml} /$ \\
$10.000 \mu \mathrm{g} / \mathrm{ml})$ & & $100 \mu \mathrm{g} / \mathrm{ml})$ \\
\hline FBS & & $87,2 \mathrm{ml}$ \\
\hline
\end{tabular}

\subsubsection{Passagieren von riPSC}

In der Regel sieben Tage nach Ausplatierung wurden die riPSC passagiert. Dazu wurden die Zellen mit $3 \mathrm{ml}$ TrypLE gewaschen und anschließend mit erneut $3 \mathrm{ml}$ TrypLE für drei Minuten im Inkubator vereinzelt. Anschließend wurde die enzymatische Wirkung des TrypLE mit $9 \mathrm{ml}$ humanem embryonalem Stammzellmedium (hES-Medium) inhibiert und die Kulturflasche einige Male damit gespült. Die so entstandene Zellsuspension wurde mit einer Pipette aspiriert und in einem Reaktionsgefäß aufgenommen. Nach Zentrifugation für vier Minuten bei 300 x g wurde das Zellpellet in $10 \mathrm{ml}$ hES-Medium aufgenommen und jeweils etwa 950.000 Zellen in einer mit bestrahlten HFF-1 bewachsenen T75er-Flasche ausgesät. An Tag null, dem Tag des Passagierens, wurden 30 ml hES-Medium hinzugegeben, ab Tag drei wurde das Medium dann zur Hälfte $(15 \mathrm{ml})$ ausgetauscht.

Tabelle 5: Zusammensetzung des hES-Mediums.

\begin{tabular}{|l|c|}
\hline \multicolumn{2}{|l|}{ Humanes embryonales Stammzellmedium (hES-Medium) } \\
\hline KnockOut DMEM & $500 \mathrm{ml}$ \\
\hline KnockOut-Serum-Replacement & $130 \mathrm{ml}$ \\
\hline MEM-NEAA (100X) & $6,5 \mathrm{ml}$ \\
\hline L-Glutamin 200 mmol/l & $6,5 \mathrm{ml}(2 \mathrm{mmol} / \mathrm{l})$ \\
\hline Penicillin/Streptomycin (Pen/Strep; 10.000 U/ml / & $6,5 \mathrm{ml} \mathrm{(100} \mathrm{U/ml} \mathrm{/}$ \\
$10.000 \mu \mathrm{g} / \mathrm{ml})$ & $100 \mu \mathrm{g} / \mathrm{ml})$ \\
\hline FGF-2 & $10 \mathrm{ng} / \mathrm{ml}$ \\
\hline
\end{tabular}




\subsubsection{Differenzierung von riPSC zu Kardiomyozyten}

Weil die Differenzierung der riPSC zu Herzmuskelzellen unter für den Menschen gut etablierten Bedingungen (Tiburcy et al. 2017) nicht erfolgreich war, wurde eine Methode zur Differenzierung nach Einkapselung in einer Alginat-Gelatine-Hülle erprobt. Das hier verwendete Protokoll wurde in Anlehnung an eine Arbeit von Sidhu et al. (2012) entwickelt.

\subsubsection{Alginat-Gelatine-Lösung für die Zelleinkapselung}

Zur Herstellung einer 1,1-prozentigen Alginat-Lösung wurden 0,275 g Alginatpulver in $25 \mathrm{ml}$ einer sterilen 0,1-prozentigen Gelatine-Lösung aufgelöst, 30 Sekunden vermischt (Vortex) und über Nacht auf einem Wippschüttler bei Raumtemperatur inkubiert. Die Gelatine-Lösung wurde durch Zugabe von 0,5 g Gelatine zu $500 \mathrm{ml}$ Wasser hergestellt und zur Sterilisation autoklaviert. Am nächsten Tag wurden 2,778 ml einer 9-prozentigen sterilen Natriumchlorid-Lösung hinzugegeben. Nach Vermischen (30 Sekunden, Vortex) und Zentrifugation bei $95 \mathrm{x}$ g für fünf Minuten wurde die so hergestellte Alginat-GelatineLösung zur Sterilisierung mit einem Spritzenfiltersystem filtriert. Die Alginat-GelatineLösung war für ein bis zwei Monate bei $4^{\circ} \mathrm{C}$ stabil verwendbar. Durch ein Pipettieren von Tropfen dieser Alginat-Gelatine-Lösung in eine Einkapselungslösung mit hohem Kalziumanteil (14,7 g Kalziumchloriddihydrat und 2,38 g HEPES in einem Liter sterilem Wasser, ein pH-Wert von 7,4 wurde mittels $1 \mathrm{~N} \mathrm{NaOH}$ oder $1 \mathrm{~N} \mathrm{HCl}$ eingestellt) kam es $\mathrm{zu}$ einer Aushärtung der Alginat-Gelatine-Lösung in Form einer Kugel mit einem definierten Hohlraum. Nach Sterilfiltration mittels eines 500-ml-Filtriersystems konnte diese Einkapselungslösung bei Raumtemperatur aufbewahrt werden.

\subsubsection{Differenzierungsprotokoll}

Zwei Stunden vor Einkapselung wurden riPSC mit $5 \mu \mathrm{mol} / 1$ ROCK-Inhibitor Y-27632 inkubiert, um eine durch die enzymatische Vereinzelung induzierte Apoptose zu verhindern (Watanabe et al. 2007). Darauf wurden die riPSC mit $3 \mathrm{ml}$ TrypLE für drei Minuten im Inkubator abgelöst und in frischem hES-Medium aufgenommen. Anschließend wurden jeweils zwei Millionen suspendierte Zellen für vier Minuten bei $300 \mathrm{xg}$ zentrifugiert und das Zellpellet in je $1 \mathrm{ml}$ Alginat-Gelatine-Lösung aufgenommen, in ein 2-ml-Gefäß transferiert und mit $20 \mu \mathrm{mol} / \mathrm{l}$ ROCK-Inhibitor und $10 \mathrm{ng} / \mathrm{ml}$ FGF-2 ergänzt. 
Anschließend wurden je $25 \mu 1$ der Zell-Alginat-Gelatine-Suspension in $25 \mathrm{ml}$ Einkapselungslösung pipettiert. Bei Kontakt mit der Einkapselungslösung entstanden so Alginatkügelchen mit einer darin eingeschlossenen definierten Zellsuspension von jeweils

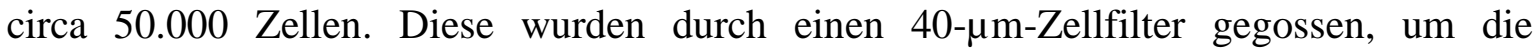
Alginatkügelchen aufzufangen, und daraufhin auf zwei T25-Flaschen verteilt. Etwa 20 Alginatkügelchen pro Flasche, insgesamt eine Million Zellen enthaltend, wurden auf diese Weise in $10 \mathrm{ml}$ hES-Medium aufgenommen, das mit $10 \mu \mathrm{mol} / \mathrm{l}$ ROCK-Inhibitor und 5 ng/ml FGF-2 versetzt wurde. Der Tag des Einkapselns wurde als Tag minus vier festgesetzt. An den Tagen minus drei und minus 2 wurde das Medium durch je $10 \mathrm{ml}$ hESMedium mit $5 \mu \mathrm{mol} / \mathrm{l}$ ROCK-Inhibitor und $5 \mathrm{ng} / \mathrm{ml} \mathrm{FGF-2} \mathrm{sowie} \mathrm{an} \mathrm{Tag} \mathrm{minus} \mathrm{eins} \mathrm{durch}$ $10 \mathrm{ml}$ hES-Medium mit $5 \mathrm{ng} / \mathrm{ml}$ FGF-2 ersetzt. Hierzu wurde das verbrauchte Medium erneut durch einen 40- $\mu \mathrm{m}$-Zellfilter gegossen, um die Alginatkügelchen auszusieben. Ab Differenzierungslauf \#16 wurde das Protokoll dahingehend verändert, dass die Behandlung der Tage minus drei und minus zwei wegfiel und an Tag minus eins $10 \mathrm{ml} \mathrm{hES}$-Medium mit $1 \mu \mathrm{mol} / \mathrm{l}$ ROCK-Inhibitor und 5 ng/ml FGF-2 verwendet wurde.

An Tag null wurden die Alginatkügelchen erneut durch ein $40-\mu \mathrm{m}-Z$ Zellsieb gegossen und mit $5 \mathrm{ml}$ RPMI-1640 mit Glutamax gewaschen. Durch Aufnahme in $10 \mathrm{ml}$ mesodermales serumfreies Medium wurde eine mesodermale Differenzierung induziert. An den Tagen eins und zwei wurde das alte Medium vorsichtig mit einer Pipette aufgenommen, wobei darauf geachtet wurde, dass die Alginatkügelchen möglichst in der Kulturflasche verblieben. Dieser Überstand, der bereits aus den Alginatkügelchen gelöste Zellen enthielt, wurde nun bei 300 x g für vier Minuten zentrifugiert. Das entstehende Pellet wurde in $10 \mathrm{ml}$ mesodermalem serumfreiem Medium resuspendiert und in die jeweilige Kulturflasche gegeben. An Tag drei erfolgte ein Mediumwechsel mit der Zugabe von $10 \mathrm{ml}$ von kardialem serumfreiem Differenzierungsmedium bei erneuter Zentrifugation des alten Mediums und Resuspensierung des entstehenden Zellpellets. Ab Tag fünf waren die Zellen vollständig adhäriert und somit erfolgte an den Tagen fünf, sechs, acht und zehn ein Mediumwechsel mit lediglich $5 \mathrm{ml}$ kardialem serumfreiem Differenzierungsmedium unter Verwerfung des verbrauchten Mediums. An Tag zwölf wurde dieses durch $5 \mathrm{ml}$ serumfreies Medium ersetzt. Bei den Differenzierungsrunden 16 und 18 erfolgte die Kultur in kardialem serumfreiem Differenzierungsmedium bis Tag 13. 
Tabelle 6: Zusammensetzung der Zellkulturmedien zur kardialen Differenzierung.

\begin{tabular}{|c|c|}
\hline Serumfreies Medium & \\
\hline RPMI 1640 with Glutamax & $500 \mathrm{ml}$ \\
\hline L-Ascocbic acid solution (200 mmol/l in Aqua dest.) & $520 \mu \mathrm{l}(60 \mathrm{mg} / \mathrm{l})$ \\
\hline $\begin{array}{llll}\text { Penicillin/Streptomycin } & (\text { Pen/Strep; } & 10.000 & \mathrm{U} / \mathrm{ml} \\
10.000 \mu \mathrm{g} / \mathrm{ml}) & & & \end{array}$ & $\begin{array}{c}5,2 \mathrm{ml}(100 \mathrm{U} / \mathrm{ml} / \\
100 \mu \mathrm{g} / \mathrm{ml})\end{array}$ \\
\hline Natrium-Pyruvate $(100 \mathrm{mmol} / \mathrm{l})$ & $5,2 \mathrm{ml}(1 \mathrm{mmol} / \mathrm{l})$ \\
\hline B27 Supplement & $10,4 \mathrm{ml}$ \\
\hline Mesodermales serumfreies Medium & \\
\hline Serumfreies Medium & $998 \mathrm{ml}$ \\
\hline CHIR 99021 (10 mmol/l in DMSO) & $0,1 \mathrm{ml}(1 \mu \mathrm{mol} / \mathrm{l})$ \\
\hline BMP-4 (10 $\mu \mathrm{g} / \mathrm{ml}$ stock $)$ & $0,5 \mathrm{ml}(5 \mathrm{ng} / \mathrm{ml})$ \\
\hline Activin A $(10 \mu \mathrm{g} / \mathrm{ml}$ stock $)$ & $0,9 \mathrm{ml}(9 \mathrm{ng} / \mathrm{ml})$ \\
\hline FGF-2 $(10 \mu \mathrm{g} / \mathrm{ml})$ & $0,5 \mathrm{ml}(5 \mathrm{ng} / \mathrm{ml})$ \\
\hline Kardiales serumfreies Differenzierungsmedium & \\
\hline Serumfreies Medium & $999 \mathrm{ml}$ \\
\hline IWP-4 (5 mmol/l in DMSO) & $1 \mathrm{ml}(5 \mu \mathrm{mol} / \mathrm{l})$ \\
\hline
\end{tabular}

\subsubsection{Laktatselektion der differenzierten Kardiomyozyten}

Nach Differenzierung wurde an Kulturtag 13 eine metabolische Selektion gestartet, um die Kardiomyozytenpopulation aufzureinigen. Dabei wird die Fähigkeit der Laktatverstoffwechselung von Herzmuskelzellen explizit genutzt. Die Zellen wurden an Kulturtag 13 zweimal mit $5 \mathrm{ml}$ sterilem DPBS gewaschen und mit $7 \mathrm{ml}$ Selektionsmedium versetzt. An den Tagen 14 bis 16 erfolgte jeweils ein Mediumwechsel mit $6 \mathrm{ml}$ Selektionsmedium. An Tag 17 wurde die Selektion durch einen Wechsel auf $5 \mathrm{ml}$ serumfreies Medium beendet und die Zellen bis Tag 21 in diesem kultiviert, um eine Erholung von durch die Selektion bedingten Stress zu ermöglichen. 
Tabelle 7: Zusammensetzung des Selektionsmediums.

\begin{tabular}{|c|c|}
\hline Selektionsmedium & \\
\hline RPMI (ohne Glukose / ohne Glutamin) & $49,15 \mathrm{ml}$ \\
\hline $\begin{array}{llll}\text { Penicillin/Streptomycin } & (\text { Pen/Strep; } 10.000 \mathrm{U} / \mathrm{ml} \quad / \\
10.000 \mu \mathrm{g} / \mathrm{ml}) & & \end{array}$ & $\begin{array}{l}0,5 \mathrm{ml}(100 \mathrm{U} / \mathrm{ml} / \\
100 \mu \mathrm{g} / \mathrm{ml})\end{array}$ \\
\hline Natrium-Laktat (440 mmol/l) & $0,25 \mathrm{ml}(2,2 \mathrm{mmol} / \mathrm{l})$ \\
\hline 2-Mercaptoethanol (50 mmol/l) & $0,1 \mathrm{ml}(0,1 \mathrm{mmol} / \mathrm{l})$ \\
\hline
\end{tabular}

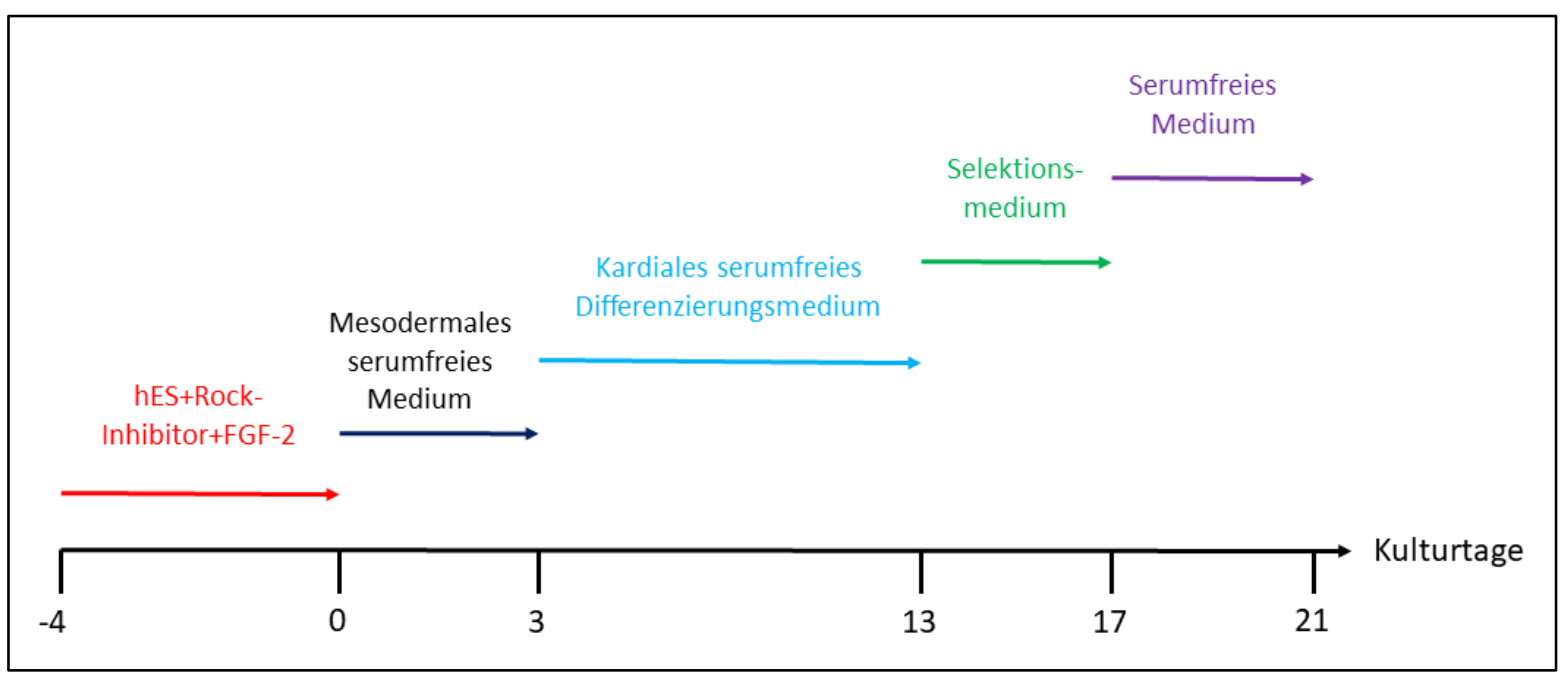

Abbildung 2: Schema des Differenzierungsprotokolls. Schema bis Differenzierungslauf \#16.

\subsubsection{Zellvereinzelung von aus riPSC differenzierten Kardiomyozyten}

Die Zellen wurden in den T25-Flaschen zweimal mit 2,5 ml DPBS gewaschen und anschließend für 10 bis 30 min bei Raumtemperatur mit 2,5 ml Verdaulösung pro Flasche inkubiert. Daraufhin wurden 7,5 ml serumfreies Medium mit $5 \mu \mathrm{mol} / \mathrm{l}$ ROCK-Inhibitor hinzugegeben, um den enzymatischen Verdau zu stoppen. Die Zellsuspension wurde einige Male vorsichtig hoch und herunter pipettiert, um verbliebene Zellverbände zu lösen und eine Suspension mit vereinzelten Zellen zu erhalten. Die Zellen wurden fünf Minuten bei $300 \mathrm{x} \mathrm{g}$ und $20^{\circ} \mathrm{C}$ zentrifugiert und anschließend erneut in serumfreiem Medium mit $5 \mu \mathrm{mol} / 1$ ROCK-Inhibitor resuspendiert. Zur Analyse der absoluten Zellzahl wurde ein CASY counter benutzt (siehe 2.6.2). 
Tabelle 8: Zusammensetzung der Verdaulösung.

\begin{tabular}{|l|c|}
\hline Verdaulösung \\
\hline Accutase Solution & $97 \mathrm{ml}$ \\
\hline Trypsin 2,5\% & $1 \mathrm{ml}$ \\
\hline DNAse stock $(1 \mathrm{mg} / \mathrm{ml})$ in Aqua dest. & $2 \mathrm{ml}(20 \mu \mathrm{g} / \mathrm{ml})$ \\
\hline
\end{tabular}

\section{$\underline{\text { 2.3.2.5 Einfrieren von Zellen }}$}

riPSC wurden nach dem Passagieren bei 300 x g für vier Minuten zentrifugiert. Das Zellpellet wurde schließlich in eiskaltem FBS mit 10\% DMSO aufgenommen, in Kryogefäße (Mr. Frosty) transferiert und über Nacht bei $-80^{\circ} \mathrm{C}$ kontrolliert eingefroren. Die Zellen wurden dann in einen $-152^{\circ} \mathrm{C}$-Gefrierschrank für die Langzeitlagerung transferiert. Kardiomyozyten wurden analog in FBS mit 10\% DMSO kryokonserviert.

\subsubsection{Beschichtung von Kulturplatten für die Kultur von Kardiomyozyten}

12-well-Zellkulturplatten wurden mit $0,5 \mathrm{ml}$ Matrigel-Lösung (1:30 in PBS) pro well bedeckt und für 30 min inkubiert. Anschließend wurden Zellen in entsprechendem Medium ausgesät.

\subsubsection{Durchflusszytometrie zur Analyse von riPSC und differenzierten Kardiomyozyten}

Mittels Durchflusszytometrie wurden die Pluripotenz von riPSC anhand der Quantifizierung sogenannter Stammzellmarker sowie die Kardiomyozyten-Reinheit nach Differenzierung ermittelt.

\subsubsection{Zellfixierung}

Zur Detektion der Pluripotenzmarker TRA-1-60 und Oct-3/4 wurden die riPSC in Ethanol (70\%) fixiert. Dabei erfolgte die Zugabe der Zellsuspension nach Waschung mit DPBS auf Eis und tröpfchenweise. Für die Analyse des kardialen Markers $\alpha$-Aktinin erfolgte die Zellfixierung in Formaldehyd (4\%; Histofix) für 20 min bei Raumtemperatur. Nach erneuter Waschung mit DPBS wurden die Zellen bei $4^{\circ} \mathrm{C}$ in DPBS bis zur Analyse aufbewahrt. 


\subsubsection{Immunfluoreszenzmarkierung für die Analyse mittels Durchflusszytometrie}

Zur Immunfluoreszenzmarkierung wurden die Zellen für vier Minuten bei $300 \mathrm{xg}$ pelletiert und nach Absaugen des Überstandes für zehn Minuten in Blockpuffer inkubiert. Die Zellsuspension wurde mit einem $70-\mu \mathrm{m}$-Zellfilter von Zellaggregaten befreit, in FACS-Röhrchen überführt und erneut für vier Minuten bei $300 \mathrm{x}$ g pelletiert. Nach Entfernen des Überstandes wurden $100 \mu 1$ Antikörperlösung pro Probe zugesetzt. Die Inkubation mit den primären Antikörpern erfolgte für 45 min (siehe Antikörper und Verdünnungen in Tabelle 9). Zur Markierung von Zellkernen wurde der Farbstoff Hoechst 33342 (10 mg/ml Stammlösung) in einer Verdünnung von 1:1.000 hinzugegeben. Daran schlossen sich zwei Waschschritte mit jeweils $1 \mathrm{ml}$ Blockpuffer pro Röhrchen an. Nach Zentrifugation für vier Minuten bei $300 \mathrm{x} g$ und Absaugen des Überstandes erfolgte bei Verwendung von nicht primär fluorochrom-konjugierten Antikörpern die Inkubation mit Anti-Maus-IgG Alexa Fluor 488 als sekundärem Antikörper für 30 Minuten (siehe Antikörper und Verdünnung in Tabelle 3).

Tabelle 9: Liste der bei der Immunfluoreszenzmarkierung verwendeten primären Antikörper.

\begin{tabular}{|c|c|c|c|c|}
\hline Antikörper & Anti- $\alpha$-Aktinin & $\begin{array}{c}\text { Isotype } \\
\text { control mouse } \\
\text { IgG1 }\end{array}$ & $\begin{array}{c}\text { Anti-TRA-1- } \\
60 \text { Alexa } \\
\text { Fluor } 488\end{array}$ & $\begin{array}{c}\text { Anti-Oct- } \\
3 / 4 \text { Alexa } \\
\text { Fluor } 647\end{array}$ \\
\hline Spezies & Maus & Maus & Maus & Maus \\
\hline Antikörperklasse & IgG1 & IgG1 & IgM & IgG1 \\
\hline Verdünnung & $1: 2000$ & $1: 100$ & $1: 50$ & $1: 50$ \\
\hline Klon & EA-53 & \#11711 & $\begin{array}{c}\text { TRA-1-60 } \\
\text { (RUO) }\end{array}$ & $40 /$ Oct-3 \\
\hline Firma & Sigma-Aldrich & R\&D Systems & BD & BD \\
\hline Label & ohne & ohne & Alexa Fluor & Alexa Fluor \\
& A7811 & MAB002 & 560173 & Ab19847 \\
\hline Artikelnummer & & & & Pharmingen \\
\hline
\end{tabular}

Es folgten erneut zwei Waschschritte analog zu dem oben beschriebenen Vorgehen, bevor die Zellen schließlich in 0,4-1 ml DPBS resuspendiert und der Analyse mittels 
Durchflusszytometrie zugeführt wurden. Alle Schritte erfolgten bei $4^{\circ} \mathrm{C}$. Dabei wurden die Zellen anhand ihrer Vorwärts- und Seitwärtsstreuung auf einem Punktdiagramm eingeordnet (gating), wobei jeweils 10.000 Zellen pro Probe, erfasst anhand des HoechstSignals, vermessen wurden.

\subsection{Morphologische und funktionelle Charakterisierung differenzierter Kardiomyozyten}

Aus riPSC abgeleitete Herzmuskelzellen wurden einer fluoreszenzmikroskopischen Analyse zugeführt, um die Sarkomerstruktur sowie Zell-Zell-Kontakte qualitativ zu bestimmen.

2.4.1 Immunfluoreszenzfärbung fixierter Kardiomyozyten zur Analyse der $\underline{\text { Sarkomerstruktur }}$

Aus riPSC differenzierte Kardiomyozyten wurden nach Zellvereinzelung auf runden und mit Matrigel beschichteten Objektträgern in 12-well-Kulturplatten kultiviert und in 4\%-Formaldehyd (Histofix) fixiert. Nach einer Inkubation in Blockpuffer für zehn Minuten wurden die Herzmuskelzellen über Nacht bei $4^{\circ} \mathrm{C}$ in einer Lösung mit den primären Antikörpern (siehe Antikörper und Verdünnungen in Tabelle 2) inkubiert. Zur Markierung von Zellkernen wurde erneut der Farbstoff Hoechst $33342(10 \mathrm{mg} / \mathrm{ml}$ Stammlösung) in einer Verdünnung von 1:1.000 hinzugegeben.

Nach jeweils fünfminütiger Waschung mit Blockpuffer und anschließend mit DPBS erfolgte für zwei Stunden eine Inkubation mit sekundären Antikörpern (siehe Antikörper und Verdünnungen in Tabelle 3). Zur Markierung von F-Aktin wurde Alexa Fluor 546 Phalloidin und Alexa Fluor 488 Phalloidin (Thermo Fisher Scientific) in einer Verdünnung von 1:60 verwendet. Nach erneuter, jeweils fünfminütiger Waschung mit Blockpuffer und anschließend mit DPBS wurden die runden Objektträger mit den adhärenten Zellen in Fluoromount-G eingebettet und auf Standardobjektträger transferiert.

\subsubsection{Aufzeichnung zytosolischer Kalziumkonzentration in Kardiomyozyten}

Im Rahmen des Kontraktionszyklus einer Herzmuskelzelle kommt es zu einer Erhöhung der zytosolischen Kalziumkonzentration in der Systole. Die Veränderung zwischen 
diastolischer und systolischer Kalziumkonzentration wird auch als Kalzium-Transient bezeichnet. Es wurden je 50.000 aus riPSC differenzierte vereinzelte Kardiomyozyten auf drei cell imaging dishes ausgesät und für eine Woche in Kultur gehalten. Die Rhod-2Färbelösung für die Darstellung von Kalzium-Transienten wurde nach nachfolgendem Protokoll vorbereitet: Zuerst wurde $47 \mu \mathrm{DMSO}$ mit $5 \mu \mathrm{l}$ Pluronic-F-127-Lösung vermischt; im nächsten Schritt wurden $50 \mu \mathrm{g}$ Rhod-2-AM-Ester hinzugegeben und das Ganze für zwei Minuten bei Raumtemperatur im Dunkeln inkubiert; zuletzt wurden 4,5 ml Tyrode-Lösung (Kalzium-Transienten) hinzugefügt.

Tabelle 10: Zusammensetzung der Tyrode-Lösung zur Messung der Kalzium-Transienten.

\begin{tabular}{|l|c|}
\hline \multicolumn{2}{|l|}{ Tyrode-Lösung (Kalzium-Transienten) } \\
\hline $\mathrm{NaCl}$ & $7,831 \mathrm{~g}$ \\
\hline $\mathrm{KCL}$ & $0,298 \mathrm{~g}$ \\
\hline $\mathrm{MgSO}_{4} \times \mathrm{H}_{2} \mathrm{O}$ & $0,296 \mathrm{~g}$ \\
\hline $\mathrm{NaH}_{2} \mathrm{PO}_{4}$ & $0,166 \mathrm{~g}$ \\
\hline $\mathrm{HEPES}$ & $2,383 \mathrm{~g}$ \\
\hline $\mathrm{D}-\mathrm{Glucose}_{\mathrm{CaCl}} \mathrm{xH}_{2} \mathrm{O}$ & $2,180 \mathrm{~g}$ \\
\hline $\mathrm{H} 2 \mathrm{O}$ & $0,029 \mathrm{~g}$ \\
\hline $\begin{array}{l}\text { Anschließend den pH-Wert mittels 1 N Natronlauge } \\
\text { beziehungsweise 1 N Salzsäure auf 7,4 einstellen. }\end{array}$ \\
\hline
\end{tabular}

Die cell imaging dishes mit den adhärenten Herzmuskelzellen wurden mit je $5 \mathrm{ml}$ Tyrode gewaschen, bevor die Rhod-2-Färbelösung zugegeben wurde. Nach erneutem Waschen wurden die nun mit Rhod-2 beladenen Herzmuskelzellen per Konfokalmikroskopie im Linescan-Modus für eine schnelle Darstellung der Kalzium-Transienten analysiert.

\section{$\underline{2.5 \text { Herstellung von Rhesus-EHM }}$}

\section{$\underline{\text { 2.5.1 Herstellung von Silikon-Gussformen und Silikonhaltern }}$}

EHM wurden nach einer von Zimmermann et al. (2000) beschriebenen Methode in zirkulären Gussformen aus Silikon mit einem zentralen Teflonschlauch hergestellt. Diese 
Gussformen bestanden aus Glaskulturschalen, in die Silikon gegossen wurde, dies unter Aussparung von jeweils vier Vertiefungen mit einem Durchmesser von 16 mm. Darin befand sich ein Silikonstift, auf dem sich ein abnehmbarer Teflonzylinder befand, um den herum die EHM kondensieren konnten (siehe Abbildung 3a). Dafür wurde die Silikonlösung ,SYLGARD® silicone elastomer mix“ aus 1/10 SYLGARD® silicone curing agent und 9/10 SYLGARD® silicone base durch Vermischung und fünfminütige Zentrifugation bei $1.500 \mathrm{xg}$ hergestellt und in Glaskulturschalen gefüllt (siehe Abbildung 3a). Zur Herstellung der Silikonhalter für die mechanische Beladung von EHM in Kultur (ab Tag drei) wurde die Silikonlösung in speziell gefertigte Teflonförmchen gegeben (siehe Abbildung 3b). Nach Trocknen des Silikons über Nacht wurden die befüllten Förmchen für eine Stunde bei $60^{\circ} \mathrm{C}$ im Ofen ausgehärtet und für etwa 20 min in ein Wasserbad gegeben. Nun wurden die fertigen Silikonhalter vorsichtig entnommen und vor Nutzung in der Zellkultur für eine Stunde in Wasser gekocht, getrocknet und autoklaviert. 


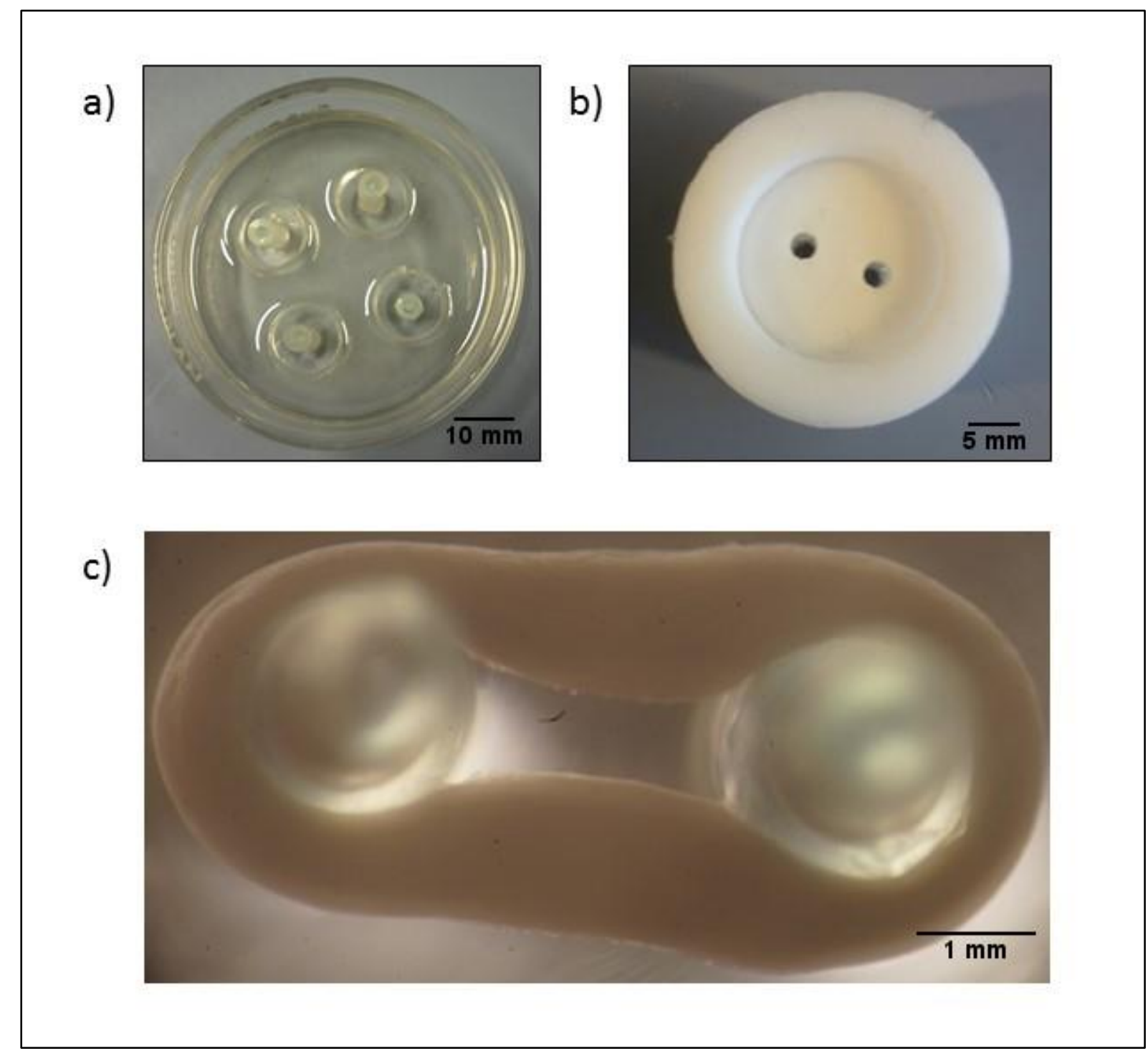

Abbildung 3: Setup zur Generierung von EHM. a) Glas-Silikonförmchen mit zentralem Teflonschlauch als Gussform zur Herstellung von EHM. b) Gussform für die Herstellung von flexiblen Silikonhaltern für die Kultur von EHM unter auxotonen Bedingungen. c) EHM aufgespannt auf einen Silikonhalter an Kulturtag 20.

\subsubsection{EHM-Herstellung}

Zur Herstellung von EHM wurden aus riPSC differenzierte Kardiomyozyten und Rhesus Vorhautfibroblasten (RhFF) benutzt. Zuerst wurden die in T175er-Flaschen kultivierten RhFF mit TrypLE vereinzelt. Dafür wurden die Zellen für 3-5 min in $14 \mathrm{ml}$ TrypLE pro T175er-Flasche inkubiert. Der Verdau wurde dann mit $25 \mathrm{ml}$ serumfreiem Medium (SFBM) gestoppt. Die RhFF-Zellsuspension wurde schließlich in 50-ml-Reaktionsgefäßen aufbewahrt. Kardiomyozyten wurden zwei Stunden vor Vereinzelung mit $5 \mu$ mol/l ROCKInhibitor behandelt und schließlich nach dem oben beschriebenen Verdau vereinzelt. Nach 
Zählung der Fibroblasten und Kardiomyozyten wurden diese in einem definierten Verhältnis (30:70) eingestellt und für fünf Minuten bei 300 x g zentrifugiert. Nach Aufnahme in serumfreiem Reifungsmedium wurde ein Master-Mix auf Eis nach dem in Tabelle 12 dargestellten Pipettierschemata hergestellt: Schema I wurde dabei für die Generierung der ersten EHM-Kohorten (bis Differenzierung 12) und Schema II für die Herstellung der folgenden EHM-Kohorten (Differenzierung 16-18) verwendet. 2X RPMI und 0,1 N Natronlauge wurden nach nachfolgenden Protokollen (siehe Tabelle 11) vorbereitet. Anschließend wurden jeweils Master-Mix und Zellsuspension nach dem Schema in Tabelle 13 vermischt (EHM-Rekonstitutionsmischung). 
Tabelle 11: Zusammensetzung der Kulturmedien zur EHM-Herstellung.

\begin{tabular}{|c|c|}
\hline \multicolumn{2}{|l|}{ Iscove serumfreies base Medium (SFBM) } \\
\hline Iscove Medium & $500 \mathrm{ml}$ \\
\hline L-ascorbic acid 2-phosphate sequimagnesium salt hydrate & $45 \mathrm{mg}$ \\
\hline MEM-NEAA (100X) & $5 \mathrm{ml}$ \\
\hline Penicillin/Streptomycin (Pen/Strep; $10.000 \mathrm{U} / \mathrm{ml} / 10.000 \mu \mathrm{g} / \mathrm{ml})$ & $\begin{array}{c}5 \mathrm{ml}(100 \mathrm{U} / \mathrm{ml} / \\
100 \mu \mathrm{g} / \mathrm{ml})\end{array}$ \\
\hline L-Glutamin $200 \mathrm{mmol} / \mathrm{l}$ & $5 \mathrm{ml}(2 \mathrm{mmol} / \mathrm{l})$ \\
\hline \multicolumn{2}{|l|}{ Anschließend wurde das Medium steril filtriert. } \\
\hline \multicolumn{2}{|l|}{ Serumfreies Reifungsmedium (SFMM) } \\
\hline Iscove serumfreies base Medium (SFBM) & $48 \mathrm{ml}$ \\
\hline B27 minus Insulin & $2 \mathrm{ml}$ \\
\hline IGF-1-Stock (in PBS mit 0,1\% rekombinantem Albumin) & $50 \mu \mathrm{l}(100 \mu \mathrm{g} / \mathrm{ml})$ \\
\hline VEGF-A-Stock (in PBS mit 0,1\% rekombinantem Albumin) & $50 \mu \mathrm{l}(5 \mu \mathrm{g} / \mathrm{ml})$ \\
\hline FGF-2-Stock (in PBS mit 0,1\% rekombinantem Albumin) & $50 \mu \mathrm{l}(10 \mu \mathrm{g} / \mathrm{ml})$ \\
\hline $\begin{array}{l}\text { TGF-beta-1-Stock (in PBS mit 0,1\% rekombinantem Albumin), } \\
\text { wurde nur bis Tag drei nach der EHM-Herstellung zugesetzt. }\end{array}$ & $50 \mathrm{ul}(5 \mu \mathrm{g} / \mathrm{ml})$ \\
\hline \multicolumn{2}{|l|}{ 10X RPMI } \\
\hline RPMI Pulver & $1,04 \mathrm{~g}$ \\
\hline Aqua dest. & $10 \mathrm{ml}$ \\
\hline \multicolumn{2}{|l|}{$\begin{array}{l}\text { Anschließend wurde die Lösung zur Auflösung des Pulvers für } 1 \\
\text { Stunde auf den Wippschüttler gestellt. }\end{array}$} \\
\hline \multicolumn{2}{|l|}{ 2X RPMI } \\
\hline 10X RPMI & $2 \mathrm{ml}$ \\
\hline B27 minus Insulin & $0,8 \mathrm{ml}$ \\
\hline Penicillin/Streptomycin (Pen/Strep; $10.000 \mathrm{U} / \mathrm{ml} / 10.000 \mu \mathrm{g} / \mathrm{ml})$ & $\begin{array}{c}0,2 \mathrm{ml}(200 \mathrm{U} / \mathrm{ml} / \\
200 \mu \mathrm{g} / \mathrm{ml})\end{array}$ \\
\hline $\mathrm{H}_{2} \mathrm{O}$ & $7 \mathrm{ml}$ \\
\hline \multicolumn{2}{|l|}{ Anschließend wurde die Lösung steril filtriert. } \\
\hline \multicolumn{2}{|l|}{$0,1 \mathrm{~N} \mathrm{NaOH}$} \\
\hline $\mathrm{NaOH} 1 \mathrm{~N}$ & $1 \mathrm{ml}$ \\
\hline $\mathrm{H}_{2} \mathrm{O}$ & $9 \mathrm{ml}$ \\
\hline Anschließend wurde die Lösung steril filtriert. & \\
\hline
\end{tabular}


Tabelle 12: Zusammensetzung des Master-Mix.

\begin{tabular}{|c|c|c|c|}
\hline EHM-Anzahl & $\mathbf{4}$ & $\mathbf{8}$ & $\mathbf{1 2}$ \\
\hline $\begin{array}{c}\text { Schema I: Bovine Collagen } \\
(6,9 \mathrm{mg} / \mathrm{ml})\end{array}$ & $271 \mu \mathrm{l}$ & $542 \mu \mathrm{l}$ & $813 \mu \mathrm{l}$ \\
\hline $2 \times \mathrm{RPMI}$ & $271 \mu \mathrm{l}$ & $542 \mu \mathrm{l}$ & $813 \mu \mathrm{l}$ \\
\hline $0,1 \mathrm{~N} \mathrm{NaOH}$ & $53 \mu \mathrm{l}$ & $106 \mu \mathrm{l}$ & $159 \mu \mathrm{l}$ \\
\hline $\begin{array}{c}\text { Schema II: } \text { Bovine Collagen } \\
(7,13 \mathrm{mg} / \mathrm{ml})\end{array}$ & $256 \mu \mathrm{l}$ & $512 \mu \mathrm{l}$ & $768 \mu \mathrm{l}$ \\
\hline $2 \times \mathrm{RPMI}$ & $256 \mu \mathrm{l}$ & $512 \mu \mathrm{l}$ & $768 \mu \mathrm{l}$ \\
\hline $0,1 \mathrm{~N} \mathrm{NaOH}$ & $50 \mu \mathrm{l}$ & $100 \mu \mathrm{l}$ & $150 \mu \mathrm{l}$ \\
\hline
\end{tabular}

Tabelle 13: Mischungsverhältnis der EHM-Rekonstitutionsmischung.

\begin{tabular}{|c|c|c|c|}
\hline EHM-Anzahl & $\mathbf{4}$ & $\mathbf{8}$ & $\mathbf{1 2}$ \\
\hline Schema I: Master-Mix-Volumen & $595 \mu \mathrm{l}$ & $1190 \mu \mathrm{l}$ & $1785 \mu \mathrm{l}$ \\
\hline Zellsuspensionsvolumen & $1506 \mu \mathrm{l}$ & $3012 \mu \mathrm{l}$ & $4518 \mu \mathrm{l}$ \\
\hline Zellzahl (in Mio.) & 5,8 & 11,6 & 17,4 \\
\hline Gesamtvolumen & $2101 \mu \mathrm{l}$ & $4202 \mu \mathrm{l}$ & $6303 \mu \mathrm{l}$ \\
\hline Schema II: Master-Mix-Volumen & $562 \mu \mathrm{l}$ & $1124 \mu \mathrm{l}$ & $1686 \mu \mathrm{l}$ \\
\hline Zellsuspensionsvolumen & $1525 \mu \mathrm{l}$ & $3050 \mu \mathrm{l}$ & $4575 \mu \mathrm{l}$ \\
\hline Zellzahl (in Mio.) & 5,8 & 11,6 & 17,4 \\
\hline Gesamtvolumen & $2087 \mu \mathrm{l}$ & $4174 \mu \mathrm{l}$ & $6261 \mu \mathrm{l}$ \\
\hline
\end{tabular}

Pro zirkuläre Gussform wurden $450 \mu 1$ der EHM-Rekonstitutionsmischung eingefüllt. Bei einem Volumen von $450 \mu \mathrm{l}$ wurde eine Kollagenmenge von $0,4 \mathrm{mg}$ bei einer Zellzahl von 1,24 Mio. (Schema 1) bzw. 1,25 Mio. (Schema 2) pro EHM eingesetzt. Dies entspricht dem von Zimmermann et al. (2002) beschriebenen Mischungsverhältnis. Die EHMKonsolidierung wurde für eine Stunde bei $37^{\circ} \mathrm{C}$ in einem Zellkulturinkubator unterstützt. Anschließend wurden etwa $7 \mathrm{ml}$ serumfreies Reifungsmedium (SFMM, inklusive TGFbeta 1) hinzugegeben, an Tag eins wurde das Medium gewechselt (erneut inklusive TGFbeta 1). An Tag drei wurden die EHM auf Silikonhalter transferiert, um eine physiologische Vordehnung zu simulieren (siehe Abbildung $3 \mathrm{c}$ ). Darauf folgte alle zwei Tage ein Mediumwechsel mit SFMM, ohne TGF-beta 1. Die Kulturdauer der EHM betrug 
insgesamt 20 Tage. Anschließend wurden die EHM einer Kontraktionskraftmessung unter isometrischen Bedingungen unterzogen.

\subsection{Morphologische und funktionelle Charakterisierung von EHM}

\subsubsection{Dissoziierung von EHM für Einzelzellanalysen}

Nach erfolgter Kontraktionskraftmessung wurde das Feuchtgewicht aller EHM bestimmt. Dafür wurde adhärierte Flüssigkeit mittels Löschpapiers entfernt. Die Messung erfolgte auf einer Feinwaage. Für die EHM-Dissoziation wurde ein EHM pro well in einer 12-wellPlatte für $1 \mathrm{~h}$ bei $37^{\circ} \mathrm{C}$ mit $1 \mathrm{ml}$ der Kollagenase-Lösung inkubiert. Anschließend wurde die Zellsuspension in ein 15-ml-Reagiergefäß transferiert, ohne dabei die noch makroskopisch sichtbaren EHM-Reste zu aspirieren. Diese wurden mit je $1 \mathrm{ml}$ PBS gewaschen und mit $1 \mathrm{ml}$ der Verdaulösung für $30 \mathrm{~min}$ bei Raumtemperatur inkubiert sowie anschließend durch Pipettieren mechanisch dissoziiert. Wasch- und Verdaulösungen wurden ebenfalls in einem Reagiergefäß pro EHM gesammelt. Die wells wurden anschließend mit je $1 \mathrm{ml}$ 5\%-FBS-Lösung (verdünnt in DPBS) ausgewaschen. Die Waschsuspension wurde darauf ebenfalls in das jeweilige Reagiergefäß gegeben. Die gesammelte Zellsuspension wurde für vier Minuten bei $300 \mathrm{x} \mathrm{g}$ und $4^{\circ} \mathrm{C}$ zentrifugiert. Die Zellpellets wurden in je $1 \mathrm{ml}$ 5\%-FBS-Lösung aufgenommen und auf Eis aufbewahrt.

Tabelle 14: Zusammensetzung der Kollagenase-Lösung.

\begin{tabular}{|l|c|}
\hline Kollagenase-Lösung \\
\hline PBS $(+\mathrm{Ca} / \mathrm{Mg})$ & $79,8 \%$ \\
\hline FBS & $20 \%$ \\
\hline Kollagenase Typ 1 & $0,2 \%$ \\
\hline $\begin{array}{l}\text { Anschließend wurde die Lösung steril filtriert und bei }-20^{\circ} \mathrm{C} \\
\text { gelagert. }\end{array}$ \\
\hline
\end{tabular}

\subsubsection{Bestimmung des Anteils von Kardiomyozyten in EHM}

Zur Analyse der absoluten Zellzahl wurde ein $C A S Y$ counter benutzt. Dieses Gerät nutzt das Stromausschlussverfahren, um tote und lebende Zellen von Zelldebris zu unter- 
scheiden. Zellen mit intakter Zellmembran sind elektrisch isoliert und leiten keinen Strom, während die Zellmembran bei toten Zellen durchlässig und das Zytoplasma leitfähig wird. Mittels Pulsflächenanalyse werden die Zellen entsprechend ihrer Größenverteilung aufgeteilt: vitale Zellen werden entsprechend ihres tatsächlichen Volumens gemessen, „während tote Zellen nur noch mit ihrem Zellmatrixvolumen detektiert werden, was in etwa dem Volumen ihres Zellkerns entspricht“ (Glauner 2006). Mittels einer Totprobe (mit CASY blue lysierte Zellen) kann dann ein gating vorgenommenen werden, um den Größenbereich für tote und lebende Zellen festzulegen (Glauner 2006, siehe Abbildung 4).

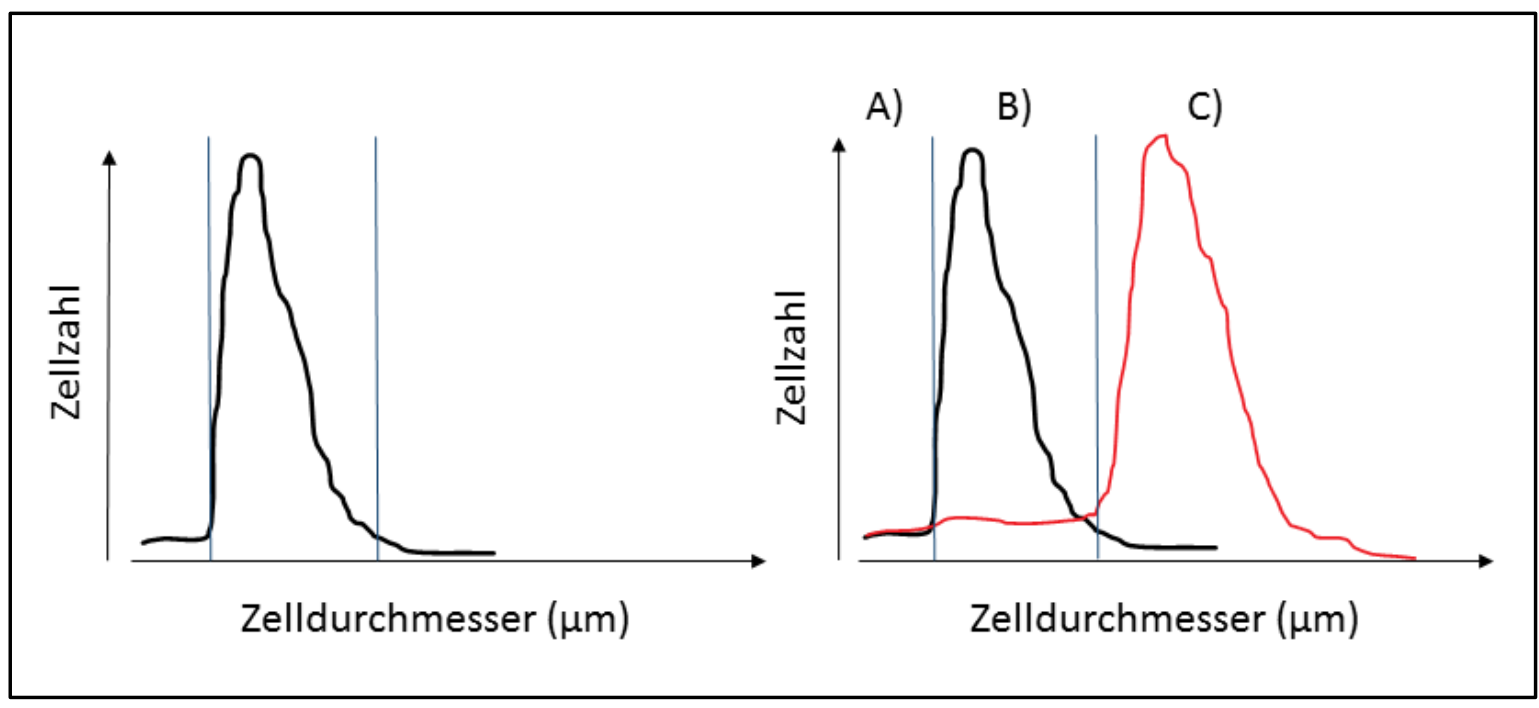

Abbildung 4: Zellzählung mittels Stromausschlussverfahren. Schematische Darstellung: Auf der linken Seite wurde mittels einer Totprobe ein gating (blaue Linien) vorgenommen, sodass dann auf der rechten Seite zwischen A) Zelldebris, B) toten und C) lebenden Zellen differenziert werden konnte. Auf der $\mathrm{x}$-Achse ist der Zelldurchmesser in $\mu \mathrm{m}$ und auf der $\mathrm{y}$-Achse die Zellzahl aufgetragen.

Es ergaben sich dann jeweils Gesamtzellzahl, Lebendzellzahl, Lebendzellrate sowie Volumen und Durchmesser der gemessenen Zellsuspension.

Anschließend wurden die Zellen mit 4\%-Formaldehyd (Histofix) fixiert und einer Immunfluoreszenzfärbung für den Herzmuskelzellmarker $\alpha$-Aktinin bei gleichzeitiger DNA-Färbung (Hoechst oder DAPI) zugeführt. Der Herzmuskelzellanteil wurde dann per Durchflusszytometrie bestimmt (analog zu 2.3.3) und mittels Gesamtzellzahl und Lebendzellzahl konnte dann die Gesamtzahl an Kardiomyozyten bzw. die Anzahl lebender Kardiomyozyten errechnet werden. 


\subsubsection{Vibrotomschnitte von EHM}

Um die zelluläre Verteilung in verschiedenen Ebenen der EHM zu analysieren, wurden diese mit einem Vibrotom (Leica) in $100 \mu \mathrm{m}$ dicke Scheiben geschnitten. Dafür wurden die EHM zunächst in 4\%-Agarose (in PBS) eingebettet. Die Agaroseblöcke wurden dann geschnitten und die Gewebescheiben einer Immunfluoreszenzfärbung zugeführt.

2.6.4 Immunfluoreszenzfärbung von Vibrotomschnitten und kompletten EHM zur morphologischen Charakterisierung

Alle Inkubationsschritte erfolgten bei $4^{\circ} \mathrm{C}$ unter kontinuierlicher Rotation, um eine gleichmäßige Verteilung der Antikörperlösungen zu gewährleisten. Zunächst wurden Vibrotomschnitte oder komplette EHM über Nacht in 2-ml-Reaktionsgefäßen in $500 \mu 1$ Blocklösung inkubiert. Anschließend erfolgte eine 48-stündige Inkubation in $500 \mu 1$ primärer Antikörperlösung. Es wurden Anti- $\alpha$-Aktinin, Anti-Connexin-43 und Antisarkomerisches Tropomyosin aus Tabelle 5 verwendet. Zellkerne wurden über Inkubation mit Hoechst 33342 (Verdünnung 1:1.000) markiert. Daran schlossen sich drei einstündige Waschschritte mit zweimal $2 \mathrm{ml}$ DPBS und einmal $2 \mathrm{ml}$ Blocklösung an. Daraufhin wurden $500 \mu \mathrm{l}$ der sekundären Antikörperlösung über Nacht hinzugegeben. Verwendet wurde dabei Anti-Maus-IgG Alexa Fluor 488 (siehe Tabelle 6) bei gleichzeitiger Zugabe von Alexa Fluor 488 Phalloidin zur Markierung von f-Aktin. Nach erneuter Waschung mit jeweils 2 ml DPBS (1x), Blocklösung (1x) und DPBS (2x) für jeweils eine Stunde wurden die Gewebe in Fluoromount-G eingebettet und mit einem Deckgläschen auf einem Objektträger fixiert.

\subsubsection{Analyse der kontraktilen Funktion von EHM}

Zur Analyse der kontraktilen Funktion wurden folgende EHM verwendet: EHM aus Kardiomyozyten der Differenzierung 12 (12-1,-2,-6,-7,-10,-12,-14,-16; n = 8), EHM aus Kardiomyozyten der Differenzierung $16(16-3,-5-10,-11 ; n=4)$, EHM aus Kardiomyozyten der Differenzierung $17(17-1,-5,-12,-13 ; \mathrm{n}=4)$ und EHM aus Kardiomyozyten der Differenzierung $18(18-11,-12,-13 ; \mathrm{n}=3)$. Die Messung erfolgte unter isometrischen Bedingungen unter elektrischer Feldstimulation bei 1,5 Hz (Zimmermann et al. 2000). Dafür wurden die EHM vorsichtig mit einer Pipettenspitze von den Silikonhaltern abgenommen und zwischen einem Haltehaken und einem, an einem induktiven 
Kraftaufnehmer befestigten, hakenförmigen Draht aufgespannt (siehe Abbildung 5). Die EHM wurden dann in einem Organbad mit Tyrode-Lösung (20 ml pro Organbad) bei $37^{\circ} \mathrm{C}$ und kontinuierlicher Begasung mit Carbogen $\left(95 \% \mathrm{O}_{2}, 5 \% \mathrm{CO}_{2}\right)$ für die Einstellung eines pH-Wertes von 7,4 analysiert. Nach Kalibrierung der Messplätze wurde bei einer Stimulationsfrequenz von $1,5 \mathrm{~Hz}$ eine Kalziumkonzentration von $2 \mathrm{mmol} / \mathrm{l}$ eingestellt und bei dieser, mittels schrittweiser Dehnung der EHM entsprechend des Frank-Starling Mechanismus eine optimale Vordehnung bis zum Erreichen des maximalen Kontraktionskraftniveaus eingestellt (Lmax). Alle weiteren Messungen erfolgten dann bei Lmax. Nach einer Äquilibrationszeit von etwa drei Minuten wurde die Messung mit einer Stimulation von $1,5 \mathrm{~Hz}$ (beziehungsweise $2 \mathrm{~Hz}$ bei EHM aus der KardiomyozytenDifferenzierungrunde 16) und einer Kalziumkonzentration von $0,2 \mathrm{mmol} / \mathrm{l}$ begonnen und dann schrittweise auf 3,6 mmol/l erhöht. Anschließend erfolgten ein Tyrodenwechsel und eine Einstellung der Kalziumkonzentration auf den Wert der halbmaximalen Kraftentwicklung (EC50). Nun wurde eine Kraft-Frequenz-Kurve erstellt, indem die Stimulationsfrequenz schrittweise um $0,5 \mathrm{~Hz}$ erhöht wurde $(1-3 \mathrm{~Hz})$. Nach erneutem Wechsel der Tyrode-Lösung wurde das Ansprechen auf beta-adrenerge und muskarinerge Stimulation untersucht. Dazu erfolgte die Zugabe von Isoprenalin, beginnend bei einer Konzentration von $10^{-4} \mu \mathrm{mol} / \mathrm{l}$ bis zu einer Konzentration von $1 \mu \mathrm{mol} / \mathrm{l}$. Als funktioneller Antagonist wurde schließlich Carbachol $(10 \mu \mathrm{mol} / \mathrm{l})$ kumulativ hinzugegeben. Kontraktionswerte wurden immer drei Minuten nach Zugabe von Isoprenalin bzw. Carbachol im steady state ausgewertet. 
Tabelle 15: Zusammensetzung der Tyrode-Lösung für die Kontraktionskraftmessung.

\begin{tabular}{|c|c|}
\hline \multicolumn{2}{|c|}{ Tyrode-Lösung (Kontraktionskraftmessung) } \\
\hline Stamm I & $200 \mathrm{ml}$ \\
\hline Stamm II & $190 \mathrm{ml}$ \\
\hline Stamm III & $50 \mathrm{ml}$ \\
\hline D-Glukose & $5 \mathrm{~g}$ \\
\hline Ascorbinsäure & $250 \mathrm{mg}$ \\
\hline $\mathrm{H} 2 \mathrm{O}$ & $5000 \mathrm{ml}$ \\
\hline \multicolumn{2}{|l|}{ Stamm I } \\
\hline $\mathrm{Ca}^{2+}$ & $0,2 \mathrm{mmol} / \mathrm{l}$ \\
\hline $\mathrm{NaCl}(\mathrm{MG} 58,44)$ & $175 \mathrm{~g}$ \\
\hline $\mathrm{KCl}(\mathrm{MG} 74,56)$ & $10 \mathrm{~g}$ \\
\hline $\mathrm{CaCl}_{2} \mathrm{Stamm}$ & $2,22 \mathrm{ml}$ \\
\hline $\mathrm{MgCl}_{2} \mathrm{Stamm}$ & $25 \mathrm{ml}$ \\
\hline $\mathrm{H} 2 \mathrm{O}$ & $1000 \mathrm{ml}$ \\
\hline \multicolumn{2}{|l|}{ Stamm II } \\
\hline $\mathrm{NaHCO}_{3}(\mathrm{MG} 84,01)$ & $50 \mathrm{~g}$ \\
\hline $\mathrm{H} 2 \mathrm{O}$ & $1000 \mathrm{ml}$ \\
\hline \multicolumn{2}{|l|}{ Stamm III } \\
\hline $\mathrm{NaH}_{2} \mathrm{PO}_{4}(\mathrm{MG} 137,99)$ & $5,8 \mathrm{~g}$ \\
\hline \multicolumn{2}{|l|}{ CaCl-Stamm 2,25 M } \\
\hline $\mathrm{CaCl}_{2} \times \mathrm{H}_{2} \mathrm{O}(\mathrm{MG} 147,02)$ & $165,57 \mathrm{~g}$ \\
\hline $\mathrm{H} 2 \mathrm{O}$ & $500 \mathrm{ml}$ \\
\hline \multicolumn{2}{|l|}{$\mathrm{MgCl}_{2}$-Stamm } \\
\hline $\mathrm{MgCL}_{2} \times 6 \mathrm{H}_{2} \mathrm{O}(\mathrm{MG} 203,31)$ & $106,83 \mathrm{~g}$ \\
\hline $\mathrm{H} 2 \mathrm{O}$ & $500 \mathrm{ml}$ \\
\hline
\end{tabular}


a)

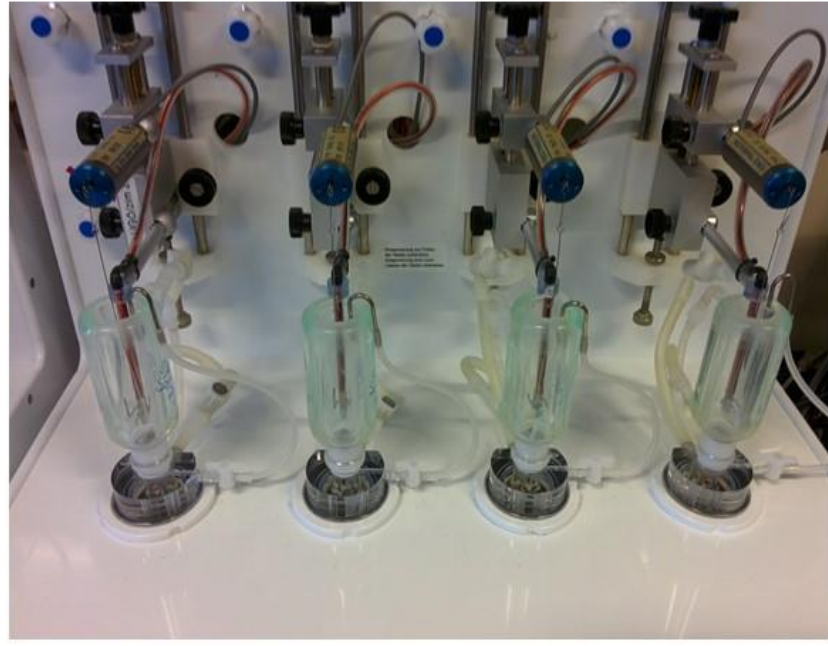

b)

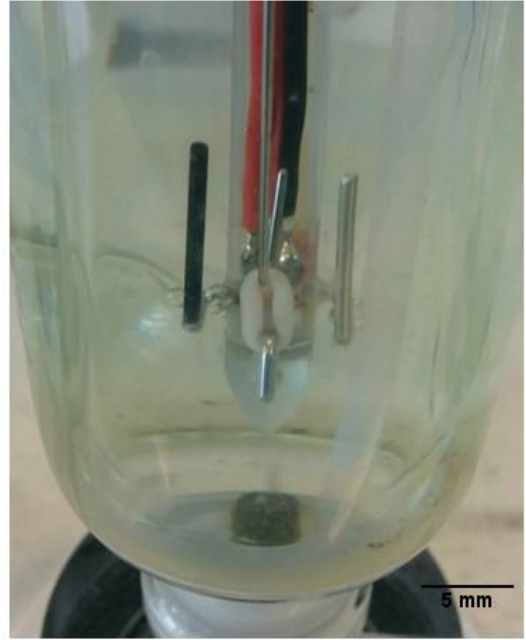

Abbildung 5: Setup zur Kontraktionskraftmessung. a) Kontraktionssetup: zu sehen sind vier Organbäder mit ihrer Versorgungseinheit und dem jeweiligen Kraftmesser. b) Zu sehen ist ein EHM von frontal innerhalb eines Organbades, eingespannt im Kontraktionssetup zwischen Haltehaken unten und kraftaufnehmendem Haken oben, der mit einem induktiven Kraftmesser verbunden ist. An den Seiten befinden sich Elektroden für die elektrische Feldstimulation. 


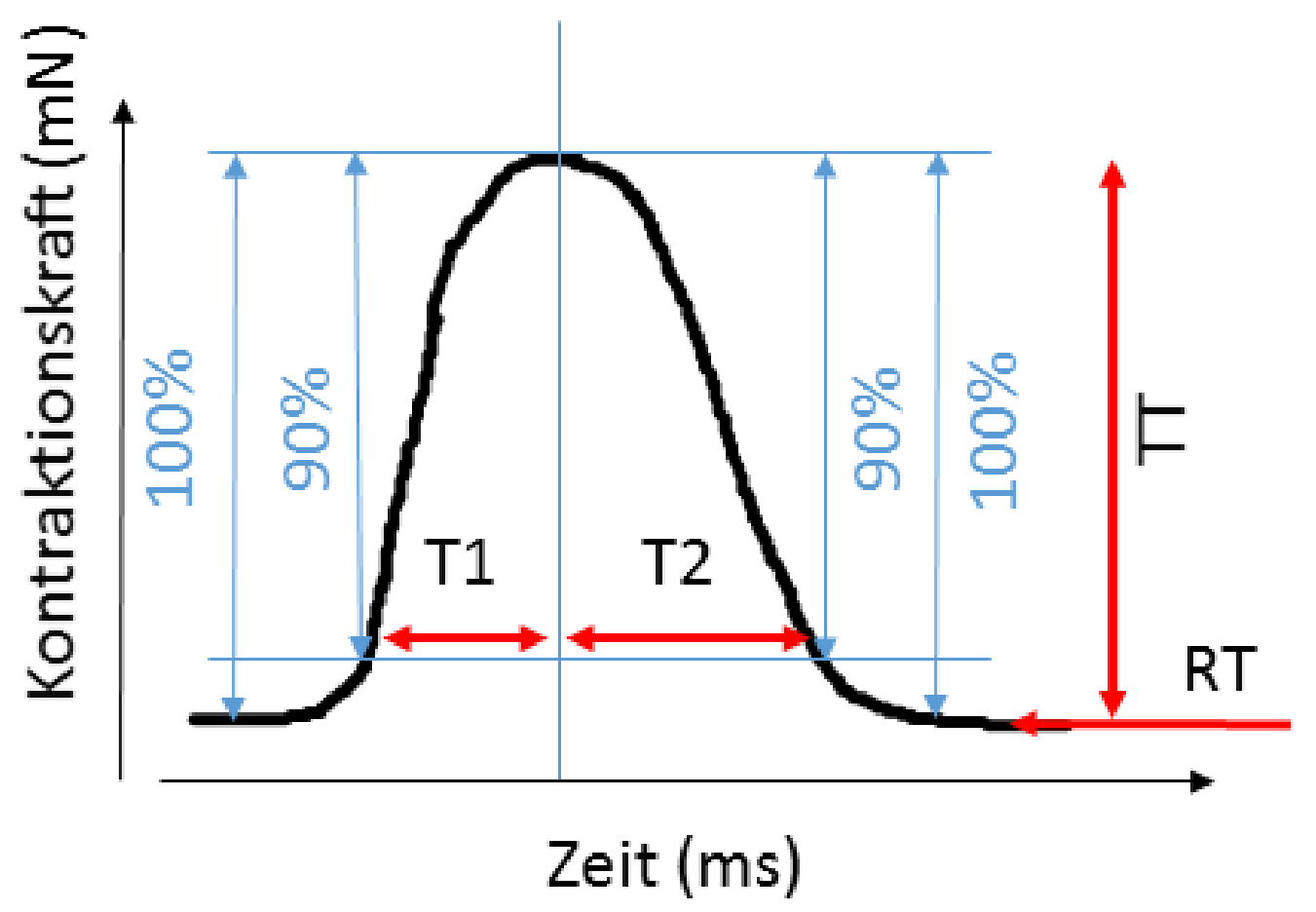

Abbildung 6: Schematische Darstellung einer Kontraktionsamplitude. TT $=$ systolische Kraftamplitude, $\mathrm{RT}=$ diastolische Kraft, $\mathrm{T} 1=$ Kontraktionszeit, $\mathrm{T} 2=$ Relaxationszeit. Auf der $\mathrm{x}$-Achse ist die Zeit (ms) und auf der y-Achse die Kontraktionskraft (mN) aufgetragen.

2.6.6 Elektrophysiologische Analysen von EHM zur Untersuchung von Aktionspotentialen

EHM (16-1, 17-3, 17-7 und 18-6) wurden halbiert und mit 35-37 ${ }^{\circ} \mathrm{C}$ warmer TyrodeLösung bei einer Flussgeschwindigkeit von $1 \mathrm{ml} / \mathrm{min}$ umspült: Natriumchlorid $150 \mathrm{mmol} / \mathrm{L}$, Kaliumchlorid 5,4 mmol/L, Magnesiumchlorid $2 \mathrm{mmol} / \mathrm{L}$, Kalziumchlorid 1,8 mmol/L, HEPES $10 \mathrm{mmol} / \mathrm{L}$ und Glukose $10 \mathrm{mmol} / \mathrm{L}$ (pH-Wert 7,4). Nach $60 \mathrm{~min}$ Äquilibration erfolgte eine elektrische Stimulation bei $1 \mathrm{~Hz}$ mit einer Stromstärke von 5\% über der Reizschwelle. Mikroelektroden mit Widerständen zwischen 30 und $50 \mathrm{M} \Omega$ und gefüllt mit $2 \mathrm{~mol} / \mathrm{l} \mathrm{Kaliumchlorid-Lösung} \mathrm{dienten} \mathrm{der} \mathrm{Erfassung} \mathrm{von} \mathrm{Aktionspotentialen.}$ Die durch ein LIH8+8 interface (HEKA) erfassten Signale wurden mittels Verstärker SEC05X (NPI) amplifiziert und auf einem Oszilloskop dargestellt. Die Analyse der Daten erfolgte mit der Software LabChart (ADInstruments). 


\subsection{Messung der Sarkomerlänge in Herzmuskelzellen}

Um die Sarkomerlänge zu bestimmen, wurden Immunfluoreszenzfärbungen nach Markierung von $\alpha$-Aktinin ausgewertet. Herzmuskelzellen wurden mit einem LSM 710/NLOMikroskop (Zeiss) aufgenommen. Pro Herzmuskelzelle wurde der individuelle Sarkomerabstand von insgesamt 50 Sarkomeren mittels ZEN Software (Zeiss) vermessen.

\subsection{RNA-Präparation aus schockgefrorenen EHM}

An Kulturtag 20 wurden die EHM (12-3, 12-4, 12-5, 16-2, 17-6, 18-4) vorsichtig von den Silikonhaltern abgenommen, in Kryogefäße transferiert und in flüssigem Stickstoff schockgefroren. Nach Wiegen der gefrorenen EHM auf einer Feinwaage wurden diese in 0,6 $\mathrm{ml}$ Trizol pro EHM aufgenommen und daraufhin auf Eis unter Zugabe von mit $0,5 \mathrm{~mol} / \mathrm{l} \mathrm{NaOH}$ gereinigten Wolfram Kugeln homogenisiert (tissue lyser). Nach fünf Minuten bei Raumtemperatur wurde $0,12 \mathrm{ml}$ Chloroform hinzugegen und die Proben für 15 sek gemischt (Vortex). Nach einer weiteren Inkubation von drei Minuten bei Raumtemperatur sowie durch Zentrifugation bei $12.000 \mathrm{x} \mathrm{g}$ und $4^{\circ} \mathrm{C}$ für 15 Minuten wurde eine Phasentrennung erreicht. Die wässrige Phase wurde abgenommen, mit $0,3 \mathrm{ml}$ Isopropanol versetzt und für zehn Minuten bei Raumtemperatur inkubiert. Durch Zentrifugation für zehn Minuten mit $12.000 \mathrm{x}$ g bei $4^{\circ} \mathrm{C}$ wurde die RNA pelletiert. Diese wurde in $75 \%$-Ethanol $(0,6 \mathrm{ml})$ gewaschen. Nach einer weiteren Zentrifugation für fünf Minuten bei $7.500 \mathrm{x}$ g und $4^{\circ} \mathrm{C}$ wurden die Überstande verworfen und die RNA-Pellets für 5-10 min getrocknet. Nach Aufnahme in $20 \mu \mathrm{DEPC}-\mathrm{H}_{2} \mathrm{O}$ erfolgte eine Inkubation der Proben für zehn Minuten bei $55-60^{\circ} \mathrm{C}$. Nach Abkühlung für fünf Minuten auf Eis wurde eine photometrische Konzentrationsbestimmung durchgeführt. Die RNA wurde bei $-80^{\circ} \mathrm{C}$ gelagert.

\subsection{Statistik/Software}

Die Aufzeichnung und Auswertung der Kontraktionsdaten erfolgte mit den Programmen AMon32 und BMon32 (Ingenieurbüro Jäckel, Hanau). Alle Daten wurden jeweils mit arithmetischem Mittelwert und Standardfehler des Mittelwertes (SEM) angegeben und mittels der Software Excel 2016 berechnet. Die statistische Signifikanz wurde mit einem zweiseitigen, ungepaarten t-Test (bei zwei Gruppen) oder einer ANOVA Varianzanalyse 
mit Posthoc-Test mittels der Software GraphPad Prism 7 berechnet. Es wurde ein p-Wert kleiner als 0,05 als signifikant angenommen. Graphen wurden mittels GraphPad Prism Version 7 erstellt. Zur Bildbearbeitung und -auswertung wurden ImageJ und Zeiss LSM ZEN Software verwendet. Durchflusszytometrische Daten wurden mittels der Software FACSDiva erhoben und ausgewertet. Als Zitationssoftware wurde Zotero verwendet.

2.10 Substanzen, Geräte und Hilfsmittel

2.10.1 Substanzliste

Tabelle 16: Liste der verwendeten Substanzen.

\begin{tabular}{|c|c|c|}
\hline Substanzen & Firma & $\begin{array}{l}\text { Bestellnummer, } \\
\text { wenn vorhanden }\end{array}$ \\
\hline 2-Mercaptoethanol (50 mM) & ThermoFisher Scientific & 31350010 \\
\hline Accutase & Merck Millipore & SCR005 \\
\hline Activin A & R\&D Systems & 338-AC \\
\hline Albumin (human) & SIGMA Aldrich & A9731-10G \\
\hline Alginat & MP Biomedicals & 11414761 \\
\hline Wasser für Injektionszwecke & B Braun & $75 / 12604052 / 1212$ \\
\hline Ascorbinsäure & AppliChem & A1052.0100 \\
\hline B27 supplement (+Insulin) & Invitrogen ThermoFisher Scientific & $17504-044$ \\
\hline B27 supplement (-Insulin) & Invitrogen ThermoFisher Scientific & A18956-01 \\
\hline BD FACS Flow & BD Bioscience & 342003 \\
\hline BMP-4 & R\&D Systems & 314-BP \\
\hline Bovines Kollagen & Collagen Solutions LLC & A04501035332 \\
\hline Bovines Serumalbumin & Sigma Aldrich & A3311-50G \\
\hline $\mathrm{CaCl}_{2} \times \mathrm{H}_{2} \mathrm{O}$ & AppliChem & A1873,1000 \\
\hline Carbamoylcholinchlorid & SIGMA Aldrich & C4382 \\
\hline Casy ton & Omni Life Science GmbH\&Co KG & 5651808 \\
\hline CHIR 99021 & Stemgent & $130-095-555$ \\
\hline Chloroform & Roth & 4432.1 \\
\hline Collagenase Type 1 & Sigma Aldrich & Cat C0130 \\
\hline DEPC- $\mathrm{H}_{2} \mathrm{O}$ & ThermoFisher Scientific & AM9906 \\
\hline
\end{tabular}




\begin{tabular}{|c|c|c|}
\hline Substanzen & Firma & $\begin{array}{l}\text { Bestellnummer, } \\
\text { wenn vorhanden }\end{array}$ \\
\hline D-Glucose Pulver & AppliChem & A3666, 1000 \\
\hline DMEM & ThermoFisher Scientific & $61965-059$ \\
\hline DMSO & Sigma Aldrich & D2650 \\
\hline DNAse1 & Merck Millipore & 260913 \\
\hline $\begin{array}{l}\text { DPBS (ohne Calcium/ } \\
\text { Magnesium) }\end{array}$ & Invitrogen ThermoFisher Scientific & 14190-094 \\
\hline Ethanol 70\% & Roth & T868 \\
\hline Fetales Kälberserum & Invitrogen ThermoFisher Scientific & $10270-160$ \\
\hline FGF-2 & Miltenyi Biotec GmbH / Stemgent & $130-093-841$ \\
\hline Fluoromount-G & Biozol GmbH & SBA-0100-01 \\
\hline Gelatine & Sigma Aldrich & G2500 \\
\hline HEPES Puffer (1M) & ThermoFisher Scientific & $15630-122$ \\
\hline HEPES Pulver & Roth & $\mathrm{H} 77,5$ \\
\hline Histofix (4\% PFA) & Roth & P087 \\
\hline Hoechst 33342 & Life Technologies GmbH & $\mathrm{H} 3570$ \\
\hline humanes FGF-2 & Peprotech & AF-100-18B \\
\hline IGF-1 & Peprotech & AF-100-11 \\
\hline Iscove`s Medium & Biochrom Merck Millipore & F0465 \\
\hline Isoprenalin Hydrochlorid & Sigma Aldrich & $1351005-125 \mathrm{MG}$ \\
\hline IWP-4 & Miltenyi Biotec & $130-095-586$ \\
\hline KCl Pulver & Roth & HN02.3 \\
\hline Knockout DMEM & Invitrogen ThermoFisher Scientific & 10829018 \\
\hline Knockout Serum Replacement & Invitrogen ThermoFisher Scientific & 10828 \\
\hline $\begin{array}{l}\text { L-ascorbic acid } 2 \text { phosphate } \\
\text { sesquimagnesium salt hydrate }\end{array}$ & Sigma Aldrich & A8960-5G \\
\hline L-Glutamine $100 \mathrm{X}$ & Invitrogen ThermoFisher Scientific & 25030 \\
\hline $\begin{array}{l}\text { Matrigel (growth factor } \\
\text { reduced) }\end{array}$ & BD Bioscience & 354320 \\
\hline $\mathrm{MgCl}_{2} \times 6 \mathrm{H}_{2} \mathrm{O}$ & AppliChem & A4425,1000 \\
\hline $\mathrm{MgSO}_{4} \times 7 \mathrm{H}_{2} \mathrm{O}$ & Roth & T888.1 \\
\hline
\end{tabular}




\begin{tabular}{|c|c|c|}
\hline Substanzen & Firma & $\begin{array}{l}\text { Bestellnummer, } \\
\text { wenn vorhanden }\end{array}$ \\
\hline $\begin{array}{l}\text { Minimal Essential Medium } \\
\text { Non-essential amino acids } \\
100 \mathrm{X}\end{array}$ & Invitrogen ThermoFisher Scientific & 11140035 \\
\hline $\mathrm{NaCl}$ Pulver & Roth & 9265.2 \\
\hline $\mathrm{NaH}_{2} \mathrm{PO}_{4}$ & AppliChem & A1047,1000 \\
\hline $\mathrm{NaHCO}_{3}$ & Roth & 0965.3 \\
\hline Natronlauge $(1 \mathrm{~N}) \mathrm{NaOH}$ & Roth & K021.1 \\
\hline $\begin{array}{l}\text { PBS (mit Calcium/ } \\
\text { Magensium) }\end{array}$ & Invitrogen ThermoFisher Scientific & 14190 \\
\hline Penicillin/Streptomycin 100X & Invitrogen ThermoFisher Scientific & 15140 \\
\hline Phalloidin Alexa Fluor 546 & ThermoFisher Scientific & A22283 \\
\hline Phalloidin Alexa Fluor 488 & ThermoFisher Scientific & A12379 \\
\hline Pluronic F-127 stock & ThermoFisher Scientific & P3000MP \\
\hline Rhod2 AM Ester & Invitrogen ThermoFisher Scientific & R1245MP \\
\hline Rock-Inhibitor Y-27632 & Stemgent & 04-0012-10 \\
\hline $\begin{array}{l}\text { RPMI } 1640 \text { (ohne Glutamin/D- } \\
\text { Glucose) }\end{array}$ & Biological Industries & $01-101-1 \mathrm{~A}$ \\
\hline RPMI 1640 mit Glutamax & Invitrogen ThermoFisher Scientific & 61870-044 \\
\hline RPMI 1640 Pulver & Gibco ThermoFisher Scientific & $51800-035$ \\
\hline Salzsäure (1N) HCl & Roth & K025.1 \\
\hline Sodium pyruvate $100 \mathrm{X}$ & Invitrogen ThermoFisher Scientific & 11360 \\
\hline $\begin{array}{l}\text { Softa-Man } \\
\text { Händedesinfektionsmittel }\end{array}$ & BBraun & 08504964 \\
\hline Succhrose & AppliChem & A3935,1000 \\
\hline SYLGARD® Silicone Base & Dow Corning & 1023993 \\
\hline $\begin{array}{l}\text { SYLGARD® Silicone Curing } \\
\text { Agent }\end{array}$ & Dow Corning & 1024001 \\
\hline TGF-beta 1 & Peprotech & AF 100-21C \\
\hline Tissue Tek O.C.T. & Sakura Finetek & 200258 \\
\hline TritonX-100 & Sigma Aldrich & $\mathrm{X} 100$ \\
\hline Trizol Reagent & ThermoFisher Scientific & 15596018 \\
\hline TrypLE Express & Invitrogen ThermoFisher Scientific & 12604-039 \\
\hline
\end{tabular}




\begin{tabular}{|l|l|l|}
\hline Substanzen & Firma & $\begin{array}{l}\text { Bestellnummer, } \\
\text { wenn vorhanden }\end{array}$ \\
\hline Trypsin 0,25\% mit EDTA & Invitrogen ThermoFisher Scientific & $25050-014$ \\
\hline Trypsin 2,5\% & Invitrogen ThermoFisher Scientific & $15090-046$ \\
\hline Ultra Pure Agarose & Invitrogen ThermoFisher Scientific & 16500500 \\
\hline VEGF-A & Peprotech & AF-100-20 \\
\hline
\end{tabular}

$\underline{2.10 .2 \text { Geräteliste }}$

Tabelle 17: Liste der verwendeten Geräte.

\begin{tabular}{|c|c|c|}
\hline Gerät & Modell & Firma \\
\hline Autoklave & $V X-150$ & Systec \\
\hline CASY cell counter & Model TT & Roche Innovatis AG \\
\hline Durchflusszytometer & LSRII & BD Bioscience \\
\hline Eismaschine & ZBE-150 & Ziegra Eis Maschinen \\
\hline Elektrische Pipette & XP2 & Drummond \\
\hline Feinwaage & LA120S & Sartorius \\
\hline Gefrierschrank & VIP-Series $-86^{\circ} \mathrm{C}$ & SANYO \\
\hline Handycam & HDR-HC9 6,1 Megapixels & Sony \\
\hline Heizplatte & MATS & Leica \\
\hline Inkubationsschüttler & MaxQ 4450 & ThermoFisher Scientific \\
\hline Inkubator & Heracell 2401 & Thermo Fischer Scientific \\
\hline Konfokalmikroskop & LSM710 & Zeiss \\
\hline Kryotom & CM3050S & Leica \\
\hline Kühlschrank & profi line & Liebherr \\
\hline Mikroskop & Primo Vert & Zeiss \\
\hline Mikroskop & M80 & Leica \\
\hline Mikrotom & RM2255 & Leica \\
\hline MilliQ & Z00QSV0WW & Millipore Merck \\
\hline Organbäder & IOA-5301-GOW & FMI GmbH \\
\hline Paraffineinbett-automat & EG1150H & Leica \\
\hline $\mathrm{pH}-$ Meter & $\begin{array}{l}\text { Wissenschaftlich-Technische } \\
\text { Werkstätten Weilheim AG }\end{array}$ & PH 523 \\
\hline
\end{tabular}




\begin{tabular}{|l|l|l|}
\hline Gerät & Modell & Firma \\
\hline Pipetten & Research Plus & Eppendorf \\
\hline Reinluftwerkbank & Hera Guard & ThermoFisher Scientific \\
\hline Sterilbank & Steril Guard Hood & The Baker Company Inc. \\
\hline Stimulator & STI-08 & FMI GmbH \\
\hline Tissue Lyser & unbekannt & Quiagen \\
\hline Versorgungseinheit der & IOA-5310 & FMI GmbH \\
\hline Organbäder & & \\
\hline Vibrotom & VT1000S & Leica \\
\hline Vortexgerät & Genie 2 & Bender \& Hobein AG \\
\hline Waage & AZ612 & Sartorius \\
\hline Wasserbad mit Heizfunktion & DC10 & ThermoFisher Scientific \\
\hline Wippschüttler & Duomax 1030 & Rettberg \\
\hline Zentrifuge & Megafuge 3OR & Thermo Fischer Scientific \\
\hline Zentrifuge & 5804R & Eppendorf \\
\hline
\end{tabular}

\section{$\underline{\text { 2.10.3 Materialliste }}$}

Tabelle 18: Liste der verwendeten Materialien.

\begin{tabular}{|l|l|l|}
\hline Materialien & Firma & $\begin{array}{l}\text { Bestellnummer, } \\
\text { wenn vorhanden }\end{array}$ \\
\hline 12-well Zellkulturplatten & Greiner Bio-One & 665180 \\
\hline 24-well Zellkulturplatten & Greiner Bio-One & 662160 \\
\hline 500ml-Filtriersystem & Corning Inc. & 431096 \\
\hline 5 ml Polystyren Röhrchen & Falcon & 352235 \\
\hline Braunüle & B Braun & 4268333413 \\
\hline Casy tubes & Sarstedt & 58.487 \\
\hline Cell imaging dish & Zell-Kontakt & $5160-30$ \\
\hline Cellstar Reagenzgefäße 15 ml & Greiner Bio-One & $227-261$ \\
\hline Cellstar Reagenzgefäße 50 ml & Greiner Bio-One & $183-271$ \\
\hline Deckgläschen & Roth & 1871 \\
\hline FACS-Röhrchen & Thermo-Fisher Scientific & 352052 \\
\hline
\end{tabular}




\begin{tabular}{|l|l|l|}
\hline Materialien & Firma & $\begin{array}{l}\text { Bestellnummer, } \\
\text { wenn vorhanden }\end{array}$ \\
\hline Kryogefäße (Nunc) & ThermoFisher & 377267 \\
\hline Nitril-Handschuhe & Meditrade & 7696901 \\
\hline Nunclon 24-well Delta Surface & ThermoFisher & 142475 \\
\hline Objektträger superfrost plus & ThermoFisher & 31800 AMNZ \\
\hline Parafilm & Bemis & 9170002 \\
\hline Pasteurpipetten Glas & Brand GmbH\&Co & 747715 \\
\hline Pipettenspitzen 1 ml & Star Lab & S1122-1730 \\
\hline Pipettenspitzen $10 \mu 1,200 \mu \mathrm{l}$ & Star Lab & S1120-3710 \\
\hline Reagiergefäß 1,5 ml & Sarstedt & 72.690 .001 \\
\hline Reagiergefäß 2 ml & Sarstedt & 72.691 \\
\hline Schott Flaschen & Schott & Keine Angabe \\
\hline Serologische Pipetten $1 \mathrm{ml}$ & Sarstedt & 861251.001 \\
\hline Serologische Pipetten $2 \mathrm{ml}$ & Sarstedt & 861252.001 \\
\hline Serologische Pipetten $5 \mathrm{ml}$ & Sarstedt & 861253.001 \\
\hline Serologische Pipetten $10 \mathrm{ml}$ & Sarstedt & 861254.001 \\
\hline Serologische Pipetten 50 ml & Sarstedt & 861256.001 \\
\hline Spritzen steril 10 ml & BD Bioscience & 300296 \\
\hline Spritzen steril 20 ml & BD Bioscience & 309110 \\
\hline Spritzenfilter & Sarstedt & 67000 \\
\hline T25-Kulturflasche & Sarstedt & 83.3911 .002 \\
\hline T75-Kulturflasche & Sarstedt & 83.3910 .002 \\
\hline Zellfilter 40 $\mu \mathrm{m}$ & Sarstedt & 83.3945 .040 \\
\hline Zellfilter 70 $\mu \mathrm{m}$ & Sarstedt & 83.3945 .070 \\
\hline
\end{tabular}




\section{Ergebnisse}

\subsection{Testung der Antikörperspezifität an Gewebe aus Rhesusaffen}

Um die Spezifität der verwendeten Antikörper für Muskelgewebe des Rhesusaffen zu überprüfen, wurden Anti- $\alpha$-Aktinin- und Anti-Connexin-43-Antikörper an Herzmuskel und Skelettmuskel eines Rhesusaffen (Macaca mulatta) getestet. Das Gewebe wurde freundlicherweise aus dem Deutschen Primatenzentrum (DPZ; Prof. R. Behr) zur Verfügung gestellt. Zunächst wurden drei Verdünnungen des Anti- $\alpha$-Aktinin-Antikörpers getestet (siehe Tabelle 19). Hierbei zeigte sich eine charakteristische sarkomerische Querstreifung durch Anfärbung der Z-Banden (siehe Abbildung 7). Ein optimales Ergebnis hinsichtlich spezifischem Signal zu Hintergrund wurde bei einer Antikörperverdünnung von 1:500 erzielt (siehe Abbildung 8, Tabelle 19).

Tabelle 19: Ergebnisse der Verdünnungsreihe des primären Antikörpers Anti-a-Aktinin.

\begin{tabular}{|c|c|c|}
\hline Verdünnung Anti- $\alpha$-Aktinin & Spezifisches Signal & Hintergrund \\
\hline $1: 250$ & +++ & ++ \\
\hline $1: 500$ & +++ & + \\
\hline $1: 1000$ & + & + \\
\hline
\end{tabular}

Dabei stehen folgende Symbole für die Intensität des Signals: $+=$ schwach, $++=$ mittelgradig, $+++=$ stark.

Bei Negativkontrollen unter ausschließlicher Anwendung des sekundären Antikörpers zeigte sich kein Signal (siehe Abbildung 9). Bei der Verwendung von Anti-Connexin-43 Antikörpern zeigte sich entgegen der erwarteten Markierung der Glanzstreifen ein diffuses Signal entlang potentieller Zellgrenzen, sodass von einer unspezifischen Färbung auszugehen ist (siehe Abbildung 10); von einer weiteren Anwendung dieses Antikörpers wurde daher abgesehen. Entgegen der Befunde im Herzmuskelgewebe konnte in Skelettmuskelgewebe keine spezifische Markierung von Aktinin beobachtet werden (siehe Abbildung 11). Dies könnte auf Epitopunterschiede hinweisen, die allerdings in menschlichen Proben nicht zu beobachten sind. 


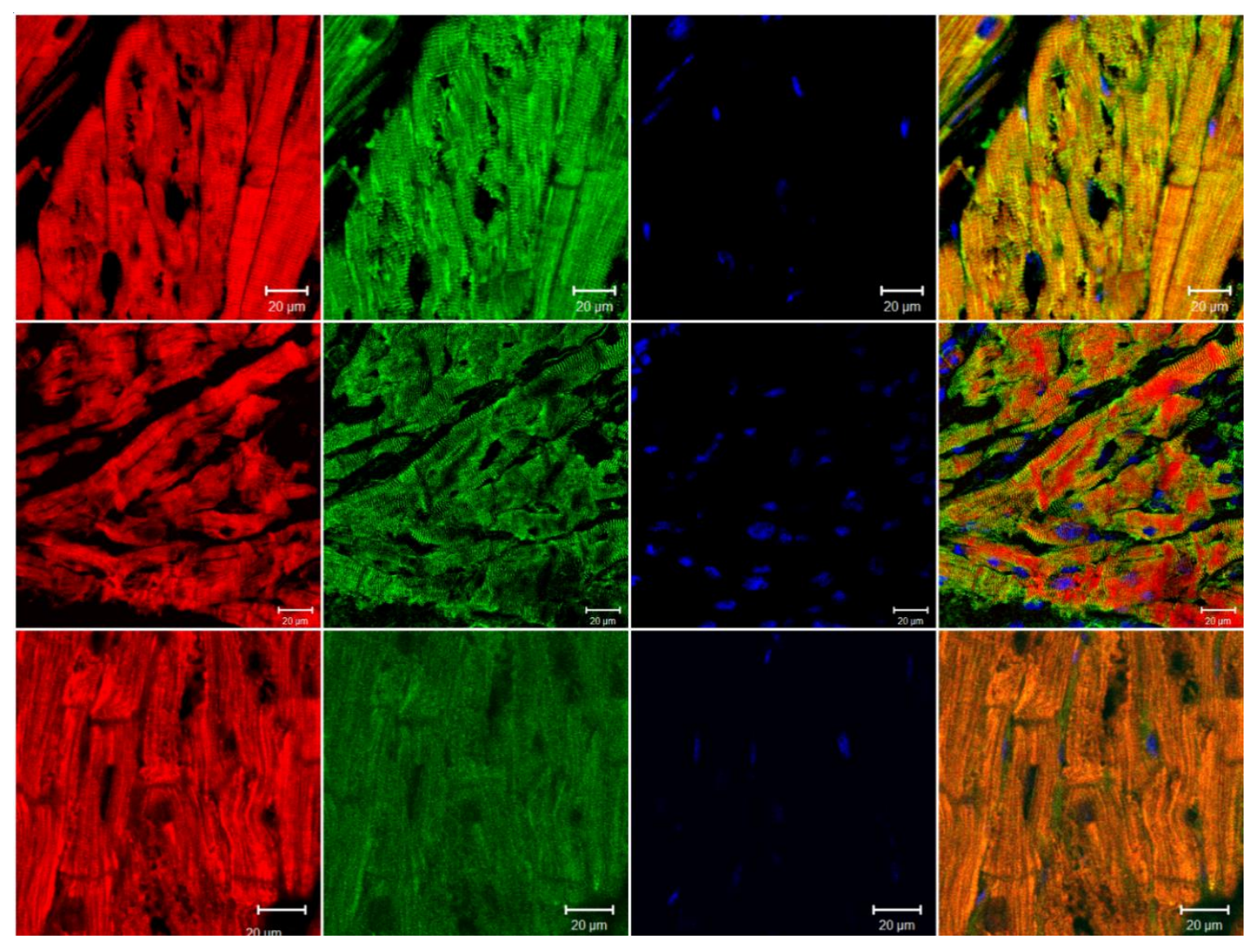

Abbildung 7: Immunfluoreszenzfärbung von Herzmuskelgewebe des Rhesusaffen, Verdünnungsreihe des Anti-alpha-Aktinin-Antikörpers. Rot =f-Aktin, grün=alpha-Aktinin, blau $=$ Hoechst. Konzentration des Anti-alpha-Aktinin-Antikörpers: obere Reihe 1:250, mittlere Reihe 1:500, untere Reihe 1:1000. Rechte Abbildungsreihe: Überlagerung der Fluoreszenzkanäle. 


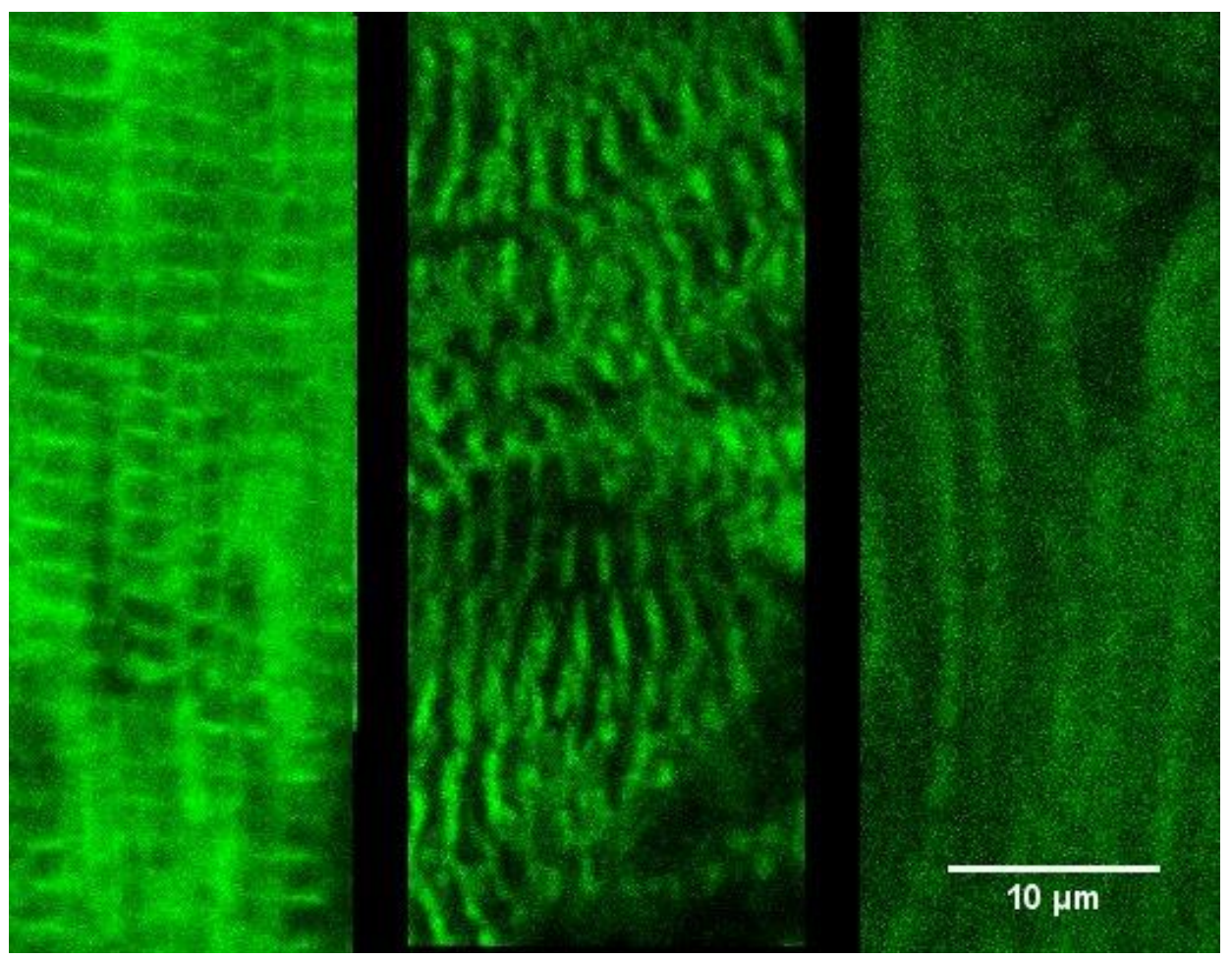

Abbildung 8: Immunfluoreszenzfärbung von Herzmuskelgewebe des Rhesusaffen, Verdünnungsreihe des Anti-alpha-Aktinin-Antikörpers in Detailaufnahme. Grün $=$ alphaAktinin. Konzentration des Anti-alpha-Aktinin-Antikörpers: von links nach rechts 1:250, 1:500, 1:1000. 


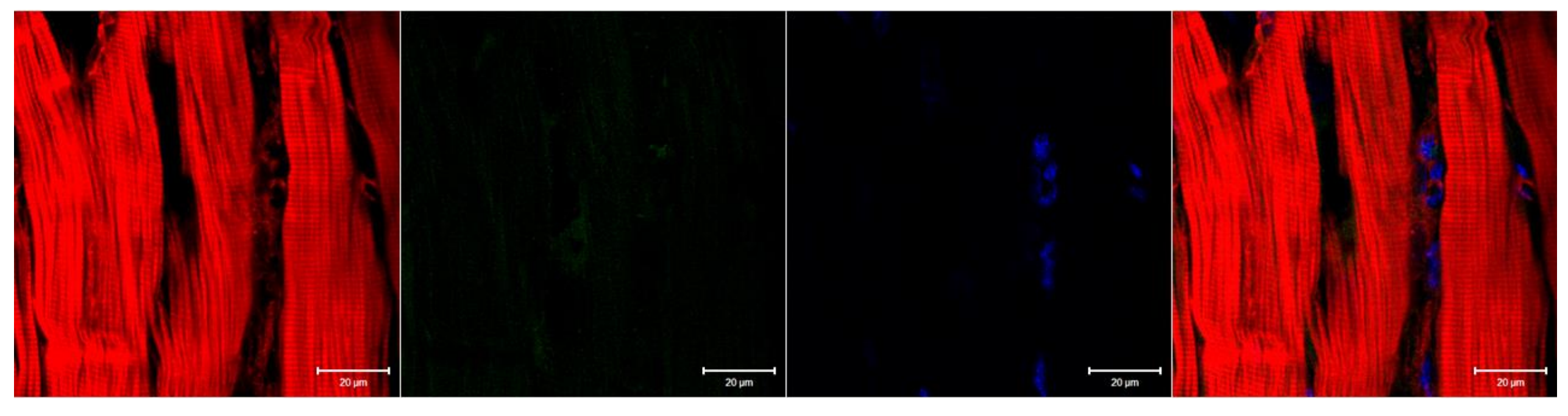

Abbildung 9: Negativkontrolle der Immunfluoreszenzfärbung von Herzmuskelgewebe des Rhesusaffen. Rot $=$ f-Aktin, grün = Negativkontrolle, blau = Hoechst. Die Negativkontrolle unter ausschließlicher Verwendung des sekundären Antikörpers zeigt keine spezifische Anfärbung. 


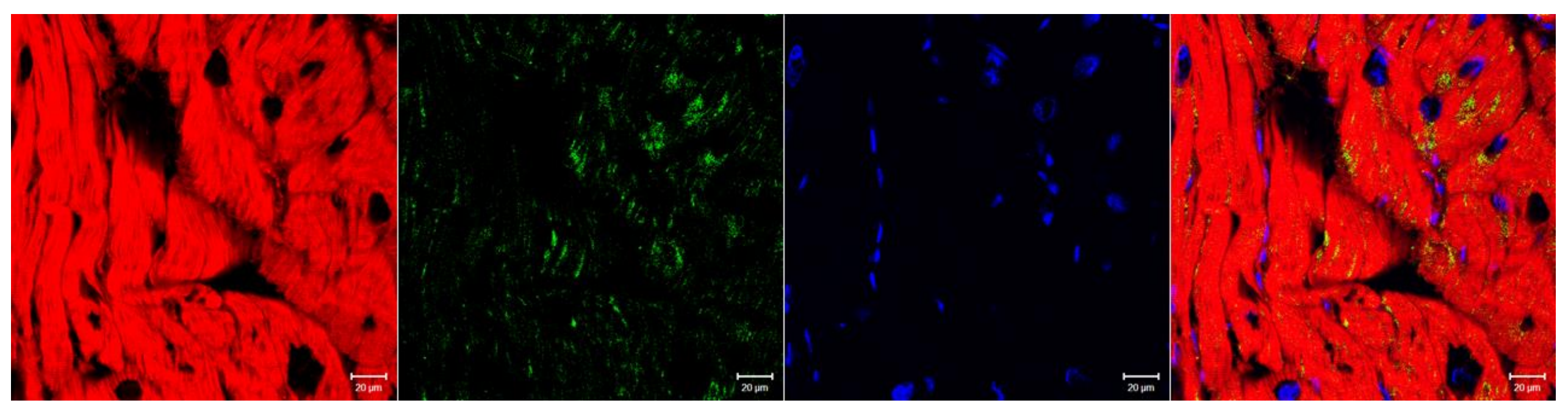

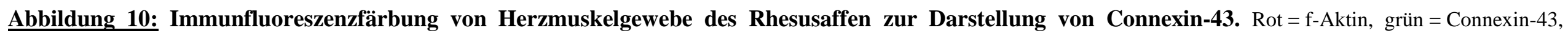
blau = Hoechst. Anti-Connexin-43 zeigt eine diffuse Anfärbung. 


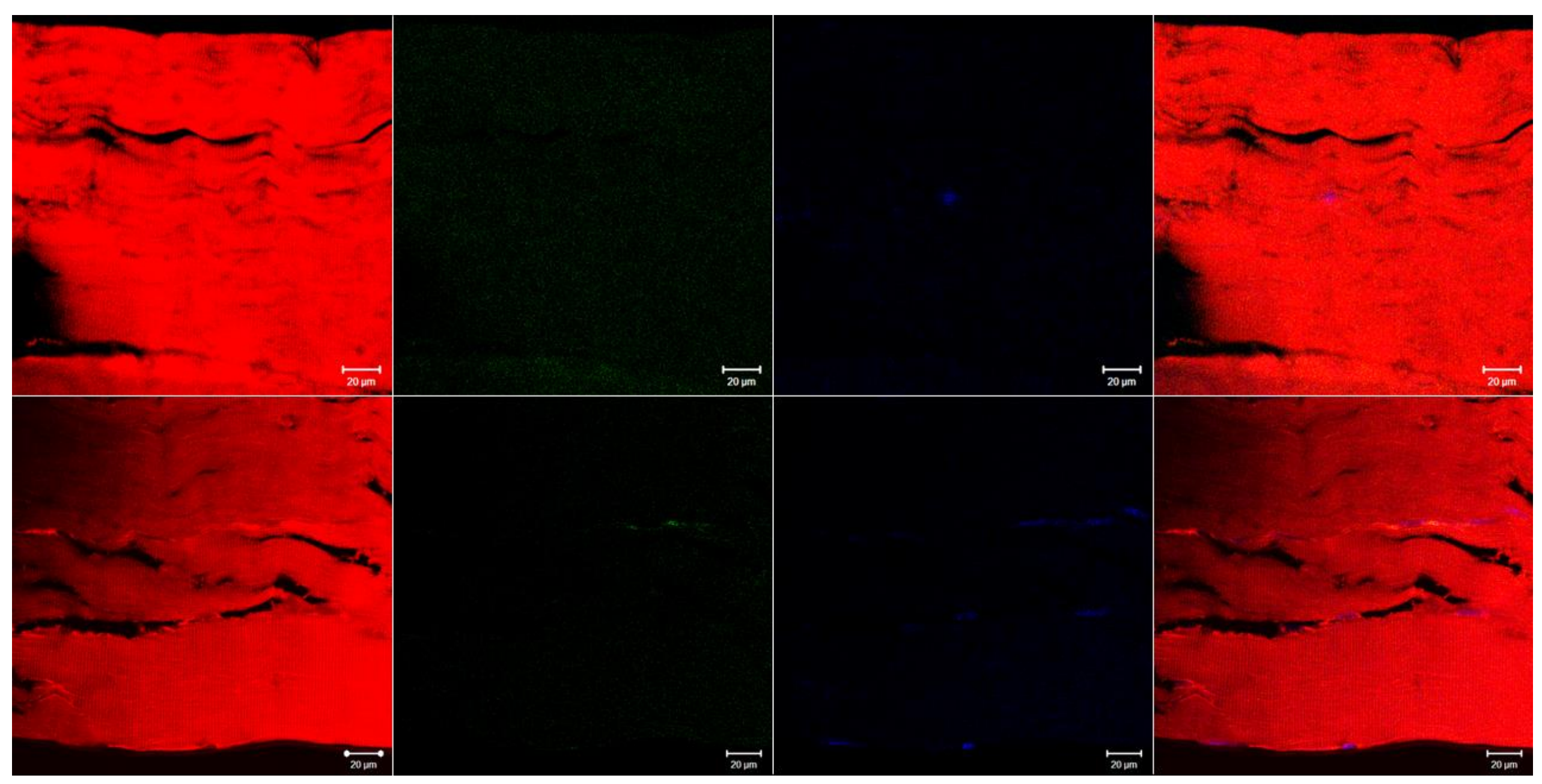

Abbildung 11: Immunfluoreszenzfärbung von Skelettmuskelgewebe des Rhesusaffen. Obere Reihe: rot = f-Aktin, grün = alpha-Aktinin, blau = Hoechst. Untere Reihe: rot = f-Aktin, grün = Negativkontrolle, blau $=$ Hoechst. Anti-alpha-Aktinin zeigt keine Reagibilität mit Skelettmuskulatur des Rhesusaffen. 


\subsection{Differenzierung von riPSC zu Kardiomyozyten}

\subsubsection{Output und Pluripotenz der riPSC-Kultur}

In Suspension ausplattierte riPSC (950.000 / T75er-Kulturflasche) setzten sich innerhalb von zwei Tagen ab, sodass ab Tag 3 ein täglicher partieller Mediumwechsel vollzogen werden konnte. In der Folge begannen die zuerst vereinzelt vorliegenden Zellen zunehmend zu konfluieren, sodass jeweils nach sieben Tagen ein Passagieren der Zellen vorgenommen werden konnte. Dabei ergab sich eine durchschnittliche Anzahl von

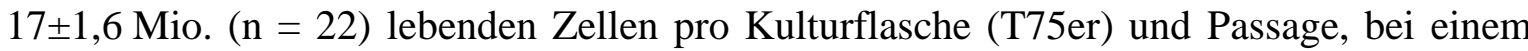

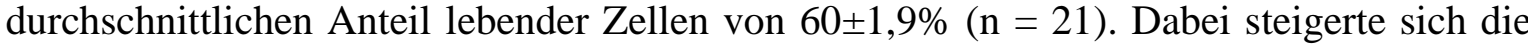
durchschnittliche Zellausbeute pro Passage während der letzten elf im Vergleich zu den ersten elf Passagen, wobei gleichzeitig der Anteil lebender Zellen sank. So konnten zu Beginn im Durchschnitt 12,9 $\pm 1,4$ Mio. lebende Zellen (Lebendzellrate durchschnittlich $64,5 \pm 2,5 \%)$ und im Verlauf eine beinahe doppelte Anzahl von 21,1 2,5 Mio. lebenden

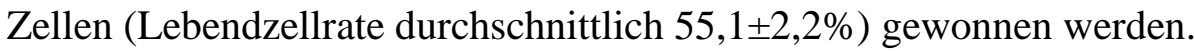

Um die Pluripotenz der riPSC-Kultur zu prüfen, wurde mehrfach eine Durchflusszytometrieanalyse unter Verwendung von Anti-TRA-1-60-Alexa-Fluor-488- und Anti-Oct3/4-Alexa-Fluor-647-Antikörpern an verschiedenen Passagen durchgeführt. Dabei wurde jeweils eine Negativkontrolle verwendet, bei der lediglich Hoechst zugesetzt wurde, um so in der Auswertung Zellen von Zelldetritus differenzieren zu können (siehe Abbildung 12). Dabei zeigte sich eine inkonstante Expression großer Variabilität dieser beiden Pluripotenzfaktoren, die tendenziell jedoch mit steigender Passagenzahl sank. Dieses Faktum ist jedoch auch in Zusammenschau mit der oben beschriebenen Zunahme der absoluten Zellzahlen bei zunehmender Höhe der Passage zu betrachten (siehe Tabelle 10, Abbildung 13). In humanen iPSC-Kulturen sind $>90 \%$ der Zellen Oct-3/4-positiv. Der im riPSC-Modell festgehaltene niedrige Anteil an Oct-3/4-positiven Zellen erklärt mutmaßlich die suboptimale Differenzierung im Rahmen der Promotionsarbeiten. 


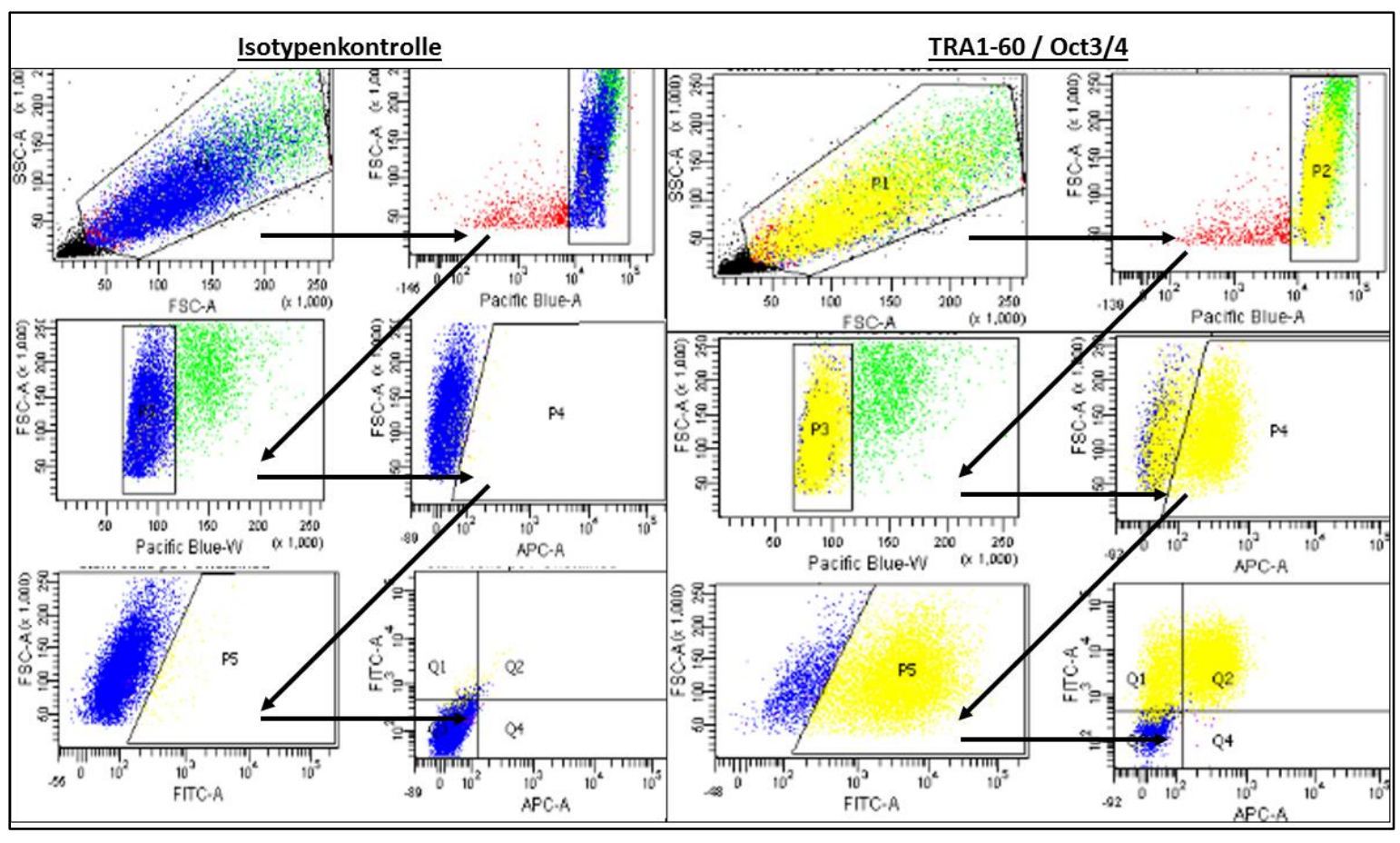

\section{Abbildung 12: Vorgehen bei der Auswertung von Ergebnissen der Durchflusszytometrie.}

Beispielhaft dargestellt ist dies anhand von riPSC p36, immunfluoreszenz-markiert mit Hoechst 33342 (Pacific-blue-Signal), Anti-TRA-1-60 (FITC-A-Signal) und Anti-Oct-3/4 (APC-A-Signal). Zuerst wurden mittels der Isotypen-Kontrolle die gates festgelegt (linke Seite), um dann TRA-1-60- und Oct-3/4-positive Zellen von für diese Marker negativen Zellen differenzieren zu können (rechte Seite). In den ersten beiden Schritten wurden zuerst anhand der Seitwärtsstreuung (1) bzw. des Pacific-blue-A-Signals (2) Zellen von Zelldetritus differenziert, um dann anhand des Pacific-blue-W-Signals (3) einkernige Zellen von Zellklumpen bzw. mehrkernigen Zellen trennen zu können. Anhand des APC-A-Signals konnten dann Oct-3/4-positive Zellen (4) und anhand des FITC-A-Signals TRA-1-60-positive Zellen (5) identifiziert werden. Bei Auftragung von APC-A- gegen FITC-A-Signal (6) konnten dann zudem doppelt positive Zellen abgegrenzt werden. 
Tabelle 20: Ergebnisse der Analyse von Pluripotenzmarkern mittels Durchflusszytometrie an riPSC.

\begin{tabular}{|c|c|c|c|}
\hline Passage & $\begin{array}{c}\text { Anti-TRA-1-60-positive } \\
\text { Zellen (gesamt) }(\boldsymbol{\%})\end{array}$ & $\begin{array}{c}\text { Anti-Oct-3/4-positive } \\
\text { Zellen (gesamt) } \mathbf{( \% )}\end{array}$ & $\begin{array}{c}\text { Doppelt positive } \\
\text { Zellen (\%) }\end{array}$ \\
\hline $\mathbf{3 2}$ & 77,5 & 53,1 & nicht bestimmt \\
\hline $\mathbf{3 3}$ & 63,7 & 38,7 & 37,3 \\
\hline $\mathbf{3 4}$ & 81,1 & 35,3 & nicht bestimmt \\
\hline $\mathbf{3 6}$ & 82,9 & 61,5 & 61,2 \\
\hline $\mathbf{3 7}$ & 27,9 & 36,4 & 5,2 \\
\hline $\mathbf{3 9}$ & 34,3 & 30,3 & 21,8 \\
\hline $\mathbf{5 6}$ & 54 & 22,2 & \\
\hline
\end{tabular}

Bei der Analyse von Passage 32 und 34 erfolgte eine separate Immunfluoreszenzfärbung von TRA-1-60 und Oct-3/4.

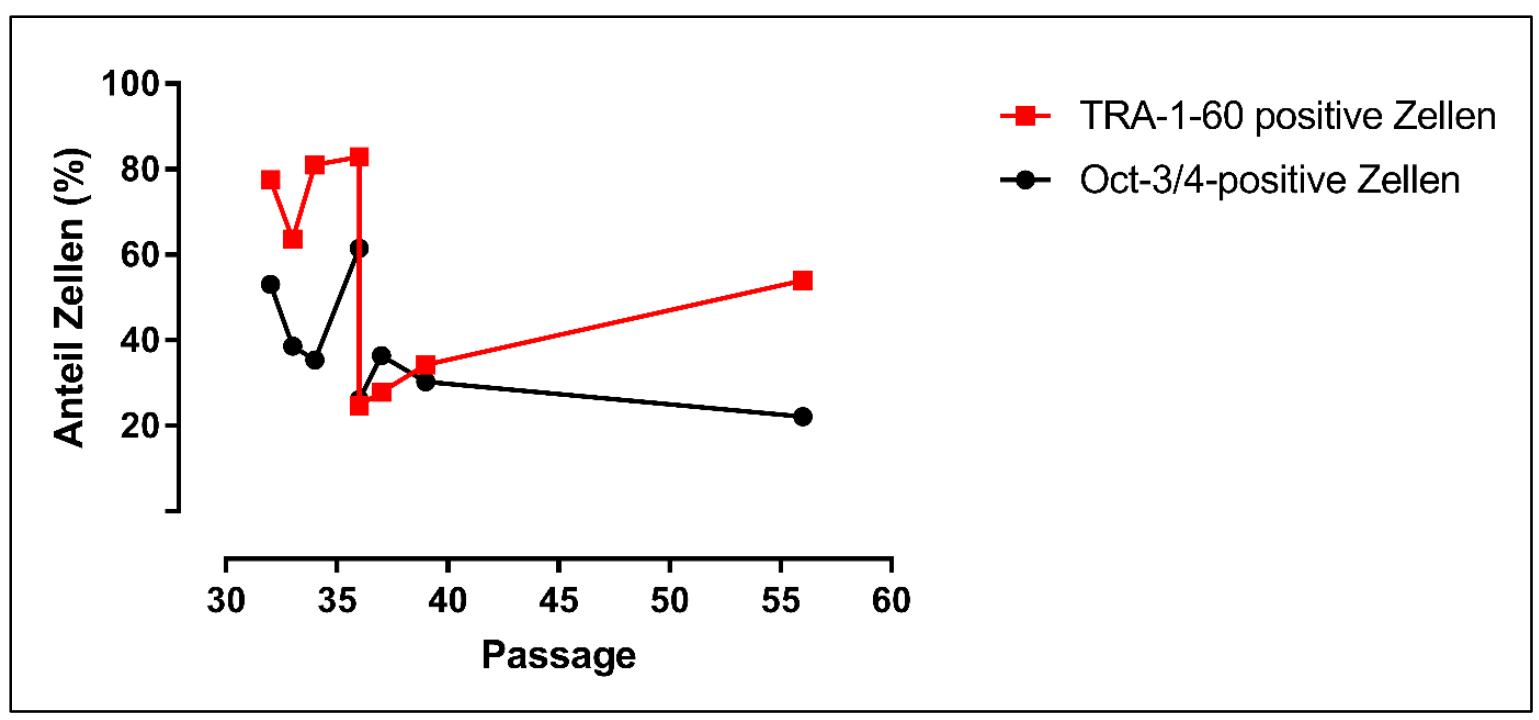

Abbildung 13: Pluripotenzfaktorenanalyse von riPSC mittels Durchflusszytometrie. Auf der $x-$ Achse ist die Passagenzahl der riPSC und auf der y-Achse der Anteil TRA-1-60- beziehungsweise Oct-3/4positiver Zellen dargestellt.

\subsubsection{Differenzierung zu Kardiomyozyten}

In der vorliegenden Arbeit wurde ein von Tiburcy et al. (2017) publiziertes gerichtetes Differenzierungsprotokoll verwendet, welches eine metabolische Selektion beinhaltet. Das 
Protokoll wurde durch Dr. Brian Golat modifiziert und durch die Verwendung der Encapsulation-Technik erweitert. Das hier verwendete Protokoll beinhaltet die frühe WntAktivierung mittels Activin A, BMP-4 und CHIR 99021 sowie den Wechsel zur WntBlockade vermittels IWP-4 an Tag drei der Differenzierung, um die einleitend dargelegte biphasische Wnt-Modulation zu gewährleisten.

Die Differenzierung begann mit dem Einkapseln der riPSC in Alginat an Tag minus 4. Dies folgte weitestgehend einem bereits von Sidhu et al. (2012) publizierten Protokoll. Dort wurde gezeigt, dass Stammzellen nach Einkapselung in Alginat weiterhin proliferieren und embryoid bodies formieren können. Außerdem zeigten Sidhu et al. (2012), dass die Differenzierung in verschiedene Zelllinien unter Verwendung dieser Technik möglich ist. Die Verwendung des Rock-Inhibitors Y-27632 verhindert eine durch Zellvereinzelung induzierte Apoptose, erhöht die Überlebensrate von Stammzellen und fördert die Bildung von Zell-Clustern (Watanabe et al. 2007; Koyanagi et al. 2008; Sidhu et al. 2012). Aus diesem Grund erfolgte die Zugabe dieses Inhibitors zwei Stunden vor Einkapselung in das Medium der Stammzellkultur, während der Einkapselung zum Alginat und im Anschluss in das Medium der Differenzierungskultur an den Tagen minus vier, minus 3, minus zwei bzw. ab Differenzierung 16 nur noch an den Tagen minus 4 und minus eins.

Während der ersten vier Tage, von Tag minus vier bis Tag minus eins, erfolgte die Kultur in hES-Medium innerhalb der Alginatkügelchen. In dieser Zeit bildeten sich aus den zu Beginn vereinzelt vorliegenden riPSC-Zellhaufen, die Zellkolonien darstellten und die in dieser Zeit kontinuierlich an Größe zunahmen. Dieser Abschnitt des Protokolls diente vor allem der Expansion der riPSC und der Anpassung an die Kultur in Alginat. Die Einkapselung wurde verwendet, um einen optimalen Zustand für eine Differenzierung einer spezifischen Zellzahl in einer definierten Umgebung vorzubereiten.

An Tag null erfolgte ein Wechsel auf mesodermales serumfreies Medium, welches wie oben erwähnt CHIR 99021, BMP-4, Activin A und FGF-2 enthält und die Differenzierung zu mesodermalen Progenitoren mittels Aktivierung des Wnt-Signalweges initiiert. Ab Tag drei der Differenzierung wurde auf kardiales serumfreies Differenzierungsmedium, welches den Wnt-Inhibitor IWP-4 enthält, gewechselt, um die kardiale Determinierung der mesenchymalen Vorläuferzellen $\mathrm{zu}$ induzieren. In der Zellkultur konnte beobachtet werden, dass die innerhalb der ersten Tage entstandenen Zellhaufen während der Tage null 
bis drei weiter an Größe zunahmen und begannen, sich aus den Alginatkügelchen zu lösen und am Boden abzusetzen. Aus den sich dort festsetzenden Zellhaufen kam es in der Folge zu einer kontinuierlichen, radiären Ausbreitung der Zellen in die Umgebung. Ab Tag fünf war das Absetzen der Zellkolonien und die Auflösung der Alginatkügelchen abgeschlossen und es konnte aus diesem Grund beim Mediumwechsel auf ein Pelletieren der Zellen verzichtet werden. Die Ausbreitung der Zellen setzte sich in der Folge fort, bis der Zellrasen den gesamten Boden der Zellkulturflaschen einnahm, wobei sich zwischen den ursprünglichen Zellhaufen Bänder höherer Zelldichte ausbildeten. Zu ersten Kontraktionen kam es in der Regel zwischen Tag 10 und Tag 13 der Differenzierung. Sie begannen dabei zunächst vereinzelt in verschiedenen Bereichen des Zellrasens in den ursprünglich abgesetzten Zellhaufen. Unter der sich ab Tag 13 anschließenden Laktatselektion, die bis Tag 17 fortgeführt wurde, verbreiterten sich die kontrahierenden Areale, bis es zu flächigen, die gesamte Kultur umfassenden Kontraktionen kam. Dabei konnte beobachtet werden, dass sich zunehmend größere Areale synchronisierten. Zudem konnten „Schrittmacherareale“ beobachtet werden, von denen Kontraktionswellen ausgingen, die über größere Bereiche hinwegliefen (siehe Abbildung 14).

Wie erwartet konnte unter der Laktatselektion das Absterben nichtkardialer Zellen beobachtet werden, während sich die Kontraktionen der Kardiomyozyten zunehmend synchronisierten und an Stärke zunahmen. Zum Teil entstanden durch dieses Zellsterben Lücken im Zellrasen. Zudem zeichnete sich im Laufe der Selektion, beginnend etwa ab Tag 14, eine Tendenz zur Entwicklung von „Zellsträngen“ ab. In diesen schienen sich synchronisierte Kardiomyozyten zu verdichten. Sie entsprachen dabei vermutlich den oben beschriebenen Zellhaufen und den sich zwischen ihnen ausbildenden „Zellbändern“. Diese entwickelten starke und synchronisierte Kontraktionen, die gegen Ende der Selektion zu einer teilweisen Ablösung vom Boden der Kulturflaschen führten. Diese Ablösung entstand vermutlich auf Grund von entstehenden Scherkräften. Sie wurde begünstigt durch das Absterben der sich zwischen den Herzmuskelzellen befindlichen nichtkardialen Zellen, da dies die Stabilität der Verankerung des Zellrasens am Kulturboden beeinträchtigte (siehe Abbildung 14). Ab Tag 17 wurden die Zellen in serumfreiem Medium kultiviert, um eine Erholung von selektionsbedingtem Stress zu ermöglichen, bevor die Zellen an Tag 21 ihrer weiteren Verwendung zugeführt wurden. Während dieser Zeit verstärkte sich die bereits oben beschriebene Tendenz zur Ausbildung von kontrahierenden Zellsträngen, die Kontraktionen nahmen leicht an Intensität zu, und die Ablösung schritt ebenfalls voran. 
Dennoch blieb der Zellrasen in der Regel überwiegend verankert, nur in Ausnahmefällen löste er sich durch die Kontraktionen vollständig ab.

Im Rahmen dieser Arbeit wurden 23 Differenzierungsdurchläufe durchgeführt, von denen elf erfolgreich waren. Dabei wurde eine Differenzierung als gelungen gewertet, wenn sie zur Ausbildung mikroskopisch deutlich sichtbarer Kontraktionen führte. In 2 Fällen konnte das Misslingen der Differenzierung auf eine vermutlich inaktive IWP-4-Charge zurückgeführt werden, da diese bei zeitgleicher Verwendung in anderen Arbeitsgruppen ebenfalls versagte. Zudem kam es während eines weiteren Durchlaufes zu einer fehlerhaften Umsetzung des Protokolls. Eine weitere Differenzierung musste wegen Kontamination verworfen werden, bevor ihre Effektivität evaluiert werden konnte. Somit müssen vier Differenzierungsdurchgänge von der Auswertung ausgeschlossen werden. Damit waren von 19 gewerteten Differenzierungen elf erfolgreich, was einem Anteil von $58 \%$ entspricht. Das Versagens des Differenzierungsprotokolls in den übrigen acht Durchläufen deutet darauf hin, dass das für humane Zellen entwickelte Protokoll weiter optimiert werden muss, um im Rhesusaffen ähnliche Ergebnisse zu erreichen.

Nach Beendigung der Differenzierung wurden die Zellen vereinzelt, gezählt und zur Herstellung von EHM verwendet. Zudem wurde jeweils eine Probe genutzt, um den Kardiomyozytenanteil mittels Durchflusszytometrie unter Verwendung eines Anti- $\alpha$ Aktinin-Antikörpers zu bestimmen. Dabei wurden $\alpha$-Aktinin-positive Zellen als Kardiomyozyten angesehen. Bei zwei Differenzierungen, darunter Diff.12, misslang die Evaluation des Kardiomyozytenanteils, weshalb im Nachfolgenden lediglich Daten aus neun Differenzierungen einbezogen werden. Aus diesen ergab sich eine Grundgesamtheit von $\mathrm{n}=48$ T25er Kulturflaschen. Daraus konnten folgende Daten ermittelt werden:

Bezogen auf eine Kulturflasche (T25er) konnten bei einem Input von einer Million Zellen durchschnittlich 2.750.417 \pm 223.894 lebende Zellen, bei einer Lebendzellrate von $41 \pm 2 \%$, gewonnen werden. Innerhalb dieser ergab sich ein Kardiomyozytenanteil von durchschnittlich $51 \pm 3 \%$ pro Flasche, was einer Anzahl von 1.481.784 \pm 119.122 lebenden Herzmuskelzellen entspricht. Daraus lässt sich ein etwa 1,5-facher Output lebender Kardiomyozyten in Bezug auf den Einsatz an riPSC ermitteln $(148 \pm 12 \%, \mathrm{n}=48)$. Diese Daten zeigen, dass das verwendete Differenzierungsprotokoll nicht die erwünschte Reinheit an Herzmuskelzellen erbrachte. Zwar lag sie mit gut 50\% über den Ergebnissen einer spontanen Differenzierung, erreichte aber auch nicht die Erfolge anderer Arbeiten. So 
konnten Tohyama et al. (2013) zeigen, dass durch die Laktatselektion Kardiomyozytenanteile von bis zu 99\% erreicht werden können. Ein weiteres Problem war die hohe Zellsterblichkeit bei der Zellvereinzelung im Anschluss an die Differenzierung, da hierbei über die Hälfte der Kardiomyozyten verloren ging. Der Output an Herzmuskelzellen lag mit knapp 150\% deutlich unter dem Niveau anderer Arbeiten. Beispielsweise erreichten Lian et al. (2012) einen 15-fachen Output. Insgesamt erfüllte das verwendete Protokoll in Bezug auf Überlebensrate und Kardiomyozytenanteil nicht die Erwartungen, genügte jedoch, um funktionstïchtige EHM aus riPSC zu gewinnen. 


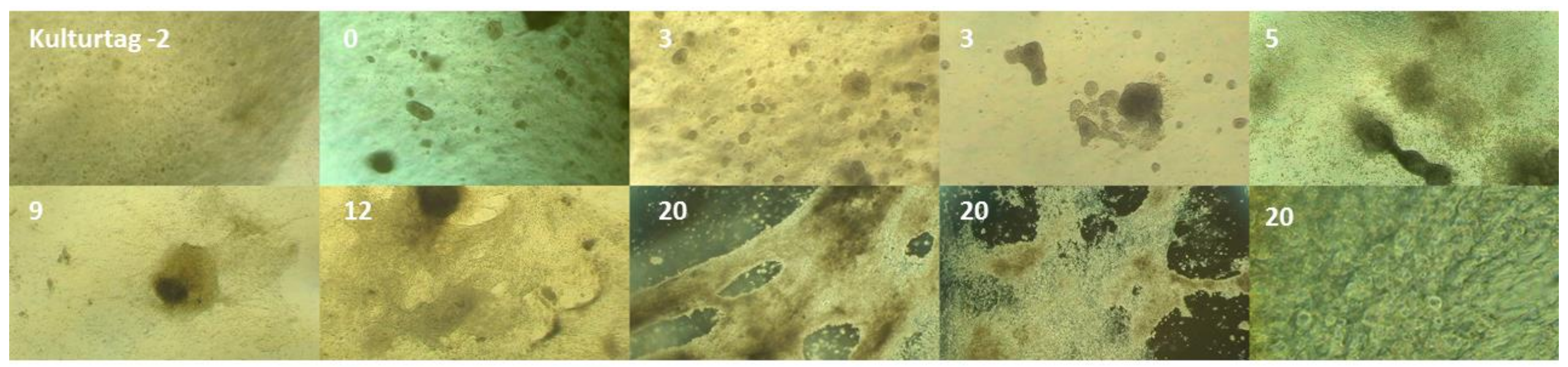

Abbildung 14: Entwicklung der Zellkultur im Verlauf der Differenzierung. Obere Reihe von links nach rechts: Alle Aufnahmen wurden in fünffacher Vergrößerung aufgenommen. Zellen der Differenzierung \#2. (Kulturtag -2) Kleine Zellhaufen formieren sich. (Kulturtag 0) Zellhaufen unterschiedlicher Größe entstehen. (Kulturtag 3) Zellhaufen innerhalb der Alginatkügelchen sind zu erkennen. (Kulturtag 3) Ein Teil der Zellhaufen hat sich bereits abgesetzt. (Kulturtag 5) Nach Auflösung der Alginatkügelchen proliferieren die sich abgesetzten Zellhaufen und breiten sich aus. Untere Reihe von links nach rechts: Bilder 1-4 wurden in fünffacher Vergrößerung akquiriert. Zellen der Differenzierung \#1. (Kulturtag 9) Die Ausbreitung eines Zellhaufens ist zu sehen. (Kulturtag 12) Standbild eines videooptisch schlagenden Areals: Zellbänder sind zu erkennen, Kontraktionswelle weitet sich von der rechten oberen Ecke aus. Dort kann ein Schrittmacherzentrum vermutet werden. (Kulturtag 20) Standbild eines videooptisch kräftig schlagenden Areals: Zu erkennen sind vom Untergrund abgelöste starke Zellstränge, die von links nach rechts laufen und am rechten Rand noch anhaften. (Kulturtag 20) Standbild eines videooptisch schlagenden Areals: Ersichtlich ist ein Areal derselben Kulturflasche, welches sich jedoch noch nicht ablöst. (Kulturtag 20) Detailaufnahme im Standbild eines kontrahierenden Areals in 63facher Vergrößerung, zum Teil sind die Zellgrenzen einzelner Kardiomyozyten auszumachen. 
3.3 Morphologische Charakterisierung der differenzierten Kardiomyozyten mittels $\underline{\text { Immunfluoreszenzfärbungen }}$

Zur morphologischen Charakterisierung der differenzierten Kardiomyozyten wurden Immunfluoreszenzfärbungen analog $\mathrm{zu}$ den Färbungen an nativem Gewebe des Rhesusaffen durchgeführt. Dazu wurden nach Standardprotokoll differenzierte Kardiomyozyten verwendet. Teilweise wurden diese freundlicherweise von Dr. Brian Golat bereitgestellt. Das Spektrum verwendeter Antikörper wurde im Vergleich zu den Gewebefärbungen um Anti-MF20 (Myosin), Anti-sarkomerisches Tropomyosin, Antikardiales Troponin I, Anti-GATA4 und Anti-NKX2.5 erweitert. Dadurch sollte eine umfassendere Untersuchung typischer Strukturproteine in Herzmuskelzellen und, mittels der beiden zuletzt genannten Antikörper, von für die kardiale Differenzierung wichtigen Transkriptionsfaktoren erfolgen.

Es zeigte sich, dass $\alpha$-Aktinin in den differenzierten Zellen exprimiert wird und zusammen mit f-Aktin eine charakteristische Querstreifung bildet. Diese entsteht entsprechend dem Aufbau von Sarkomeren: $\alpha$-Aktinin ist in den Z-Streifen lokalisiert und verankert dort die Aktinfilamente, wohingegen diese die I- und Teile der A-Bande darstellen. Zudem ist in den Immunfluoreszenzfärbungen zu erkennen, dass Kardiomyozyten Netzwerke ausbilden (siehe Abbildungen 15 und 16).

Connexin-43 ist Teil von gap junctions des Myokards. In Abbildung 17 ist zu erkennen, dass Färbungen mit Anti-Connexin-43-Antikörpern kein spezifisches Signal aufweisen.

Anti-MF20-Antikörper markieren sowohl schnelle als auch langsame schwere MyosinKetten (Bergmann et al. 2001) und somit die A-Banden im Sarkomer. In Abbildung 18 ist bei Verwendung dieses Antikörpers eine Querstreifung zu erkennen.

Tropomyosin und insbesondere kardiales Troponin I (cTnI) sind entscheidende Bindeglieder in der Umsetzung von Erregung zu Kontraktion im Herzmuskel. Abbildung 19 zeigt ein deutliches Signal in der Immunfluoreszenzfärbung mit Anti-sarkomerischenTropomyosin-Antikörpern. Da sich Tropomyosin als filamentäres Protein dem f-Aktin anlagert, ist es ebenso wie dieses Bestandteil der I- und A-Banden und erzeugt die charakteristische Querstreifung, wie hier ersichtlich. Im Gegensatz dazu ist Troponin ein globuläres Protein, das sich in regelmäßigen Abständen dem Tropomyosin anlagert, 
prinzipiell aber Anteil an denselben Banden hat. In Abbildung 20 ist dieses Bandenmuster jedoch schlecht auszumachen und nur rudimentär vorhanden. Zusätzlich zu seiner Ausprägung als Bestandteil der kontraktilen Filamente ist hier auch eine deutliche Lokalisierung in den Nuklei zu erkennen, wie an der Überlagerung von Anti-cTnIAntikörper- und Hoechst-Signal ersichtlich ist. Dies entspricht den Forschungsergebnissen von Bergmann et al. (2009). Diese Gruppe konnte nachweisen, dass cTnI und cTnT nicht nur im Zytoplasma, sondern ebenso in Zellkernen adulter humaner Kardiomyozyten lokalisiert sind.

Zuletzt zeigt Abbildung 21 eine nukleäre Lokalisation von NKX2.5. Dies entspricht dessen Funktion als Transkriptionsfaktor der Herzentwicklung. NKX2.5 wird für die Differenzierung mesenchymaler Progenitorzellen zu Kardiomyozyten benötigt, persistiert jedoch auch in adulten Herzmuskelzellen (Tanaka et al. 1999). NKX2.5 ist dabei jedoch nicht spezifisch für kardiale Zellen, sondern spielt auch eine Rolle bei der Differenzierung zu glatten Muskelzellen und endothelialen Zellen. Im Rahmen dieser Arbeit kann ein positives Anti-NKX2.5-Signal als Ausdruck einer kardialen Differenzierung verstanden werden. Immunfluoreszenzfärbungen mit Anti-GATA4-Antikörpern erbrachten kein eindeutiges Signal. Da dieser Transkriptionsfaktor eine essenzielle Rolle in der embryonalen Herzentwicklung und der Differenzierung mesenchymaler Vorläuferzellen zu kardialen Zellen spielt und zudem mit NKX2.5 interagiert, lässt sich hier eine mangelnde Spezifität des genutzten Antikörpers für Rhesusaffenzellen vermuten.

Die Zusammenschau obiger Ergebnisse zeigt, dass die aus riPSC differenzierten Zellen charakteristische kardiale Marker exprimieren. Zudem zeigen sie eine typische kardiale Morphologie, da sie kontraktile Filamente mit klassischer sarkomerischer Struktur ausbilden. Darüber hinaus exprimieren sie mit NKX2.5 einen wichtigen Transkriptionsfaktor der kardialen Differenzierung. 
Tabelle 21: Spezifität der Immunfluoreszenzfärbung von aus riPSC differenzierten Kardiomyozyten.

\begin{tabular}{|c|c|}
\hline Antikörper & Spezifisches Signal \\
\hline Anti- $\alpha$-Aktinin & + \\
\hline Anti-MF20 (Myosin) & + \\
\hline Anti-sarkomerisches Tropomyosin & + \\
\hline Anti-kardiales-Troponin I & + \\
\hline Anti-NkX2.5 & - \\
\hline Anti-GATA4 & + \\
\hline Anti-Connexin-43 & + \\
\hline
\end{tabular}

Dabei stehen folgende Symbole für die Spezifität des Signals: - = nicht vorhanden, $+=$ vorhanden. 


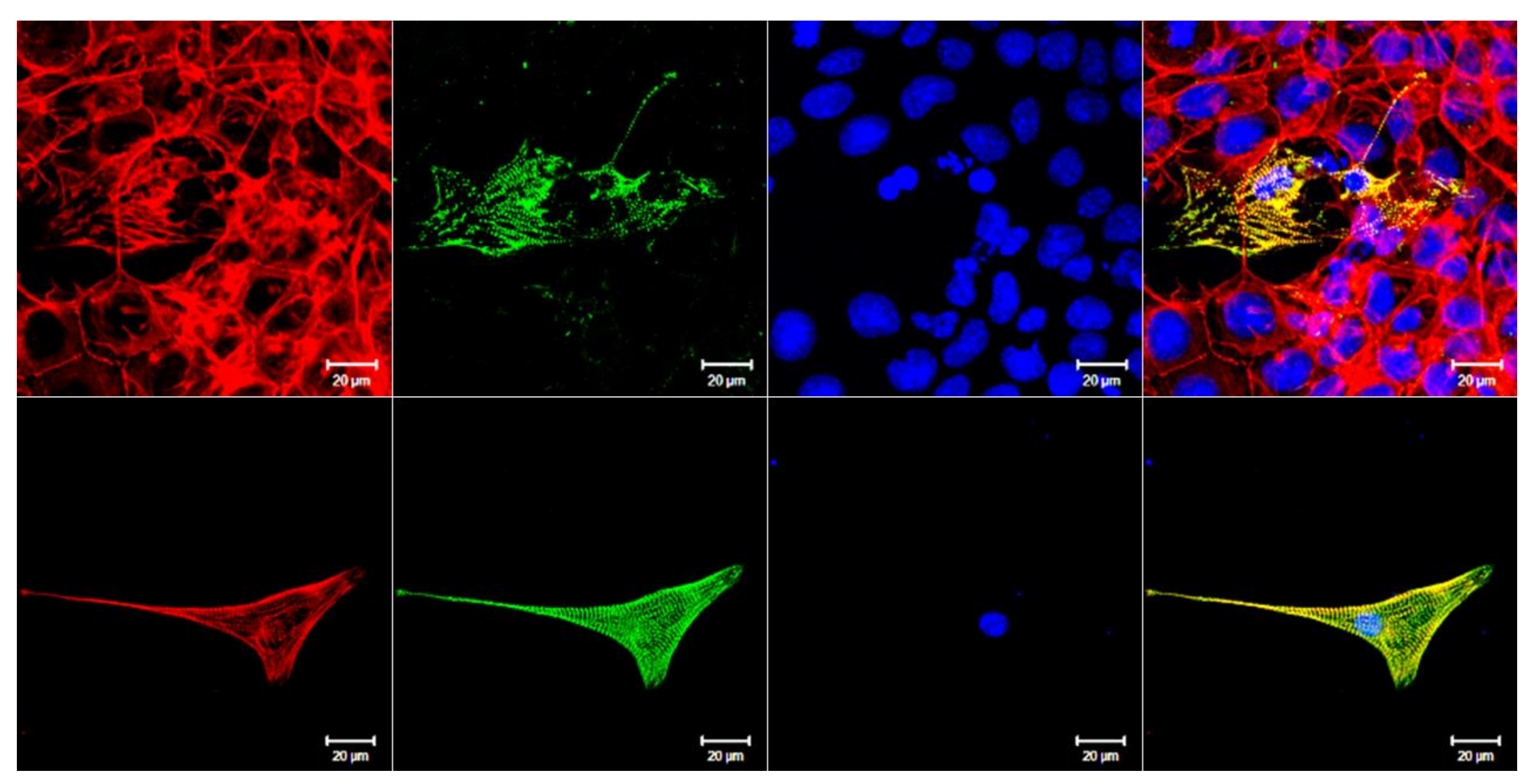

Abbildung 15: Immunfluoreszenzfärbung von aus riPSC differenzierten Kardiomyozyten zur Darstellung von $\alpha$-Aktinin (1). Verwendet wurden nach Standardprotokoll differenzierte Kardiomyozyten. Rot $=\mathrm{f}$-Aktin, grün $=\alpha$-Aktinin, blau=Hoechst. Obere Reihe: Zu sehen sind mittig liegende Kardiomyozyten, die eine regelmäßige Querstreifung aufweisen, umgeben von Nichtmyozyten. Untere Reihe: Abbildung einer singulär liegenden Kardiomyozyte. 


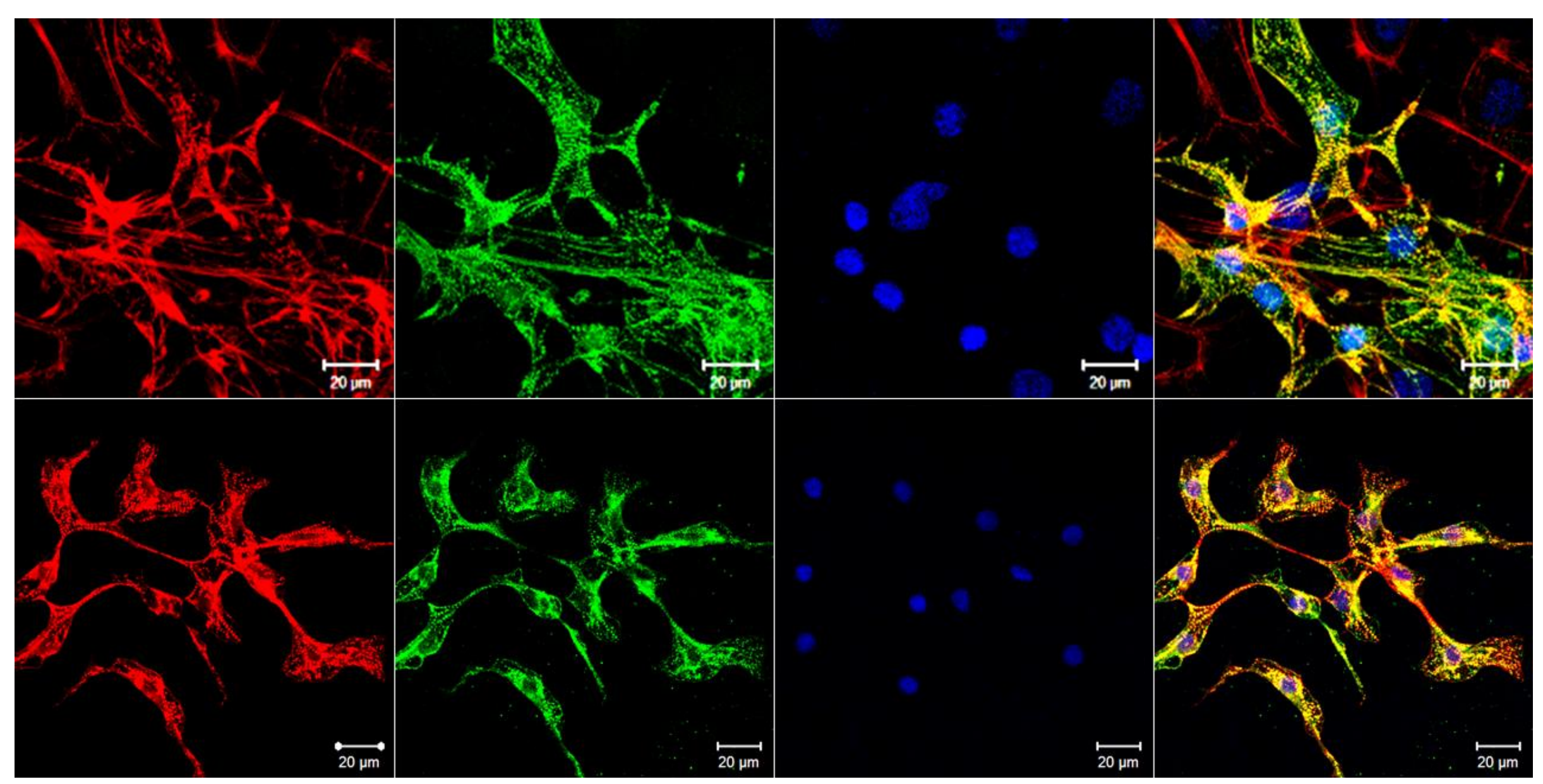

Abbildung 16: Immunfluoreszenzfärbung von aus riPSC differenzierten Kardiomyozyten zur Darstellung von $\alpha$-Aktinin (2). Verwendet wurden nach Standardprotokoll differenzierte Kardiomyozyten. Rot $=$ f-Aktin, grün $=\alpha$-Aktinin, blau= Hoechst. Obere Reihe: Zu sehen ist ein Netz aus Kardiomyozyten, umgeben von Nichtmyozyten. Sie bilden lang gestreckte Muskelfibrillen untereinander aus, die quer über das Bild verlaufen, bestehend aus Sarkomeren (Querstreifung). Untere Reihe: Ein Netzwerk aus Herzmuskelzellen. Auch hier sind Filamentbrücken zwischen den Zellen zu erkennen. 


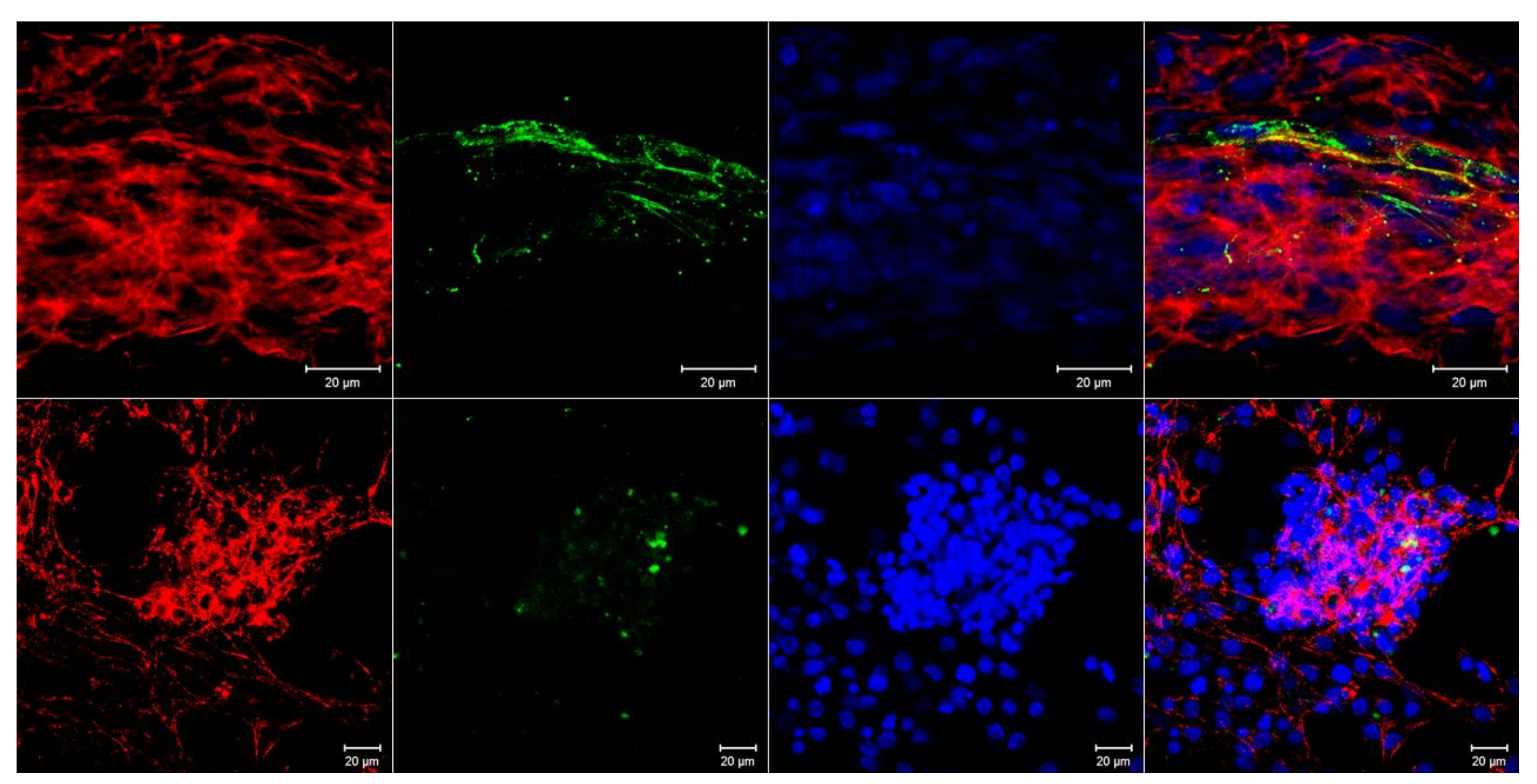

Abbildung 17: Immunfluoreszenzfärbung von aus riPSC differenzierten Kardiomyozyten zur Darstellung von Connexin-43. Verwendet wurden nach Standardprotokoll differenzierte Kardiomyozyten. Rot = f-Aktin, grün = Connexin-43, blau = Hoechst. Es zeigt sich kein spezifisches Signal. 


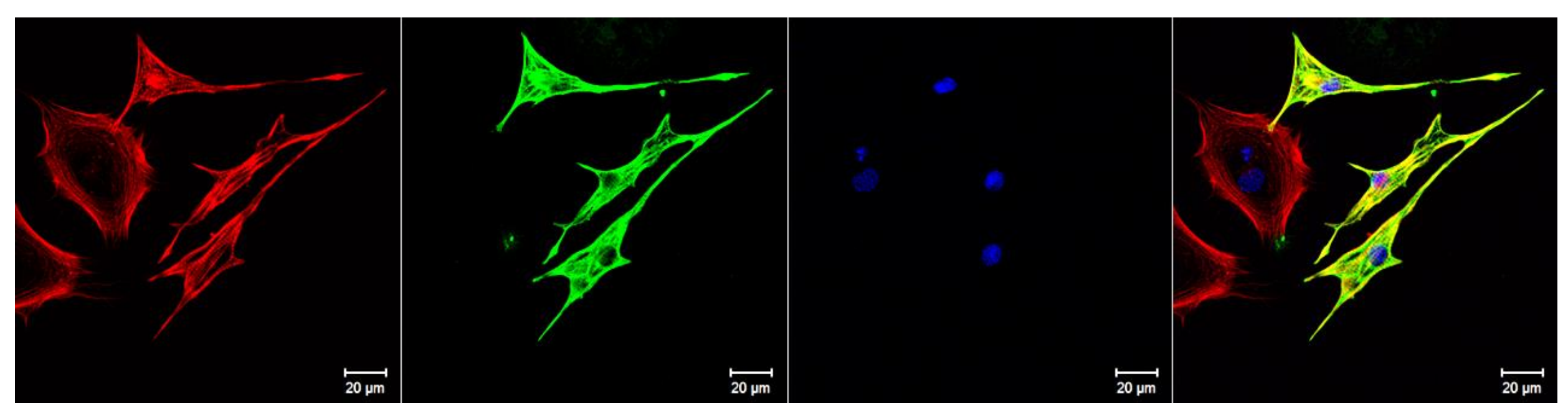

Abbildung 18: Immunfluoreszenzfärbung von aus riPSC differenzierten Kardiomyozyten zur Darstellung von Myosin. Verwendet wurden nach Standardprotokoll differenzierte Kardiomyozyten. Rot = f-Aktin, grün = Myosin, blau = Hoechst. Zu erkennen ist auch hier eine regelmäßige Querstreifung, auf der rechten Bildseite befinden sich drei Kardiomyozyten in eindeutiger Abgrenzung zu zwei Nichtmyozyten. 


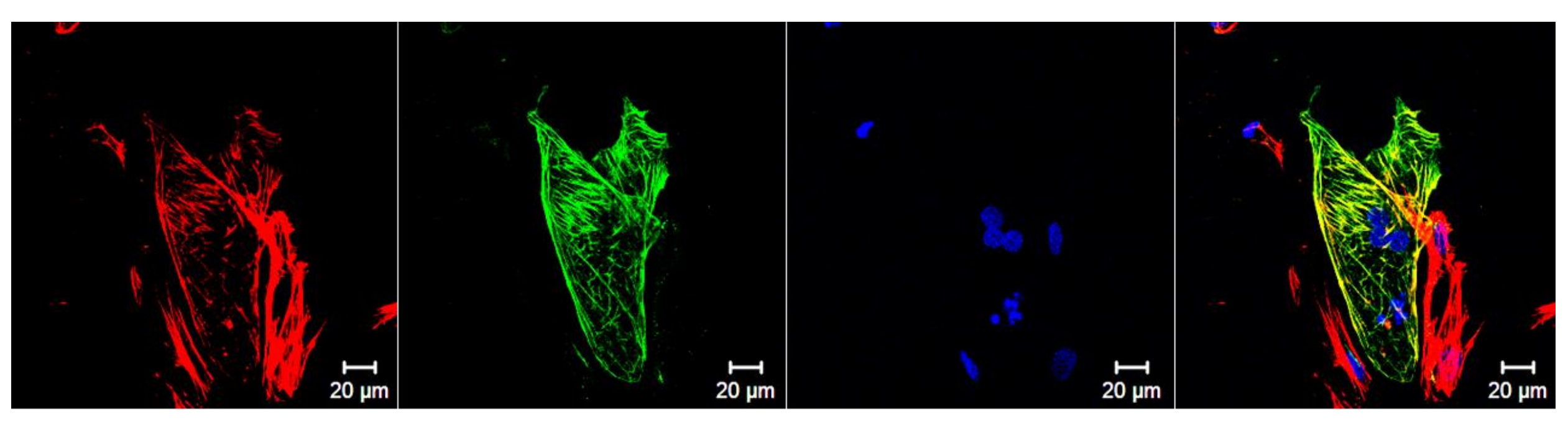

Abbildung 19: Immunfluoreszenzfärbung von aus riPSC differenzierten Kardiomyozyten zur Darstellung von Tropomyosin. Verwendet wurden nach Standardprotokoll differenzierte Kardiomyozyten. Rot = f-Aktin, grün = Tropomyosin, blau = Hoechst. Zu sehen sind mittig liegende Kardiomyozyten, die ein Filamentnetz mit Querstreifung ausbilden. 


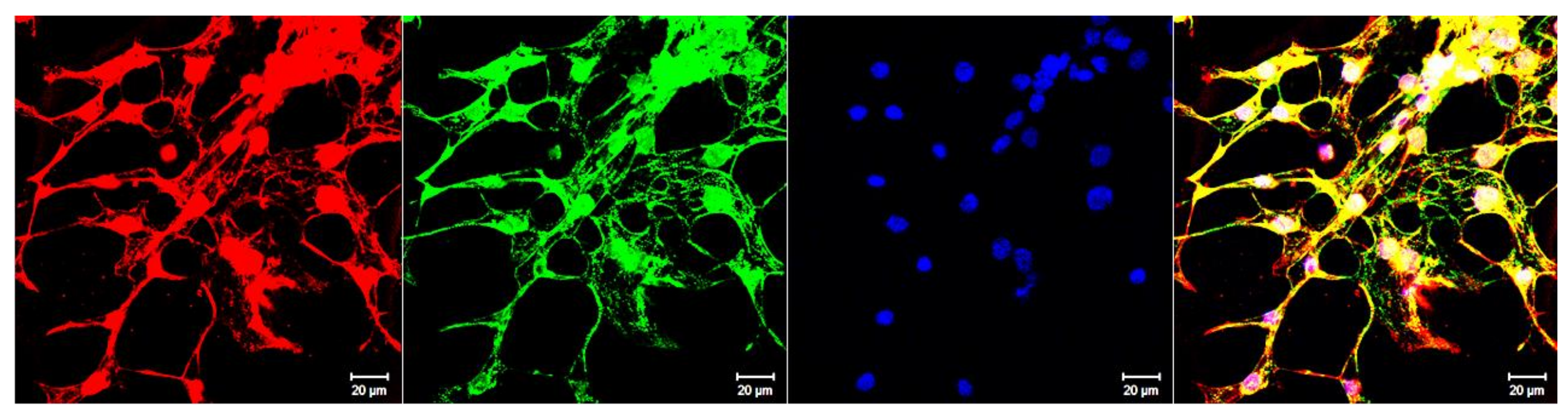

Abbildung 20: Immunfluoreszenzfärbung von aus riPSC differenzierten Kardiomyozyten zur Darstellung von kardialem Troponin I. Verwendet wurden nach Standardprotokoll differenzierte Kardiomyozyten. Rot = kardiales Troponin I, grün = f-Aktin, blau = Hoechst. Zu erkennen ist ein Netzwerk aus Kardiomyozyten, die untereinander Filamente ausbilden. Kardiales Troponin I zeigt sowohl eine regelmäßige Querstreifung in den Filamenten als auch eine besonders hohe Signaldichte in allen Zellkernen. 


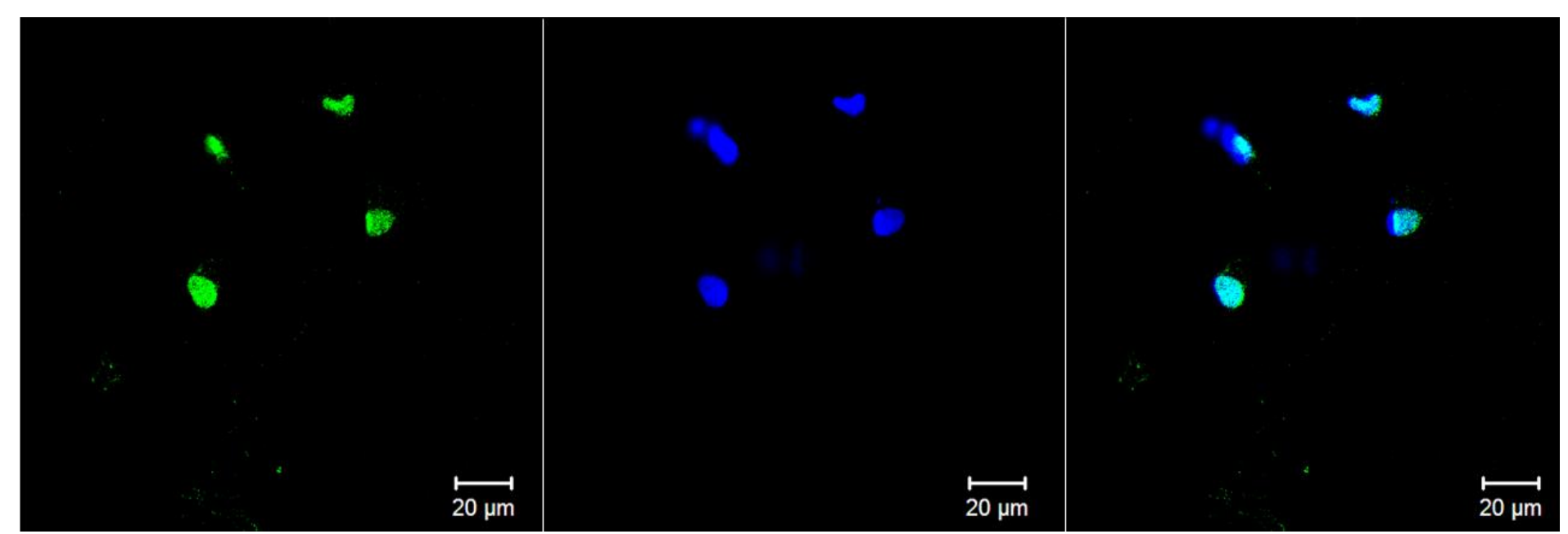

Abbildung 21: Immunfluoreszenzfärbung von aus riPSC differenzierten Kardiomyozyten zur Darstellung von NKX2.5. Verwendet wurden nach Standardprotokoll differenzierte Kardiomyozyten. Grün $=$ NKX2.5, blau $=$ Hoechst. Zu sehen ist eine Überlagerung von Hoechst- und Anti-NKX2.5-Signal. Dies entspricht der typischen Lokalisation von NKX2.5 als Transkriptionsfaktor im Zellkern. 
$\underline{3.4 \text { Funktionelle Charakterisierung der differenzierten Kardiomyozyten mittels Kalzium- }}$ $\underline{\text { Transienten }}$

Für die funktionelle Charakterisierung der aus riPSC differenzierten Herzmuskelzellen wurden so genannte Kalzium-Transienten unter dem Konfokalmikroskop dargestellt. Dazu wurden auf cell imaging dishes kultivierte Kardiomyozyten an Tag 31 der Differenzierung mit Rhod-2 Färbelösung versetzt, um so freies zytosolisches Kalzium darzustellen. Die Intensität der Fluoreszenz wurde per linescan entlang der Längsachse einzelner Zellen gemessen. Um dabei die elektrophysikalische Kopplung mehrerer Zellen nachzuweisen, wurde dies ebenso entlang adhärenter Einzelzellen durchgeführt. Die Signaländerung konnte dann, gegen die Zeit aufgetragen, dargestellt werden (siehe Abbildung 22A). Die Kalzium-Freisetzungsfrequenz lag durchschnittlich bei 34 $\pm 5,31 / \mathrm{min}(\mathrm{n}=3)$. Des Weiteren konnte gezeigt werden, dass die verwendeten Zellen zur elektrophysikalischen Kopplung fähig waren, da benachbarte Zellen synchronisierte Kalzium-Transienten aufwiesen (siehe Abbildung $22 \mathrm{~B}$ und C). 


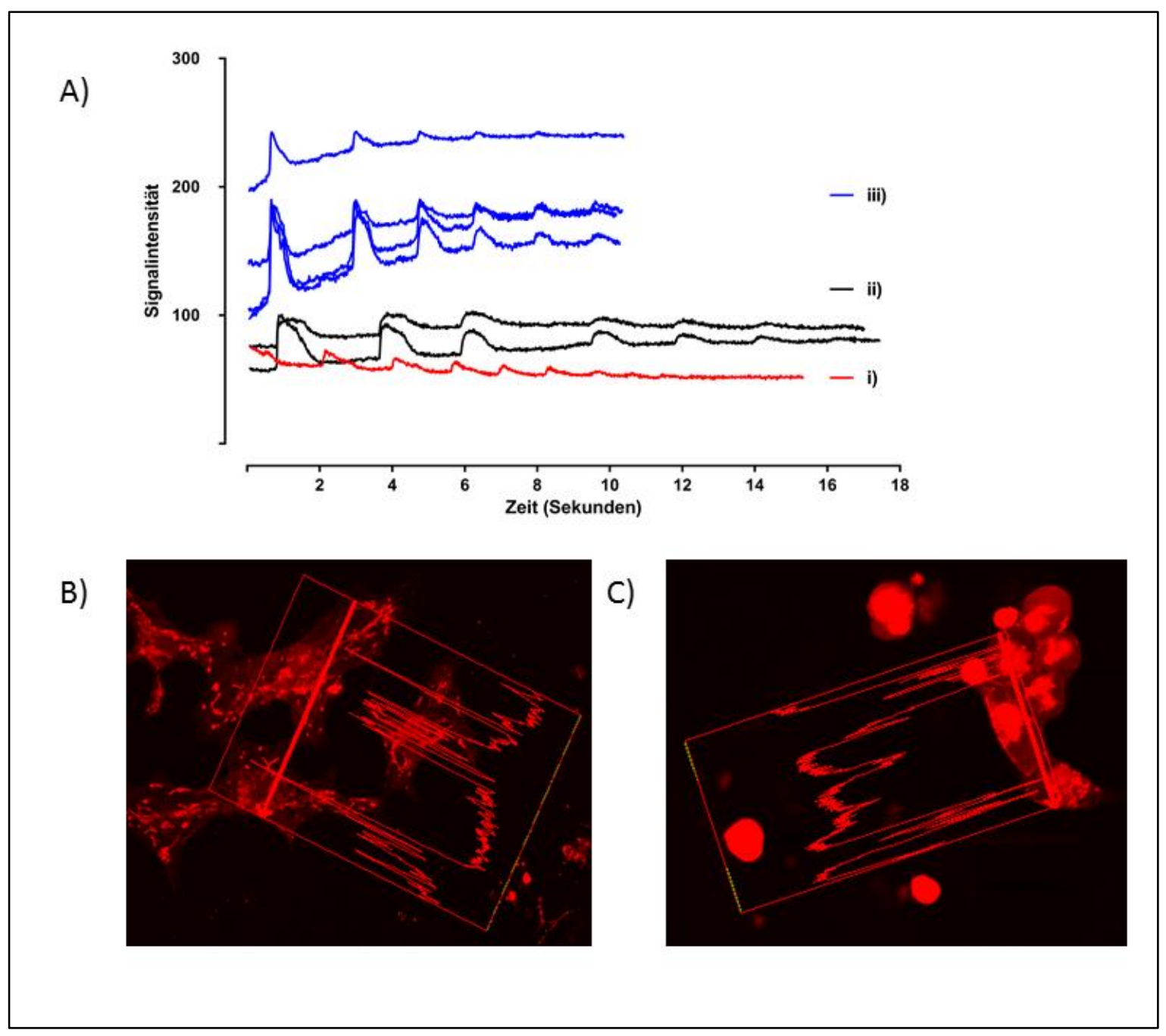

Abbildung 22: Kalzium-Transienten von aus riPSC differenzierten Kardiomyozyten an Tag 31 der Differenzierung. A) i) zeigt die Kalzium-Transienten einer einzelnen Zelle, ii) die zweier gekoppelter und iii) die von vier gekoppelten Zellen ( $n=3$ Messungen). Auf der $x$-Achse ist die Zeit in Sekunden, auf der y-Achse die Signalintensität dargestellt. Die Abbildungen B (zu ii) und C (zu iii) zeigen die Position des linescan im Rahmen der Aufnahmen der Zellen ii und iii (A).

\section{$\underline{3.5 \text { Herstellung von EHM }}$}

Die Erzeugung von EHM aus differenzierten Kardiomyozyten aus riPSC erfolgte nach der bereits durch Zimmermann et al. (2002b) etablierten und Tiburcy et al. (2017) optimierten Methode. Die EHM kondensierten bereits bis Tag eins vollständig. Die verwendeten Wachstumsfaktoren FGF-2, VEGF-A, IGF-1 und TGF-beta 1 sollten dabei die Reifung des Gewebes unterstützen. Erste schwache Kontraktionen in einzelnen EHM traten zwischen Tag 3 und Tag 17 und im Mittel an Tag 8 \pm 2 auf ( $n=8$ Differenzierungsrunden). In der Folge nahm die Anzahl kontrahierender EHM zu. Im Verlauf konnte beobachtet werden, 
dass nach initialen Teilkontraktionen die gesamten EHM zunächst asynchron und später synchronisiert kontrahierten. Dabei entwickelten die EHM eine Spontanfrequenz von $59 \pm 20$ 1/min an Tag $20(\mathrm{n}=3$, siehe Abbildung 23). Die Ruheherzfrequenz eines gesunden jungen Rhesusaffen liegt bei etwa 150 Schlägen pro Minute (Korcarz et al. 1997).

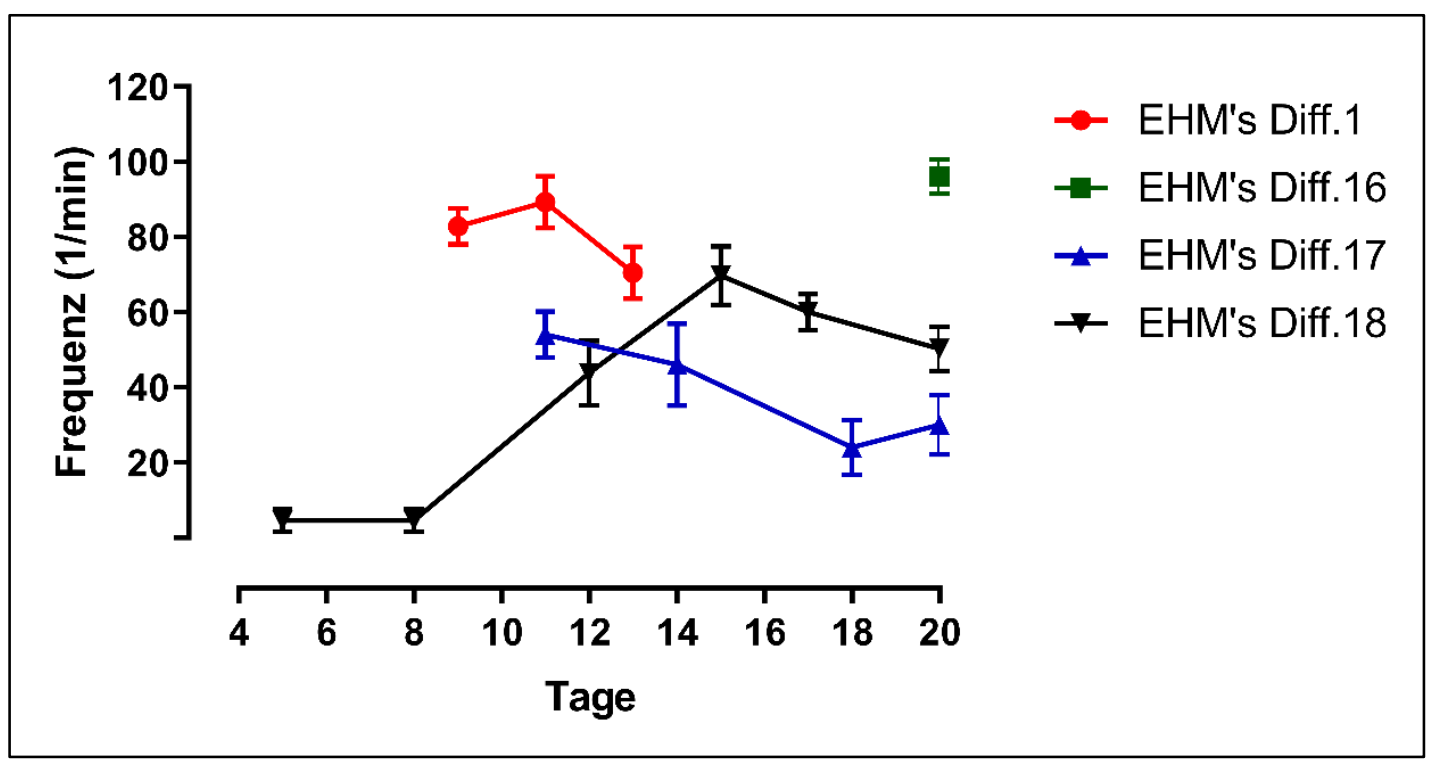

Abbildung 23: Frequenzentwicklung in riPSC-EHM. Zu sehen sind die erhobenen Werte der EHM der Differenzierungen $1(\mathrm{n}=8), 16(\mathrm{n}=12), 17(\mathrm{n}=14)$ und $18(\mathrm{n}=13)$. Auf der $\mathrm{x}$-Achse ist die Kulturzeit in Tagen und auf der y-Achse die durchschnittliche Spontankontraktionsfrequenz (1/min) aufgetragen.

\subsection{Morphologische und funktionelle Charakterisierung der EHM}

An Tag 20 wurden die Kontraktionskraftmessungen an EHM vorgenommen. Es wurden EHM aus den Differenzierungen 12, 16, 17 und 18 untersucht. Von den Differenzierungsrunden 16, 17 und 18 wurden je vier EHM zur Implantation an das Wu Lab in Stanford versendet sowie eine Auswahl funktionstüchtiger EHM zur RNA-Analyse schockgefroren, beziehungsweise für die Aktionspotentialmessungen verwendet. Von allen EHM dieser Runden wurde das Feuchtgewicht bestimmt: 20 $\pm 1,5 \mathrm{mg}(\mathrm{n}=24)$.

\subsubsection{Dissoziierung von EHM und Bestimmung des Kardiomyozytenanteils}

Zur Bestimmung des Kardiomyozytenanteils wurden die Zellen aus EHM enzymatisch isoliert und der Durchflusszytometrie zugeführt. Die EHM der Differenzierungen 16, 17 und $18(\mathrm{n}=9)$ enthielten durchschnittlich 1.008.711 \pm 148.106 lebende Zellen bei einer 
Lebendzellrate von $48 \pm 5 \%$, dies entspricht einer Gesamtzellzahl von 2.052.975 \pm 193.633 . Bei einem gemittelten Kardiomyozytenanteil von $23 \pm 5 \%$ entspricht dies $202.229 \pm 40.890$ lebenden und einer Gesamtzahl von 442.839 \pm 85.211 Kardiomyozyten pro EHM. Bei einer durchschnittlichen Menge an vitalen Kardiomyozyten von $488.958 \pm 51.750$ bei EHMHerstellung (56 $\pm 18 \%$ von 1,25 Mio. Zellen pro EHM bei Herstellung), lässt sich ein Erhalt von gemittelt $89 \pm 29 \%$ (bezogen auf die Gesamtzahl Kardiomyozyten pro dissoziiertem EHM) ermitteln (siehe Tabellen 22/23). Die Ergebnisse der EHM aus Differenzierung 12 sind hierbei nicht mit einberechnet, da der Kardiomyozytenanteil bei EHM-Herstellung nicht ermittelt werden konnte. Berechnet man deren Dissoziierungsergebnisse mit ein, reduzieren sich die Zellzahlen entsprechend Tabelle 23.

Aus diesen Zahlen ergibt sich, dass es in den EHM (bezogen auf EHM der Differenzierungen 16, 17 und 18) zu einer leichten Abnahme der Kardiomyozytenzahl kam $(-10 \%)$, bei gleichzeitiger absoluter und relativer Zunahme des Nichtmyozytenanteils. Dies deutet auf eine Proliferation der Nichtmyozyten bei einer nicht optimalen Differenzierung hin. Die Zellen in EHM zeigten einen durchschnittlichen Durchmesser von 15,2 $\pm 0,4 \mu \mathrm{m}$

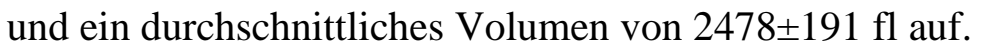


Tabelle 22: Ergebnisse der EHM-Dissoziierung (Input).

\begin{tabular}{|c|c|c|c|}
\hline \multirow{2}{*}{} & \multicolumn{2}{|c|}{ Input (EHM-Herstellung) (1,25 Mio.) } \\
\cline { 2 - 4 } & KM (875.000) & \multirow{2}{*}{ n } \\
\cline { 2 - 4 } & Nicht ermittelt & Nicht ermittelt & Fibroblasten \\
\hline EHM Diff.12 & $427.875(49 \%)$ & 447.125 & 375.000 \\
\hline EHM Diff. 16 & $446.250(51 \%)$ & 428.750 & 375.000 \\
\hline EHM Diff. 17 & $592.375(68 \%)$ & 282.625 & 375.000 \\
\hline EHM Diff. 18 & $488.833 \pm 52.042(56 \pm 18 \%)$ & $386.167 \pm 52.042$ & 375.000 \\
\hline EHM Diff. 16-18 & & 3 \\
\hline
\end{tabular}

Dargestellt sind die Zellanteile bei EHM-Herstellung der Differenzierungsrunden 16-18 ( $=3$ ): Anzahl der verwendeten Fibroblasten sowie Kardiomyozyten aus riPSC, die Kardiomyozytenpopulation aus riPSC ist weiter unterteilt in aktininpositive Kardiomyozyten (KM) und aktininnegative Nichtkardiomyozyten (NKM). 
Tabelle 23: Ergebnisse der EHM-Dissoziierung (Output).

\begin{tabular}{|c|c|c|c|c|c|c|c|c|}
\hline \multicolumn{3}{|c|}{ Output (EHM-Dissoziierung) } & \multirow{3}{*}{$\mathbf{n}=$} & \multicolumn{5}{|c|}{ Output (EHM-Dissoziierung) } \\
\hline & \multirow{2}{*}{$\begin{array}{c}\text { Zellzahl } \\
\text { Total }\end{array}$} & \multirow{2}{*}{$\begin{array}{c}\text { Zellzahl lebend } \\
\text { (\%von Total) }\end{array}$} & & \multicolumn{2}{|c|}{ Total } & \multicolumn{2}{|c|}{ lebend } & \multirow{2}{*}{$\mathbf{n}=$} \\
\hline & & & & KM (\% von Total $)$ & NKM & $\mathbf{K M}$ & NKM & \\
\hline EHM Diff.12 & $\begin{array}{l}1.075 .401 \\
\pm 462.755\end{array}$ & $\begin{array}{c}589.022 \\
\pm 181.004(64 \pm 3 \%)\end{array}$ & 9 & $\begin{array}{c}57.434 \\
\pm 6.276(8 \pm 1 \%)\end{array}$ & $\begin{array}{l}1.017 .967 \\
\pm 485.312\end{array}$ & $\begin{array}{l}35.288 \\
\pm 2.680\end{array}$ & $\begin{array}{c}533.934 \\
\pm 202.646\end{array}$ & 9 \\
\hline $\begin{array}{c}\text { EHM } \\
\text { Diff. } 16\end{array}$ & $\begin{array}{l}2.243 .811 \\
\pm 549.161\end{array}$ & $\begin{array}{c}1.123 .133 \\
\pm 200.478(52 \pm 3 \%)\end{array}$ & 3 & $\begin{array}{c}149.912 \\
\pm 23.927(7 \pm 1 \%)\end{array}$ & $\begin{array}{r}2.093 .899 \\
\pm 525.511\end{array}$ & $\begin{array}{r}75.782 \\
\pm 7.235\end{array}$ & $\begin{array}{l}1.047 .351 \\
\pm 193.452\end{array}$ & 3 \\
\hline $\begin{array}{c}\text { EHM } \\
\text { Diff. } 17\end{array}$ & $\begin{array}{l}2.263 .386 \\
\pm 131.643\end{array}$ & $\begin{array}{c}1.370 .333 \\
\pm 193.459(60 \pm 6 \%)\end{array}$ & 3 & $\begin{array}{c}589.083 \\
\pm 119.881(27 \pm 7 \%)\end{array}$ & $\begin{array}{r}1.674 .30 \\
\pm 250.962\end{array}$ & $\begin{array}{l}341.986 \\
\pm 40.542\end{array}$ & $\begin{array}{c}878.014 \\
\pm 372.920\end{array}$ & 3 \\
\hline $\begin{array}{c}\text { EHM } \\
\text { Diff. } 18\end{array}$ & $\begin{array}{l}1.651 .728 \\
\pm 100.872\end{array}$ & $\begin{array}{c}532.667 \\
\pm 18.774(32 \pm 1 \%)\end{array}$ & 3 & $\begin{array}{c}589.520 \\
\pm 88.503(36 \pm 4 \%)\end{array}$ & $\begin{array}{c}1.062 .208 \\
\pm 86.929\end{array}$ & $\begin{array}{l}188.917 \\
\pm 22.787\end{array}$ & $\begin{array}{l}343.749 \\
\pm 31.170\end{array}$ & 3 \\
\hline $\begin{array}{c}\text { ЕНM } \\
\text { Diff.16-18 }\end{array}$ & $\begin{array}{l}2.052 .975 \\
\pm 193.634\end{array}$ & $\begin{array}{r}1.008 .711 \\
\pm 148.106(48 \pm 5)\end{array}$ & 9 & $\begin{array}{c}442.839 \\
\pm 85.211(23 \pm 5)\end{array}$ & $\begin{array}{l}1.610 .137 \\
\pm 299.546\end{array}$ & $\begin{array}{l}202.229 \\
\pm 40.890\end{array}$ & $\begin{array}{r}756.371 \\
\pm 212.023\end{array}$ & 9 \\
\hline $\begin{array}{c}\text { EHM } \\
\text { Diff. 12, 16-18 }\end{array}$ & $\begin{array}{l}1.148 .356 \\
\pm 270.670\end{array}$ & $\begin{array}{c}798.967 \\
\pm 128.146(56 \pm 3 \%)\end{array}$ & 18 & $\begin{array}{c}250.136 \\
\pm 62.467(13 \pm 4 \%)\end{array}$ & $\begin{array}{l}1.314 .052 \\
\pm 257.867\end{array}$ & $\begin{array}{l}118.759 \\
\pm 28.372\end{array}$ & $\begin{array}{c}655.153 \\
\pm 123.756\end{array}$ & 18 \\
\hline
\end{tabular}




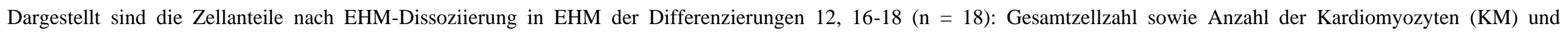

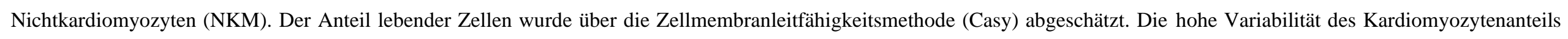
kann durch den enzymatischen Verdau methodisch bedingt sein. 


\subsubsection{Kontraktionsanalysen zur funktionellen Charakterisierung der EHM}

Die Kontraktionskraft von EHM wurde unter isometrischen Bedingungen als Differenz zwischen Grundspannung in der Diastole (RT = resting tension) und maximaler Anspannungskraft in der Systole (TT = twitch tension) errechnet. Zusätzlich wurden die Anspannungs- (T1) und Relaxationszeit (T2) vermessen, dabei ist T1 die Zeit zwischen 10\% und 100\% der maximalen Anspannung und T2 die Zeit zwischen maximaler Anspannung und 90\% der Relaxation. Im Kontraktionsexperiment entwickelte nur ein Teil der verwendeten EHM Kontraktionen (63\%), lediglich diese wurden in die Analyse mit einbezogen.

\subsubsection{Kraft-Längen-Beziehung}

Der Frank-Starling-Mechanismus beschreibt die Beziehung zwischen Vorlast des Herzens und dessen Kraftentwicklung, er dient dabei der Anpassung des Herzzeitvolumens an den venösen Rückstrom sowie der ,präzisen Abstimmung der Pumpleistung des rechten und linken Ventrikels“ (Schrader et al. 2010). Mit steigender Vorspannung erhöht sich physiologischerweise die entwickelte Kontraktionskraft.

$\mathrm{Zu}$ Beginn des Kontraktionsexperimentes wurden die EHM ausgehend von der Grundspannung $\mathrm{L}_{0}$ bis $\mathrm{zu}$ einer optimalen Vordehnung, ersichtlich am Erreichen eines stabilen, maximalen Kraftniveaus Lmax, schrittweise gedehnt. Dafür wurden die Kalziumkonzentration auf $2 \mathrm{mmol} / \mathrm{l}$ und die Stimulationsfrequenz auf $1,5 \mathrm{~Hz}$ eingestellt. Um zu untersuchen, ob die EHM eine Frank-Starling-Antwort aufweisen, wurden zu den Zeitpunkten $\mathrm{L}_{0}$ und Lmax je drei Kontraktionen pro EHM hinsichtlich RT, TT, T1 und T2 vermessen. Die Kontraktionskraft (TT) nahm dabei um 29\% ( $\mathrm{n}=19)$ im Sinne einer positiven Kraft-Frequenz-Beziehung zu. Die Grundspannung (RT) stieg dabei jedoch mit 83\% verhältnismäßig stärker an, was Hinweis auf eine hohe Steifigkeit und einen großen Stromazellanteil ist. Gleichzeitig blieben Anspannungs- und Relaxationszeit annähernd konstant (siehe Tabelle 24). 
Tabelle 24: Beziehung zwischen Vordehnung und Kraftentwicklung der EHM.

\begin{tabular}{|c|c|c|c|c|}
\hline & TT $(\mathbf{m N})$ & RT $(\mathbf{m N})$ & T1 $(\mathbf{m s})$ & T2 (ms) \\
\hline L0 & $0,14 \pm 0,01$ & $0,48 \pm 0,11$ & $111 \pm 4$ & $178 \pm 6$ \\
\hline Lmax & $0,18 \pm 0,02 *$ & $0,88 \pm 0,09 *$ & $113 \pm 4$ & $180 \pm 6$ \\
\hline
\end{tabular}

EHM der Differenzierungen 12, 16-18 bei $\mathrm{L}_{0}$ und Lmax $(\mathrm{n}=19)$. Messungen erfolgten unter isometrischen Bedingungen bei $37^{\circ} \mathrm{C}$ und $2 \mathrm{mmol} / 1$ Kalziumkonzentration unter kontinuierlicher Begasung mit Carbogen $\left(95 \% \mathrm{O}_{2}, 5 \% \mathrm{CO}_{2}\right)$ für die Einstellung eines $\mathrm{pH}-$ Wertes von 7,4 bei einer Stimulationsfrequenz von $1,5 \mathrm{~Hz}$. $* \mathrm{p}<0,05$ für $\mathrm{L}_{0}$ vs. Lmax per gepaartem, zweiseitigem $\mathrm{t}$-Test. TT $=$ systolische Kraftamplitude, $\mathrm{RT}=$ diastolische Kraft, $\mathrm{T} 1=$ Kontraktionszeit, $\mathrm{T} 2=$ Relaxationszeit .

\subsubsection{Beeinflussung der Kraftentwicklung der EHM durch Kalzium}

Um den Einfluss der extrazellulären Kalziumkonzentration auf die entwickelte Kraft der EHM zu untersuchen, wurde diese schrittweise ausgehend von $0,2 \mathrm{mmol} / \mathrm{l}$ auf $0,4 \mathrm{mmol} / \mathrm{l}$ und dann um jeweils $0,4 \mathrm{mmol} / \mathrm{l}$ auf 2,4 bzw. 3,6 mmol/1 erhöht.

Dabei nahm die systolische Kontraktionsamplitude (TT) um $144 \%$ von 0,09 $\pm 0,01 \mathrm{mN}$ bei $0,2 \mathrm{mmol} / 1$ Kalziumkonzentration auf $0,22 \pm 0,02 \mathrm{mN}$ bei $2,4 \mathrm{mmol} / 1$ Kalziumkonzentration zu. Die Anspannungszeit (T1) nahm minimal ab und die Relaxationszeit (T2) leicht zu (siehe Abbildung 24, Tabelle 25).

Tabelle 25: Beziehung zwischen extrazellulärer Kalziumkonzentration und entwickelter Kraft.

\begin{tabular}{|c|c|c|c|c|}
\hline Kalziumkonzentration (mmol/l) & TT $(\mathbf{m N})$ & RT $(\mathbf{m N})$ & T1 $(\mathbf{m s})$ & $\mathbf{T 2}(\mathbf{m s})$ \\
\hline $\mathbf{0 , 2}$ & $0,09 \pm 0,01$ & $0,68 \pm 0,15$ & $134 \pm 7$ & $175 \pm 7$ \\
\hline $\mathbf{2 , 4}$ & $0,22 \pm 0,02 *$ & $0,55 \pm 0,14 *$ & $127 \pm 5$ & $187 \pm 5$ \\
\hline
\end{tabular}

EHM der Differenzierungen 12, 16-18 bei einer Kalziumkonzentration von 0,2 mmol/l bzw. 2,4 mmol/l (n = 19). Messungen erfolgten unter isometrischen Bedingungen bei $37^{\circ} \mathrm{C}$ unter kontinuierlicher Begasung mit Carbogen $\left(95 \% \mathrm{O}_{2}, 5 \% \mathrm{CO}_{2}\right)$ für die Einstellung eines $\mathrm{pH}$-Wertes von 7,4 bei einer Stimulationsfrequenz von 1,5 Hz (beziehungsweise $2 \mathrm{~Hz}$ bei EHM aus der Kardiomyozyten-Differenzierung 16 aufgrund einer hohen Spontanfrequenz (siehe Abbildung 23)). * p < 0,05 für 0,2 mmol/l vs. 2,4 mmol/l Kalziumkonzentration per gepaartem zweiseitigem $\mathrm{t}$-Test. $\mathrm{TT}=$ systolische Kraftamplitude, $\mathrm{RT}=$ diastolische $\mathrm{Kraft}, \mathrm{T} 1=$ Kontraktionszeit, T2 = Relaxationszeit. 


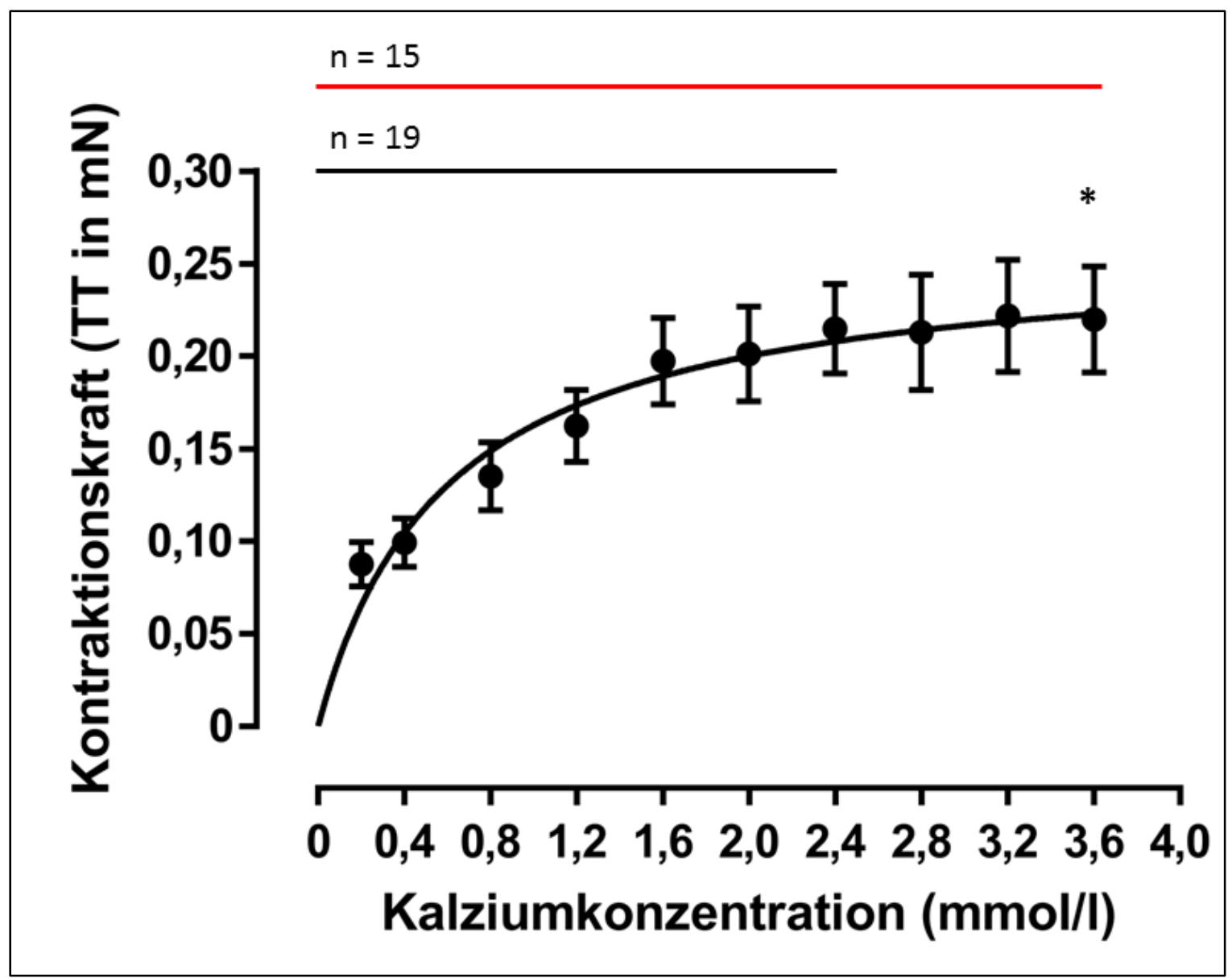

Abbildung 24: Beziehung zwischen extrazellulärer Kalziumkonzentration und entwickelter Kraft. EHM der Differenzierungen 12, 16-18 bei einer Kalziumkonzentration von 0,2 bis 2,4 mmol/l (EHM der Differenzierung 16, $\mathrm{n}=4$ ) bzw. bis 3,6 mmol/1 (EHM der Differenzierungen 12, 17 und 18, $\mathrm{n}=15)$. Messungen erfolgten unter isometrischen Bedingungen bei $37^{\circ} \mathrm{C}$ unter kontinuierlicher Begasung mit Carbogen $\left(95 \% \mathrm{O}_{2}, 5 \% \mathrm{CO}_{2}\right)$ für die Einstellung eines $\mathrm{pH}$-Wertes von 7,4 bei einer Stimulationsfrequenz von $1,5 \mathrm{~Hz}$ (beziehungsweise $2 \mathrm{~Hz}$ bei EHM aus der Kardiomyozyten Differenzierung 16). Auf der x-Achse ist die extrazelluläre Kalziumkonzentration in der Tyrode-Lösung in mmol/l und auf der $\mathrm{y}$-Achse die Kontraktionskraft in $\mathrm{mN}$ aufgetragen. * p < 0,05 vs. 0,2 mmol/1 Kalziumkonzentration per One-way-AnovaTest für verbundene Prüfung mit Tukey`s Posthoc-Test.

Um die maximale entwickelte Kraft zu errechnen, wurde diese zuerst für jedes EHM einzeln bestimmt und dann gemittelt. Es ergab sich ein Wert von durchschnittlich $0,23 \pm 0,02 \mathrm{mN}$ bei einer durchschnittlichen extrazellulären Kalziumkonzentration von 2,9 $\pm 0,2 \mathrm{mmol} / \mathrm{l}$. Die halbmaximale Kraftentwicklung zeigte sich bei einer EC50 von 0,6 $\pm 0,2 \mathrm{mmol} / 1 \mathrm{Kalzium}$. Um die durchschnittlich entwickelte Kraft pro Kardiomyozyt zu berechnen, wurde diese zuerst getrennt für jedes EHM berechnet. Dazu wurde die maximal entwickelte Kraft jedes EHM durch die Gesamtzahl der enthaltenen Kardiomyozyten unabhängig von deren Vitalität - geteilt, die mittels Durchflusszytometrie bestimmt 
worden war. Für sieben EHM wurde die Anzahl der enthaltenen Zellen nicht ermittelt, da sie nicht dissoziiert wurden. Für diese wurde die durchschnittliche Kardiomyozytenzahl der jeweiligen Differenzierungsrunde angenommen. Dabei ergab sich eine durchschnittliche Kraft von 2,4 $\pm 0,5 \mathrm{nN}$ pro Kardiomyozyt. Tabelle 26 schlüsselt dies für die einzelnen Differenzierungsrunden auf. Auffällig ist dabei, dass die Kardiomyozyten der Differenzierungen 12 und 17, die zwei Tage länger mit IWP-4 behandelt wurden, eine durchschnittlich größere Kraft entfalten. Anscheinend führte die verlängerte Differenzierung zu einer größeren Kraftentwicklung und damit zu einer weiteren Reifung der Zellen.

Tabelle 26: Durchschnittliche Kardiomyozytenzahl pro EHM und durchschnittliche, maximale Kraft pro Kardiomyozyt.

\begin{tabular}{|c|c|c|c|}
\hline & $\begin{array}{l}\text { EHM Diff. } \\
12(n=8)\end{array}$ & $\begin{array}{c}\text { EHM Diff. } \\
16(n=4)\end{array}$ & $\begin{array}{r}\text { EHM Diff. } \\
17(n=4)\end{array}$ \\
\hline $\begin{array}{c}\text { Durchschnittliche Kardiomyozyten- } \\
\text { zahl / EHM }\end{array}$ & $\begin{array}{l}57.434 \\
\pm 6.276\end{array}$ & $\begin{array}{r}149.912 \\
\pm 23.927\end{array}$ & $\begin{array}{r}589.083 \\
\pm 119.881\end{array}$ \\
\hline \multirow[t]{2}{*}{$\begin{array}{c}\text { Durchschnittliche, maximale Kraft / } \\
\text { Kardiomyozyt (nN) }\end{array}$} & $4,6 \pm 0,6$ & $1,4 \pm 0,3$ & $3,6 \pm 0,6$ \\
\hline & $\begin{array}{l}\text { EHM Diff. } \\
18(n=3)\end{array}$ & $\begin{array}{c}\text { EHM } \\
\text { gesamt }(n= \\
19)\end{array}$ & \\
\hline $\begin{array}{c}\text { Durchschnittliche Kardiomyozyten- } \\
\text { zahl / EHM }\end{array}$ & $\begin{array}{l}589.520 \\
\pm 88.503\end{array}$ & $\begin{array}{l}267.983 \\
\pm 58.034\end{array}$ & \\
\hline $\begin{array}{c}\text { Durchschnittliche, maximale Kraft / } \\
\text { Kardiomyozyt (nN) }\end{array}$ & $2,2 \pm 0,0$ & $2,4 \pm 0,5$ & \\
\hline
\end{tabular}

EHM der Differenzierungen 12, 16-18 bei einer durchschnittlichen Kalziumkonzentration von 2,9 $90,2(\mathrm{n}=$ 19). Messungen erfolgten unter isometrischen Bedingungen bei $37^{\circ} \mathrm{C}$ unter kontinuierlicher Begasung mit Carbogen $\left(95 \% \mathrm{O}_{2}, 5 \% \mathrm{CO}_{2}\right)$ für die Einstellung eines $\mathrm{pH}-$ Wertes von 7,4 bei einer Stimulationsfrequenz von 1,5 Hz (beziehungsweise $2 \mathrm{~Hz}$ bei EHM aus der Kardiomyozyten-Differenzierung 16). Die Unterschiede zwischen den Kraftwerten könnten aufgrund der niedrigen Herzmuskelausbeute in Serie 12 und 16 methodisch bedingt sein (enzymatischer Überverdau).

Um die Kraft pro Querschnitt durch beide „Arme“ der EHM zu berechnen, wurden zuerst Bilder von den EHM im Kontraktionssetup am Tag der Kraftmessung von zwei Seiten 
akquiriert, um daraus Breite und Tiefe beider Arme ermitteln zu können. Unter Annahme eines ovalen Querschnittes wurden mittels der Formel $A=\pi^{*} \mathrm{a} * \mathrm{~b}$ die Querschnittsflächen beider Arme errechnet und diese addiert, wobei a und $b$ für die Halbachsen des Ovals stehen. Dies wurde für neun EHM der Differenzierungsrunden 16-18 durchgeführt. Es ergab sich ein Durchschnittswert von 3,05 $\pm 0,3 \mathrm{~mm}^{2}(\mathrm{n}=9)$. Mit Hilfe dieses Wertes und der maximalen Kontraktionskraft konnte nun für oben verwendete EHM der Differenzierungen 12, 16, 17 und 18 näherungsweise die Kraft pro Fläche ermittelt werden. Es ergab sich eine durchschnittliche maximale Kontraktionskraft pro Fläche von $0,07 \pm 0,01 \mathrm{mN} / \mathrm{mm}^{2}(\mathrm{n}=19)$.

\subsubsection{Kraft-Frequenz-Beziehung}

Um den Einfluss der Stimulationsfrequenz auf die Kraftentwicklung zu untersuchen, wurde jeweils die Kalziumkonzentration der halbmaximalen Kraftentwicklung eingestellt (EC50) und anschließend die Stimulation schrittweise von 1 auf $3 \mathrm{~Hz}$ um je 0,5 Hz erhöht. Dabei zeigte sich, dass die maximale Kraft bei $1 \mathrm{~Hz}$ entwickelt wurde und bei Erhöhung der Frequenz kontinuierlich im Sinne einer negativen Frequenztreppe abnahm (siehe Abbildung 25). 


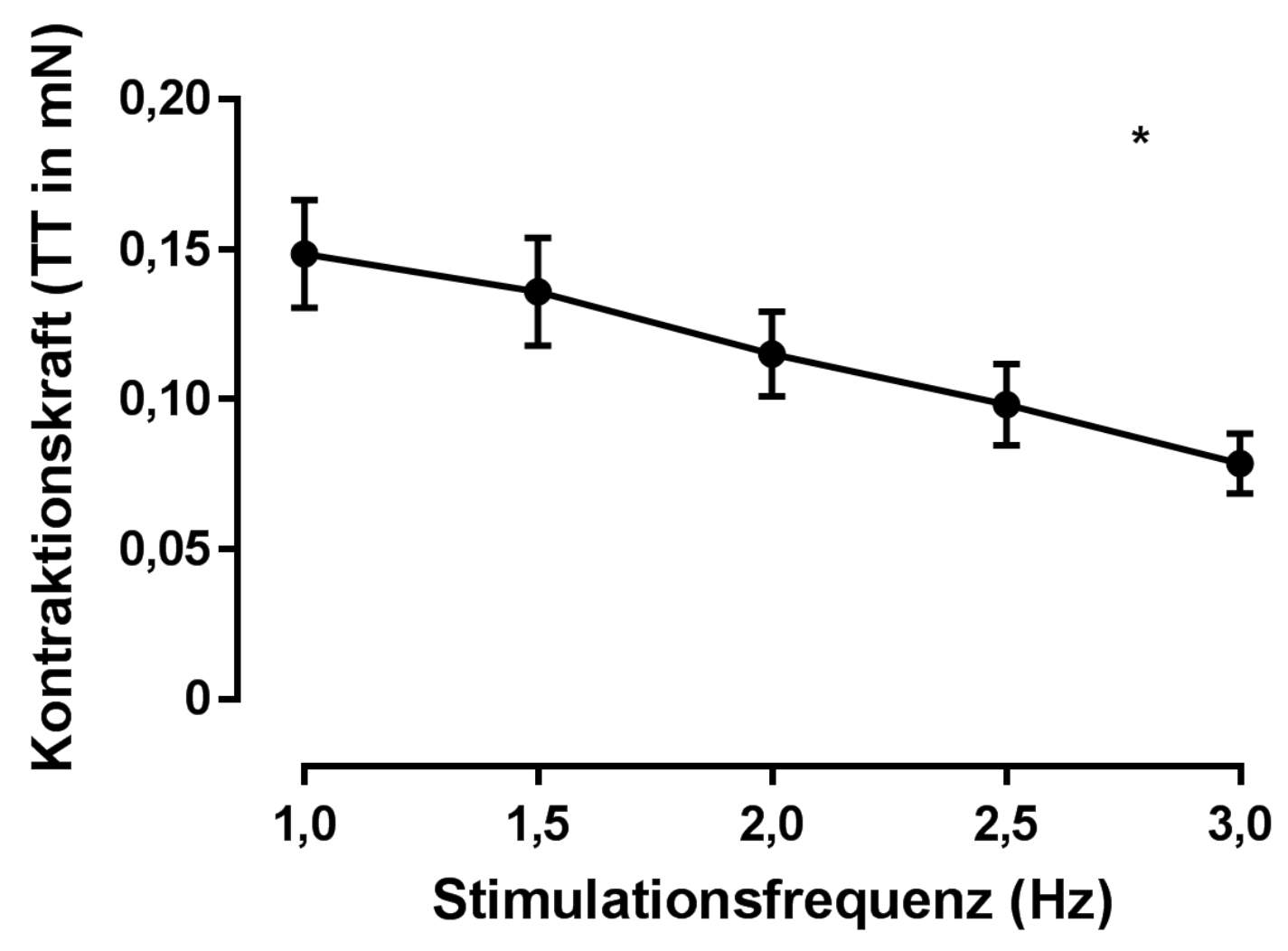

Abbildung 25: Beziehung zwischen Stimulationsfrequenz und entwickelter Kraft. EHM der Differenzierungen 12, 16-18 bei einer Stimulationsfrequenz von 1 bis $3 \mathrm{~Hz}(\mathrm{n}=19)$. Messungen erfolgten unter isometrischen Bedingungen bei $37^{\circ} \mathrm{C}$ und einer EC50-Kalziumkonzentration von durchschnittlich 0,6 $\pm 0,2 \mathrm{mmol} / \mathrm{l}$ unter kontinuierlicher Begasung mit Carbogen $\left(95 \% \mathrm{O}_{2}, 5 \% \mathrm{CO}_{2}\right)$ für die Einstellung eines $\mathrm{pH}-$ Wertes von 7,4. Auf der $\mathrm{x}$-Achse ist die Stimulationsfrequenz in $\mathrm{Hz}$ und auf der $\mathrm{y}$-Achse die Kontraktionskraft in $\mathrm{mN}$ aufgetragen. * $\mathrm{p}<0,05$ vs. $1 \mathrm{~Hz}$ per One-way-Anova-Test für verbundene Prüfung mit Tukey's Posthoc Test.

\subsubsection{Beeinflussung der Kraftentwicklung durch Isoprenalin und Carbachol}

Um die Reagibilität der EHM auf pharmakologische Stimulation durch Isoprenalin und Carbachol zu untersuchen, wurde die Isoprenalin-Konzentration schrittweise von $10^{-4} \mu \mathrm{mol} / \mathrm{l}$ auf $1 \mu \mathrm{mol} / \mathrm{l}$ erhöht und anschließend mit $10 \mu \mathrm{mol} / \mathrm{l}$ Carbachol antagonisiert. Isoprenalin bewirkt am Herzen über Aktivierung von adrenergen Beta1-Rezeptoren unter anderem positiv inotrope und lusitrope Effekte. Während kein Anstieg der Kontraktionskraft unter Isoprenalinstimulation beobachtet werden konnte, verkürzte sich T1 um 20\% (positiv chronotroper Effekt) und T2 um 18,5\% (positiv lusitroper Effekt). Carbachol wirkt hingegen über muskarinerge Acetylcholinrezeptoren (M2-Rezeptoren) negativ inotrop und wurde bei einer Isoprenalinkonzentration von $1 \mu \mathrm{mol} / 1$ hinzugegeben. Hierbei zeigte sich 
der erwartete und signifikante Abfall der entwickelten Kontraktionskraft bei $10 \mu \mathrm{mol} / \mathrm{l}$ um $53 \%$ sowie eine weitere Verkürzung von T1 um 1,9\% und von T2 um 11\% (siehe Tabelle 27, Abbildung 26).

Der fehlende signifikante Kraftanstieg unter adrenerger Stimulation deutet auf einen unreifen Kardiomyozytenphänotyp hin.

Tabelle 27: Kraftentwicklung unter pharmakologischer Intervention mittels Isoprenalin und Carbachol.

\begin{tabular}{|c|c|c|c|c|}
\hline Konzentration & TT $(\mathbf{m N})$ & $\mathbf{R T}(\mathbf{m N})$ & $\mathbf{T 1}(\mathbf{m s})$ & $\mathbf{T 2}(\mathbf{m s})$ \\
\hline Isoprenalin $\mathbf{0} \boldsymbol{\mu m o l} / \mathbf{l}$ & $0,12 \pm 0,01$ & $0,53 \pm 0,12$ & $125,7 \pm 5,2$ & $160,1 \pm 5,3$ \\
\hline Isoprenalin $1 \boldsymbol{\mu m o l} / \mathbf{l}$ & $0,14 \pm 0,02$ & $0,49 \pm 0,11 *$ & $100,6 \pm 5,0 *$ & $130,4 \pm 5,6 *$ \\
\hline Carbachol $10 \mu \mathrm{mol} / \mathbf{l}$ & $0,06 \pm 0,02 \S$ & $0,46 \pm 0,11 \S$ & $98,9 \pm 6,0$ & $116,1 \pm 5,6 \S$ \\
\hline
\end{tabular}

EHM der Differenzierungen 12, 16-18 bei einer Isoprenalinkonzentration von 0 bzw. $1 \mu \mathrm{mol} / \mathrm{l}$ und nach Antagonisierung mit $10 \mu \mathrm{mol} / \mathrm{l} \mathrm{Carbachol}(\mathrm{n}=19)$. Messungen erfolgten unter isometrischen Bedingungen bei $37^{\circ} \mathrm{C}$ und einer Kalziumkonzentration der jeweiligen EC50 von durchschnittlich 0,6 $\pm 0,2 \mathrm{mmol} / \mathrm{l}$ unter kontinuierlicher Begasung mit Carbogen $\left(95 \% \mathrm{O}_{2}, 5 \% \mathrm{CO}_{2}\right)$ für die Einstellung eines pH-Wertes von 7,4 bei einer Stimulationsfrequenz von $1,5 \mathrm{~Hz}$ (beziehungsweise $2 \mathrm{~Hz}$ bei EHM aus der Kardiomyozyten Differenzierung 16). $* \mathrm{p}<0,05$ für 0 vs. $1 \mu \mathrm{mol} / \mathrm{l}$ Isoprenalin per gepaartem zweiseitigem t-Test, $\S \mathrm{p}<0,05$ für $1 \mu \mathrm{mol} / \mathrm{l}$ Isoprenalin vs. $10 \mu \mathrm{mol} / \mathrm{l}$ Carbachol per gepaartem zweiseitigem t-Test. TT $=$ systolische Kraftamplitude, RT = diastolische Kraft, T1 = Kontraktionszeit, T2 = Relaxationszeit. 


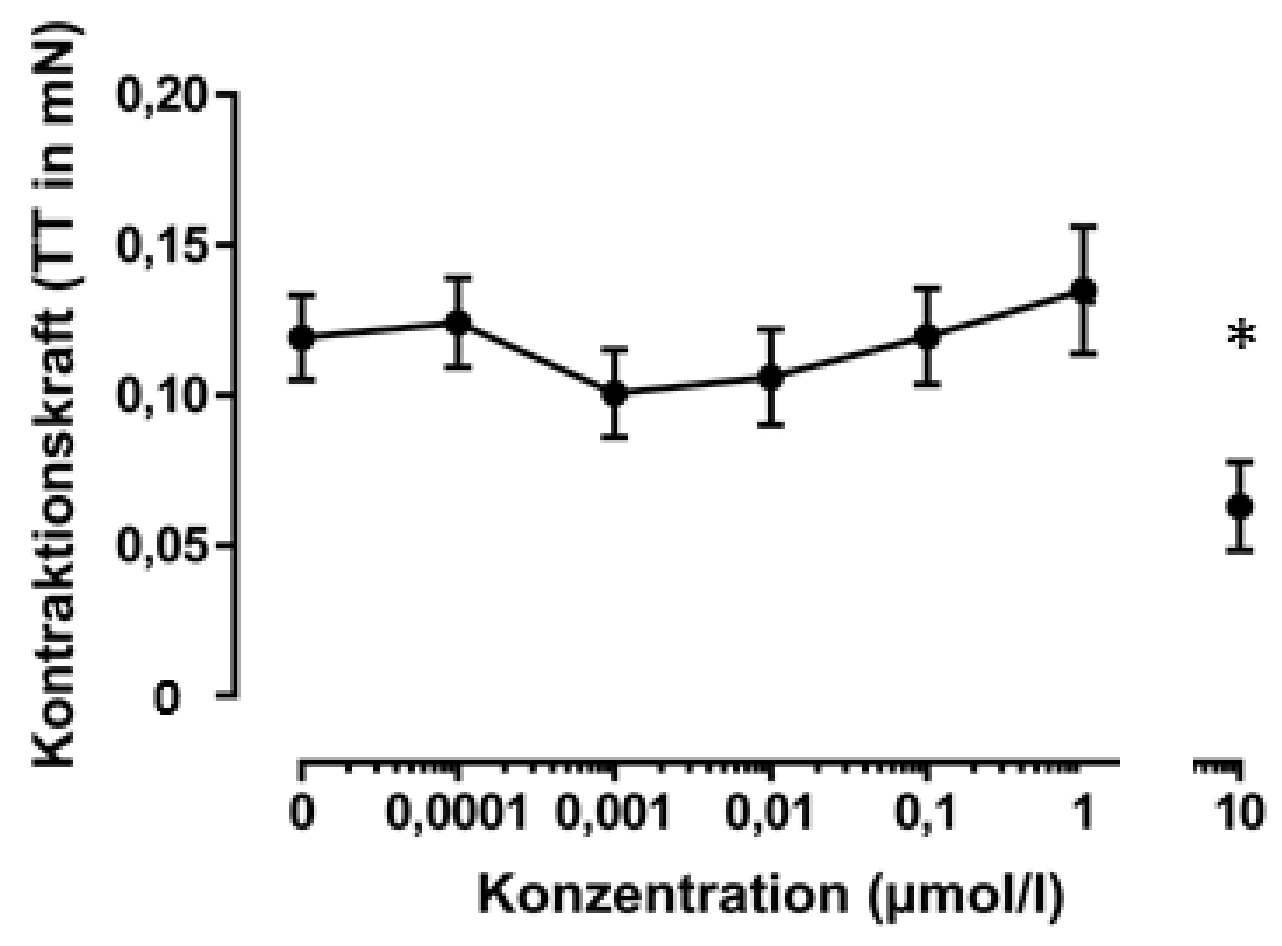

Isoprenalin

Carbachol

Abbildung 26: Kraftentwicklung unter pharmakologischer Intervention mittels Isoprenalin und Carbachol. EHM der Differenzierungen 12, 16-18 bei einer Isoprenalinkonzentration von 0 bzw. $1 \mu \mathrm{mol} / \mathrm{l}$ und nach Antagonisierung mit $10 \mu \mathrm{mol} / \mathrm{l}$ Carbachol $(\mathrm{n}=19)$. Messungen erfolgten unter isometrischen Bedingungen bei $37^{\circ} \mathrm{C}$ und einer Kalziumkonzentration der jeweiligen EC50 von durchschnittlich 0,6 $\pm 0,2 \mathrm{mmol} / \mathrm{l}$ unter kontinuierlicher Begasung mit Carbogen $\left(95 \% \mathrm{O}_{2}, 5 \% \mathrm{CO}_{2}\right)$ für die Einstellung eines $\mathrm{pH}$-Wertes von 7,4 bei einer Stimulationsfrequenz von $1,5 \mathrm{~Hz}$ (beziehungsweise $2 \mathrm{~Hz}$ bei EHM aus der Kardiomyozyten Differenzierung 16). Auf der x-Achse ist die extrazelluläre Konzentration von Isoprenalin beziehungsweise Carbachol in $\mu \mathrm{mol} / 1$ und auf der $\mathrm{y}$-Achse die entwickelte Kontraktionskraft der EHM in $\mathrm{mN}$ aufgetragen. $* \mathrm{p}<0,05$ für $1 \mu \mathrm{mol} / \mathrm{l}$ Isoprenalin vs. $10 \mu \mathrm{mol} / \mathrm{l}$ Carbachol per gepaartem zweiseitigem t-Test.

3.6.3 Elektrophysiologische Charakterisierung mittels Aktionspotentialmessungen in EHM

Aktionspotentialmessungen mittels scharfer Elektroden wurden freundlicherweise von Dr. M.L. Chang Liao durchgeführt. Dabei sollte untersucht werden, ob die Kardiomyozyten in EHM typische kardiale Aktionspotentiale entwickeln und ob sich gegebenenfalls Subgruppen (Schrittmacherzellen vs. Arbeitsmyokardzellen) differenzieren lassen. Die Untersuchungen wurden an den EHM 16-1 und 18-6 durchgeführt. Dabei wurden 3 Aktionspotentiale aufgezeichnet (siehe Abbildung 27, Tabelle 28). 


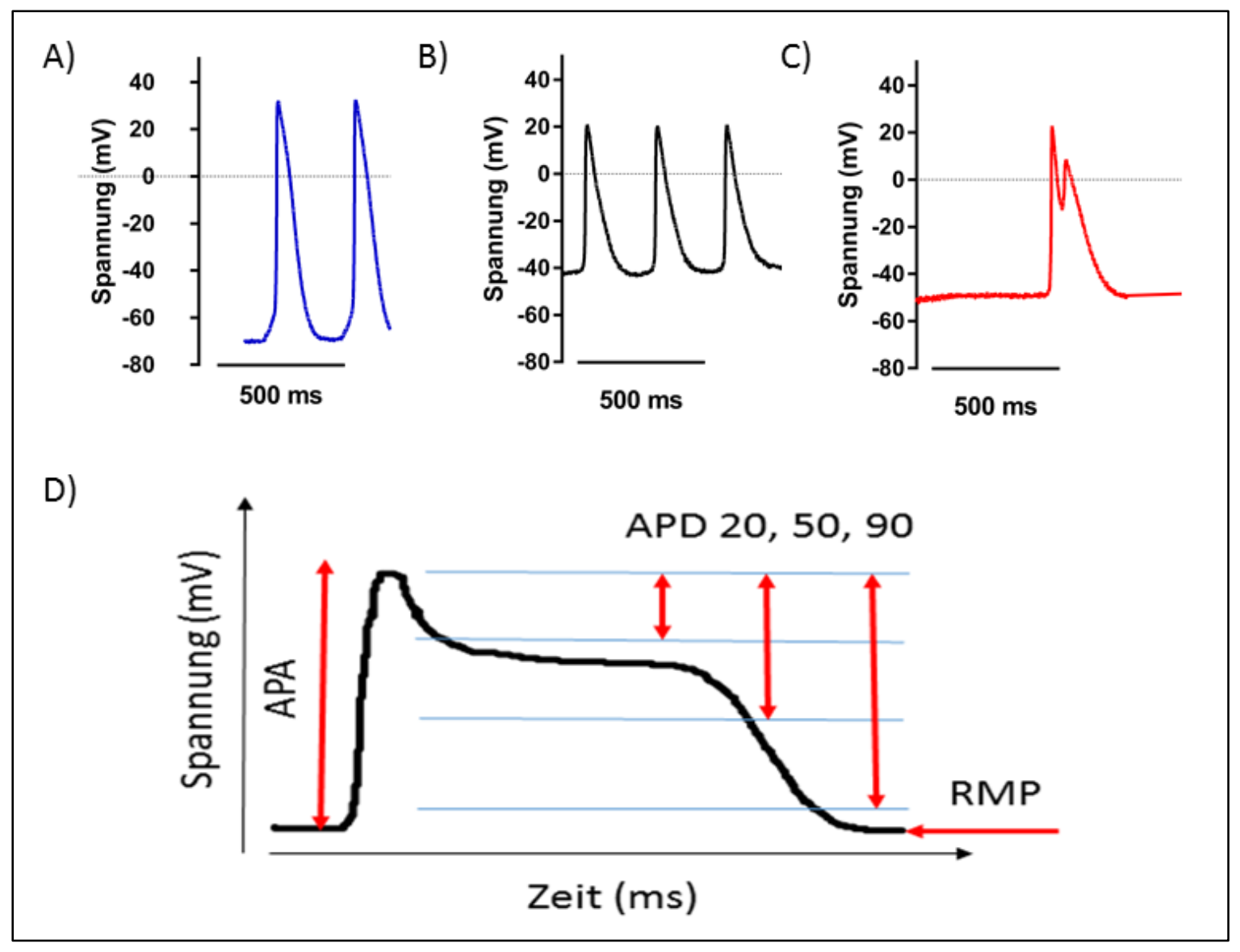

Abbildung 27: Aktionspotentialmessungen an Kardiomyozyten aus EHM. Verwendet wurden Kardiomyozyten aus EHM 16-1 und 18-6 ( $\mathrm{n}=3$ ). Aktionspotentiale A) (blau), B) (schwarz), C) (rot) ( $\mathrm{n}=3$ ), D) Schematische Darstellung eines myokardialen Aktionspotentials. RMP $=$ Ruhemembranpotential, APA $=$ Aktionspotentialamplitude,$\quad$ APD 20, 50,90 = Aktionspotentialdauer $\quad$ bei $\quad 20, \quad 50$ und $90 \%$ Repolarisation.

Das Ruhemembranpotential, die Aktionspotentialamplitude, die Aufstrichgeschwindigkeit, die Aktionspotentialdauer bei 20, 50 und 90\% Repolarisation sowie die spontane Kontraktionsfrequenz sind in der folgenden Tabelle 28 dargestellt. Die Aktionspotenzialaufzeichnungen in EHM sind im Gegensatz zu Aufzeichnungen in nativem Herzgewebe durch eine niedrige Herzmuskelzelldichte und einen hohen Matrixgehalt in EHM erschwert. 
Tabelle 28: Übersicht der Aktionspotentialparameter an Kardiomyozyten aus EHM.

\begin{tabular}{|c|c|c|c|c|c|c|c|}
\hline & \multirow{2}{*}{ AP } & \multirow{2}{*}{$\begin{array}{c}\text { RMP } \\
(\mathbf{m V})\end{array}$} & $\begin{array}{c}\text { max } \\
(\mathbf{m V})\end{array}$ & \multicolumn{4}{|c|}{ dV/dt } \\
\cline { 5 - 8 } & & & $\mathbf{V} / \mathbf{s})$ & $\mathbf{2 0}$ & $\mathbf{5 0}$ & $\mathbf{9 0}$ & \multirow{2}{*}{ Frequenz (Hz) } \\
\hline A) & -69 & 102 & 19 & 95 & 161 & 262 & 1,6 \\
\hline B) & -42 & 62 & 9,6 & 69 & 126 & 245 & 1,8 \\
\hline C) & -48 & 70 & 14 & 50 & 240 & 421 & 0,6 \\
\hline MW \pm SEM & $53 \pm 8$ & $78 \pm 12$ & $14 \pm 2,6$ & $71 \pm 13$ & $176 \pm 34$ & $309 \pm 56$ & $1,4 \pm 0,4$ \\
\hline
\end{tabular}

Verwendet wurden Kardiomyozyten aus EHM 16-1 und 18-6 ( $\mathrm{n}=3)$. AP = Aktionspotential, RMP $=$ Ruhemembranpotential, $\quad$ APA $=$ Aktionspotentialamplitude, $\max . \mathrm{dV} / \mathrm{dt}=$ maximale Aufstrichgeschwindigkeit, APD 20, 50, 90 = Aktionspotentialdauer bei 20, 50 und 90\% Repolarisation.

3.6.4 Immunfluoreszenzfärbungen von EHM zur Analyse der dreidimensionalen Verteilung von Kardiomyozyten

Immunfluoreszenzfärbungen wurden an $100 \mu \mathrm{m}$ dicken Vibrotomschnitten der EHM durchgeführt. Dabei verlief die Schnittebene tangential zu den EHM entsprechend dem Schema in Abbildung 28 A. Hierbei ging es nicht mehr um die Charakterisierung der Sarkomere, sondern vielmehr darum, die dreidimensionale Verteilung der Kardiomyozyten in den EHM zu untersuchen. Deshalb wurden Färbungen an beiden „Armen“ der EHM oben, mittig und unten durchgeführt und analysiert. In diesen war ersichtlich, dass die Kardiomyozyten auf allen Ebenen (oben, mittig, unten) annähernd gleichmäßig auf gesamter Breite der EHM verteilt waren. In Abbildung 28, die eine Übersichtsaufnahme bei 10-facher Vergrößerung darstellt, ist dies beispielhaft zu sehen. Dort verteilen sich die Kardiomyozyten im oberen Bereich auf einer Breite (senkrecht zur Längsrichtung betrachtet) von durchschnittlich $699 \pm 9 \mu \mathrm{m}$ ( $\mathrm{n}=5$ Messungen). Dabei weisen sie visuell in der oberen und mittleren Ebene eine höhere Dichte auf als in der Unteren. Im unteren Bereich erkennt man eindeutiger einzelne Muskelfibrillen, die größtenteils in Längsrichtung des „EHM-Armes“ verlaufen (siehe Abbildung 29). Diese Tendenz der Ausrichtung konnte in allen akquirierten Aufnahmen nachgewiesen werden und ist essenziell für eine optimale Kraftentwicklung. In Detailaufnahmen bei 63-facher Vergrößerung zeigte sich, dass das Herzmuskelgewebe in EHM gut geordnete 
Muskelfibrillen aufwies (siehe Abbildung 29). Auch hier konnte die Verteilung der Kardiomyozyten über alle drei Ebenen nachgewiesen werden, jedoch sind ebenso Lücken zwischen ihnen auszumachen. Die Sarkomerstruktur ist in Abbildung 30 im Einzelnen dargestellt: Muskelfibrillen bei 63-facher Vergrößerung.

A)

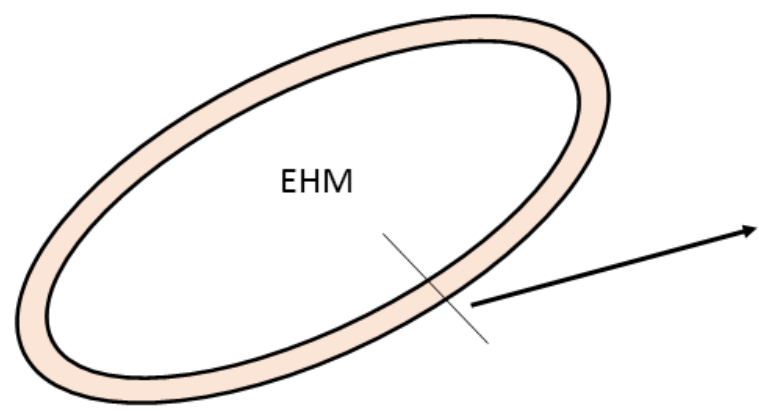

Schnittebenen

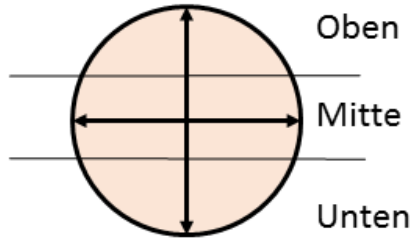

ca. $700 \times 700 \mu \mathrm{m}$

B)
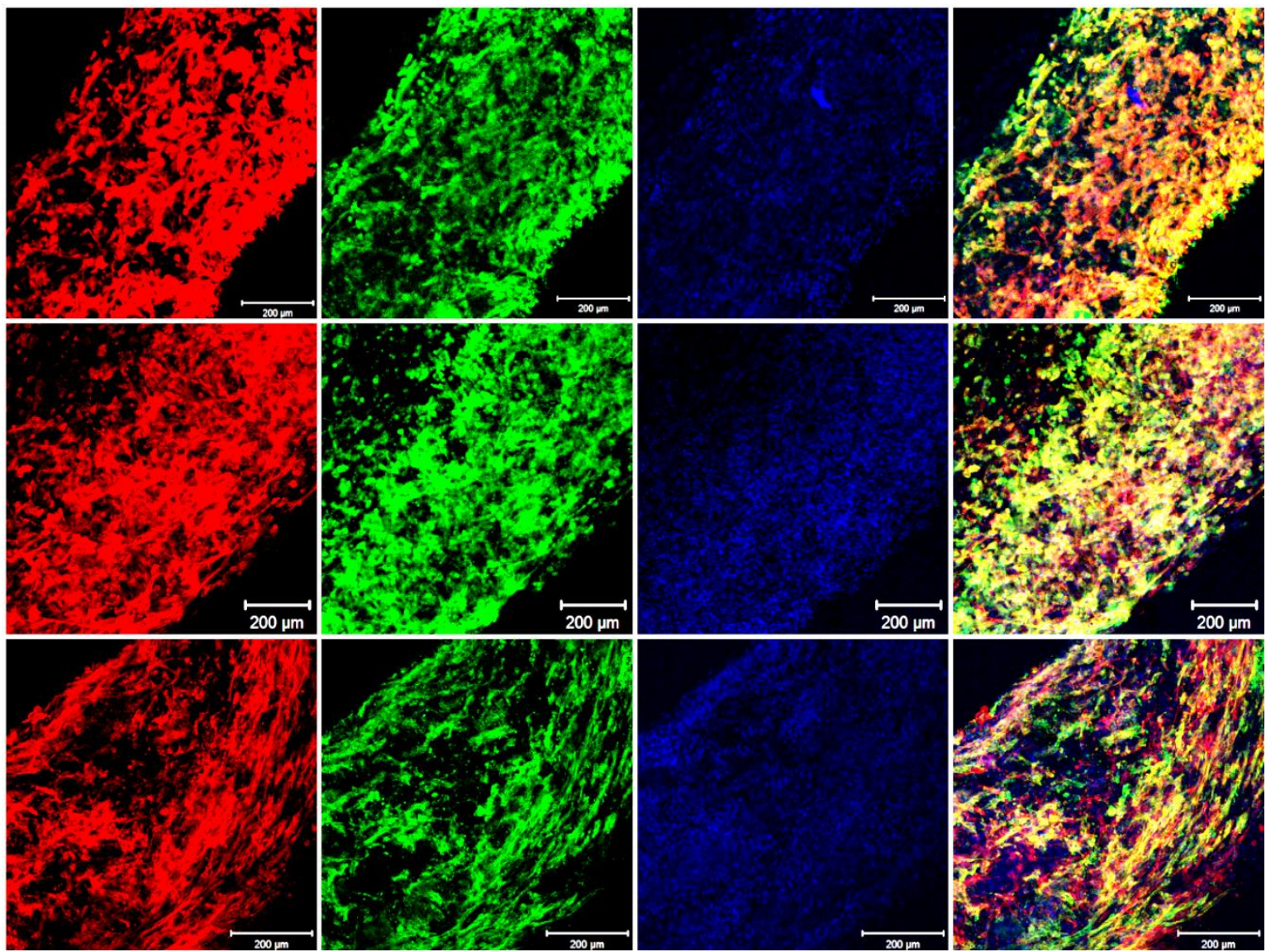

Abbildung 28: Immunfluoreszenzfärbung von Vibrotomschnitten an EHM. A) Schematische Darstellung der Schnittführung. B) $100 \mu \mathrm{m}$ dicke Schnitte aus oberem (obere Reihe), mittlerem (mittlere Reihe) und unterem (untere Reihe) Bereich eines „Armes“ des EHM 16-3. Rot $=$ f-Aktin, grün $=\alpha$-Aktinin, blau $=$ Hoechst (Kernfärbung). Zu sehen ist die gleichmäßige Verteilung von Kardiomyozyten in allen Ebenen des EHM. 


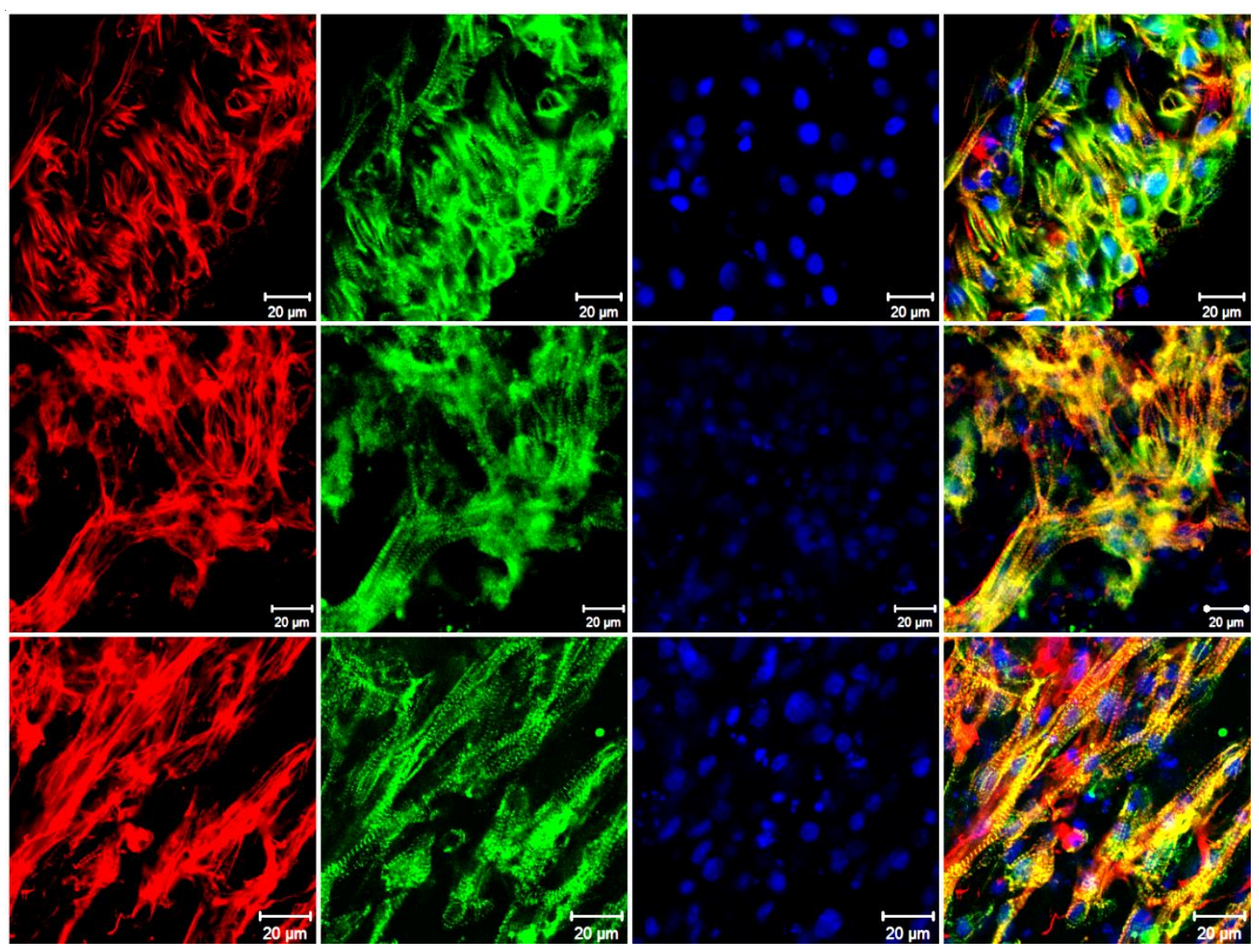

\section{Abbildung 29: Immunfluoreszenzfärbung von Vibrotomschnitten an EHM, Vergrößerungs-}

aufnahme aus Abbildung 28. $100 \mu \mathrm{m}$ dicke Schnitte aus oberem (obere Reihe), mittlerem (mittlere Reihe) und unterem (untere Reihe) Bereich eines „Armes“ des EHM 16-3. Rot $=$ f-Aktin, grün $=\alpha$-Aktinin, blau $=$ Hoechst (Kernfärbung). Gleichmäßige Verteilung der Kardiomyozyten auf alle drei Ebenen, in der unteren Reihe ist die parallele Ausrichtung von Muskelfibrillen und die charakteristische Querstreifung der Sarkomere zu erkennen. 

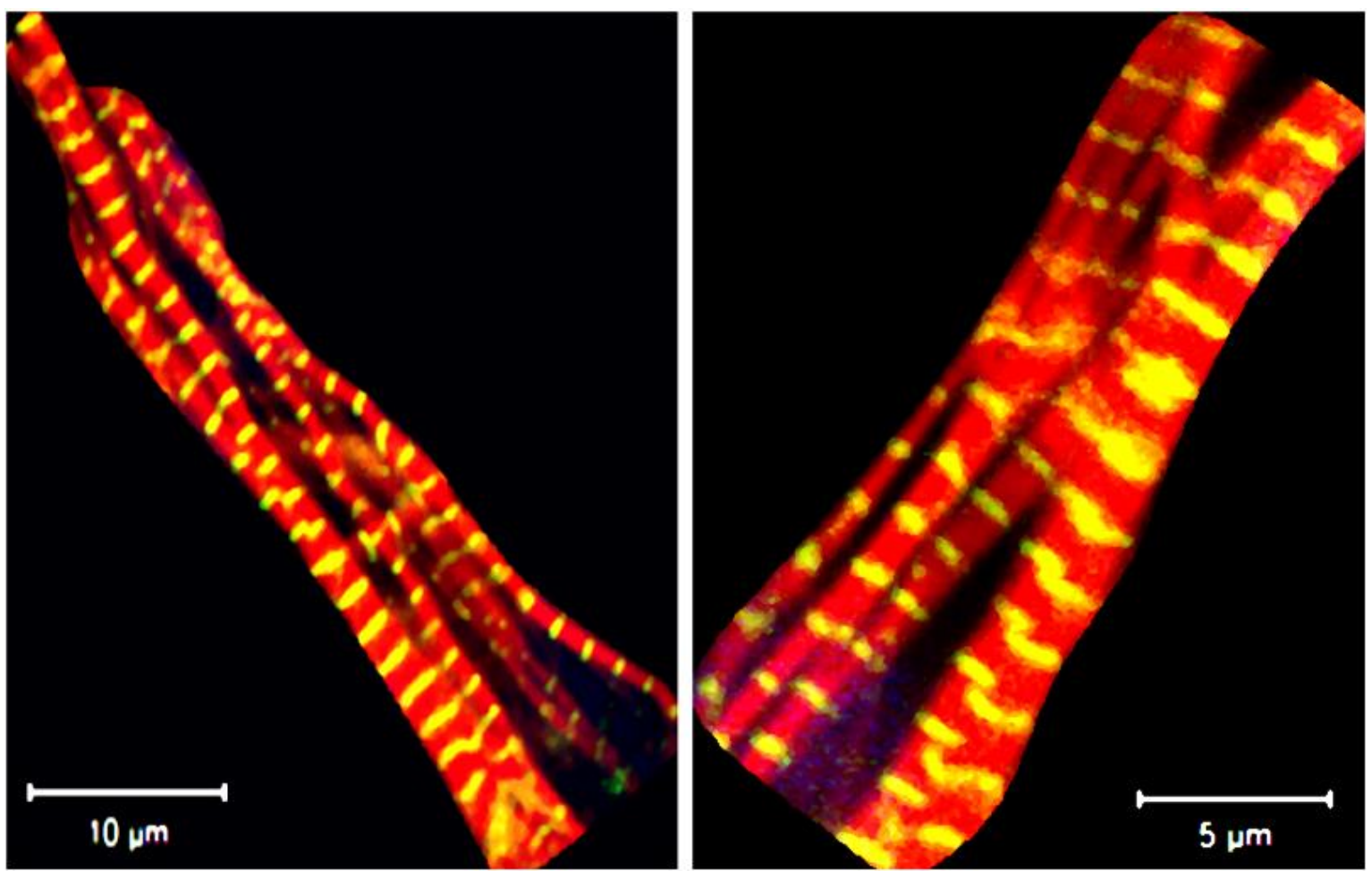

Abbildung 30: Detailaufnahme der Sarkomerstruktur mittels Immunfluoreszenzfärbung von Vibrotomschnitten an EHM. Verwendet wurde EHM 17-1. Rot $=\mathrm{f}-$ Aktin, grün $=\alpha$-Aktinin, blau $=$ Hoechst (Kernfärbung). Zu sehen sind einzelne Muskelfibrillen mit eindeutiger Querstreifung sowie eine Verzweigung von Muskelfibrillen.

\subsection{Vergleich der ermittelten Sarkomerlängen}

Die Analyse von 50 Sarkomeren in sieben Zellen zeigte eine um 11\% kürzere Sarkomerlänge in nach Standardprotokoll differenzierten und als Monolayer kultivierten Kardiomyozyten im Vergleich zu adulten Kardiomyozyten. Unreife Herzmuskelzellen weisen typischerweise kürzere Z-Diskabstände auf. In EHM entsprach die Sarkomerlänge dagegen dem Phänotyp im adulten Herzen (siehe Tabelle 29). Dies entspricht der Beobachtung von Tiburcy et al. (2017) und deutet auf die Förderung der Herzmuskelzellreifung in EHM hin. 
Tabelle 29: Analyse der Sarkomerlänge.

\begin{tabular}{|c|c|c|c|}
\hline Gewebetyp & $\begin{array}{c}\text { Natives } \\
\text { Herzmuskelgewebe }\end{array}$ & $\begin{array}{c}\text { Differenzierte Kardio- } \\
\text { myozyten (2D-Kultur) }\end{array}$ & $\begin{array}{c}\text { EHM } \\
\text { (3D-Kultur) }\end{array}$ \\
\hline $\begin{array}{c}\text { Sarkomerlänge } \\
(\boldsymbol{\mu m})\end{array}$ & $1,87 \pm 0,02$ & $1,66 \pm 0,03 *$ & $1,86 \pm 0,02 \S$ \\
\hline
\end{tabular}

Messung der Sarkomerlänge in nativem Herzmuskelgewebe des Rhesusaffen, in aus riPSC nach Standardprotokoll differenzierten Kardiomyozyten (2D) und in EHM 17-1/16-3 (3D, jeweils $\mathrm{n}=50$ Messungen in 7 (nativ), 7 (2D) bzw. ca. 52 (3D) Herzmuskelzellen). * p < 0,05 für Sarkomerlänge „Nativ“ vs. „2D-Kultur“ per ungepaartem, zweiseitigem t-Test, $\S \mathrm{p}<0,05$ für Sarkomerlänge ,2D-Kultur“ vs. „3DKultur“" per ungepaartem, zweiseitigem t-Test.

\subsection{RNA-Präparation aus EHM}

Bei der RNA-Präparation konnte die in Tabelle 19 dargestellte Menge RNA gewonnen werden. Dabei ergab sich eine RNA-Konzentration von durchschnittlich 587 \pm 306 ng pro mg Feuchtgewicht. Die große Varianz ist vermutlich ein Ausdruck der Protokollvariabilität (siehe Tabelle 30).

Tabelle 30: Ergebnisse der RNA-Präparation der EHM $(n=6)$.

\begin{tabular}{|l|c|c|c|}
\hline & $\begin{array}{c}\text { RNA / EHM } \\
(\boldsymbol{\mu g})\end{array}$ & $\begin{array}{c}\text { Feuchtgewicht / } \\
\text { EHM (mg) }\end{array}$ & $\begin{array}{c}\text { RNA / Feuchtgewicht } \\
(\mathbf{n g} / \mathbf{m g})\end{array}$ \\
\hline EHM Diff. 12-3 & 3,3 & 13,8 & 240 \\
\hline EHM Diff. 12-4 & 15,3 & 7,3 & 2096 \\
\hline EHM Diff. 12-5 & 4,5 & 12 & 374 \\
\hline EHM Diff. 16-2 & 2,8 & 23,9 & 233 \\
\hline EHM Diff. 17-6 & 6,8 & 29,3 & 460 \\
\hline EHM Diff. 18-4 & 6,4 & 13,9 & $587 \pm 306$ \\
\hline \hline Mittelwert \pm SEM & $6,5 \pm 1,9$ & $16,7 \pm 3,5$ & \\
\hline
\end{tabular}




\section{Diskussion}

Hauptziele dieser Arbeit waren a) die Differenzierung von riPSC zu Kardiomyozyten mit morphologischen und funktionellen Eigenschaften nativer Kardiomyozyten in vitro sowie b) die Generierung von EHM aus diesen Zellen. Dabei stellten sich folgende Fragen:

Reagieren etablierte Anti-humane kardiale Antikörper mit nativem Gewebe des Rhesusaffen? Lassen sich riPSC in vitro zu Kardiomyozyten differenzieren und mittels metabolischer Selektion aufreinigen? Weisen die differenzierten Zellen morphologische und funktionelle Charakteristika nativer Kardiomyozyten auf? Können sie zur Herstellung von EHM nach etablierten Methoden verwendet werden? Können diese EHM kontraktile Funktionen entwickeln und reagieren sie auf pharmakologische Intervention? Weisen sie funktionelle und morphologische Eigenschaften kardialen Gewebes auf?

Als Hauptergebnisse dieser Arbeit können folgende Punkte zusammengefasst werden:

Mit Ausnahme der gegen GATA4 und Cx-43 gerichteten Antikörper ließen sich alle gegen humane kardiale Epitope entwickelten Antikörper im Rhesusaffen verwenden.

Induzierte pluripotente Stammzellen des Rhesusaffen ließen sich mittels gerichteter Differenzierung zu Kardiomyozyten differenzieren, wenn auch nicht mit der gleichen Effizienz wie in humanen iPSC.

Diese Kardiomyozyten wiesen viele morphologische und funktionelle Eigenschaften nativer Kardiomyozyten auf.

Engineered heart muscles (EHM) ließen sich unter Vermischung von differenzierten Kardiomyozyten mit initial flüssigem Kollagen nach bereits etablierter Methode herstellen.

Diese EHM zeigten morphologische und funktionelle Eigenschaften kardialen Gewebes im Sinne eines funktionellen Synzytiums. 


\section{$\underline{4.1 \text { Differenzierung von riPSC zu Kardiomyozyten }}$}

In dieser Arbeit wurde eine riPSC-Linie verwendet, die von Dr. M. Tiburcy mittels retroviraler Transduktion der Pluripotenzfaktoren Oct-4, c-MYC, Klf-4, SOX2, Nanog und LIN-28 hergestellt wurde, ähnlich wie in zuvor publizierten Arbeiten zur Generierung von iPSC nichthumaner Primaten (Liu et al. 2008; Zhong et al. 2010; Okahara-Narita et al. 2012; Wunderlich et al. 2014). Zur Differenzierung wurde ein auf Modulation des Wnt/ $\beta$ catenin-Signalwegs beruhendes Protokoll verwendet, welches diesen zuerst über Gabe von CHIR99021 aktiviert und mesodermale Progenitorzellen induziert und im zweiten Schritt, durch Hemmung des Wnt-Signalweges mittels IWP-4 die kardiale Determinierung einleitet. Unter diesem Protokoll wurden Herzmuskelzellpopulationen mit einer 98prozentigen Reinheit und einem 15-fachen Output unter reproduzierbaren Kulturbedingungen und ohne Verwendung von Wachstumsfaktoren erreicht (Paige et al. 2010; Lian et al. 2012).

Dieses Protokoll lässt sich allerdings nicht auf den Rhesusaffen übersetzen. Daher wurde in dieser Studie die Technik der Einkapselung in Kalzium-Alginatkügelchen in Anlehnung an Arbeiten von Sidhu et al. (2012) verwendet, um eine Differenzierung unter genau definierten Bedingungen bezüglich Zellinput und 3D-Mikroumgebung zu ermöglichen und die Verwendung von Feeder-Zellen zu umgehen. Dieses System ermöglicht eine Kultur hoher Zelldichte, ohne die Versorgung mit Sauerstoff und Nährstoffen zu blockieren (Sidhu et al. 2012). Arbeiten von Bai et al. (2011) zeigten die Verwendbarkeit von Alginatkügelchen in modifizierter Form in Kombination mit Kollagen in der direkten Herstellung von Herzgewebe. Die kardiale Differenzierung von hiPSC wurde bereits vielfach gezeigt (Paige et al. 2010; Germanguz et al. 2011; Kattman et al. 2011; Lian et al. 2012; Lundy et al. 2013; Streckfuss-Bömeke et al. 2013; Kadari et al. 2015). Wenige wissenschaftliche Studien verwendeten jedoch bisher pluripotente Stammzellen nichthumaner Primaten in diesem Kontext. So konnten aus embryonalen und induzierten pluripotenten Stammzellen, unter Verwendung von BMP-2, SSEA-1-positive kardiale Progenitorzellen differenziert werden, aus denen alle drei kardialen Zelllinien (Kardiomyozyten, glatte Muskelzellen, Endothelzellen) gewonnen werden konnten. Diese Zellen integrierten sich nach Transplantation in infarziertes Gewebe des Primaten (Leschik et al. 2008; Blin et al. 2010). Zudem zeigten Wunderlich et al. (2012), dass iPSC des Maccaca fascicularis bei ungerichteter Differenzierung embryoid bodies formieren können, die Zellen aller drei Keimblätter enthalten. Gleiches zeigten sie in Teratom- 
Studien nach Transplantation der Stammzellen in immundefiziente Mäuse. Bis zu 12,8\% der embryoid bodies entwickelten spontane Kontraktionen und enthielten Kardiomyozyten unterschiedlichen Reifungsgrades. Sie wiesen also das Potential dieser Stammzellen nach, potenziell zu Kardiomyozyten zu differenzieren. Zudem wurde die Integration von aus humanen ESC differenzierten Kardiomyozyten sowie von autologen Stammzellen aus dem Knochenmark in Infarktmodellen nichthumaner Primaten untersucht (Norol et al. 2003; Chong et al. 2014). Im Verlauf konnten Liu et al. (2018) mittels Transplantation von aus humanen ESC differenzierten Kardiomyozyten im Infarktmodell des Maccaca nemestrina eine signifikante Verbesserung der kontraktilen Funktion sowie eine elektrische Kopplung innerhalb von drei Monaten zeigen. Jedoch kam es in einigen Fällen zu transplantatationsassoziierten ventrikulären Arrhythmien. Shiba et al. (2016) konnten zudem die erfolgreiche gerichtete Differenzierung über Modulation des Wnt-Signalweges von iPSC des Maccaca fascicularis und deren Integration, elektrische Kopplung und Verbesserung der kontraktilen Funktion über 12 Wochen unter Immunsuppression mit Methylprednisolon und Tacrolimus im haploidentischen allogenen Infarktmodell zeigen. Dabei erreichten sie einen Anteil von $83 \pm 1 \%$ für kardiales-Troponin-T-positiver Zellen vor Implantation. Zhang et al. (2017) erreichten über gerichtete Differenzierung von riPSC mittels Modulation von Wnt- und Retinsäure-Signalwegen 92\% für kardiales-Troponin-T-positive Zellen. Diese wiesen eine humanen Kardiomyozyten ähnliche Genexpression sowie elektrophysiologische Charakteristika humaner atrialer und ventrikulärer Kardiomyozyten auf.

Die von Tohyama et al. (2013) entwickelte und hier verwendete metabolische Selektion mittels Laktates nutzt den Umstand, dass Laktat vornehmlich von Kardiomyozyten verstoffwechselt werden kann, dies insbesondere im fetalen Zustand. Andere Ansätze nutzen die transgene Kopplung von Immunfluoreszenzfarbstoffen an bestimmte Zellmarker oder fluoreszenzmarkierte Antikörper gegen Oberflächenmarker wie vascular cell adhesion protein 1 (VCAM1) und signal regulatory protein alpha (SIRPA), gefolgt von fluorescence activated cell sorting (FACS) - also die Aufreinigung im Durchflusszytometer -, oder eine genetische Selektion mittels Erzeugung transgener Stammzelllinien durch Kopplung eines Neomycin-Resistenzgens an die $\alpha$-myosin-heavy-chain und folgender Aufreinigung von Kardiomyozyten durch Behandlung mit Neomycin (Xu et al. 2008; Hattori et al. 2010; Dubois et al. 2011; Uosaki et al. 2011). Zudem wurden spezifisch gegen kardiale Zellmarker gerichtete Hybridisierungssonden entwickelt, die bei Hybridisierung ein Fluoreszenzsignal emittieren und so für FACS genutzt werden können 
(Ban et al. 2013). All diese Verfahren haben jedoch im Gegensatz zu dem in dieser Forschungsarbeit verwendeten Ansatz den Nachteil, dass sie schwerlich unter sterilen Bedingungen eingesetzt werden können (FACS-Gerät) bzw. den Einsatz transgener Verfahren benötigen.

$\mathrm{Zu}$ Beginn dieser Arbeit stand die Frage, ob sich die verwendete riPSC-Linie zu spontan kontrahierenden Kardiomyozyten differenzieren lässt und inwieweit diese dann morphologische und funktionelle Charakteristika adulter Kardiomyozyten aufweisen. Es konnte gezeigt werden, dass die Differenzierung zu Kardiomyozyten mit der verwendeten Methode möglich ist, jedoch nur 58\% der Differenzierungsrunden spontan kontrahierende Zellen hervorbrachten. Insbesondere gegen Ende der Versuchsreihe scheiterte die Differenzierung. Deshalb stellte sich die Frage, ob die Ursache dafür in einer zunehmenden Passagenzahl und einem eventuell damit einhergehenden Verlust des pluripotenten Potenzials der riPSC zu suchen war. Aus diesem Grund wurden wiederholt die Pluripotenzmarker TRA-1-60 und Oct-3/4 mittels Durchflusszytometrie analysiert. Tatsächlich kam es mit zunehmender Passagenanzahl zu einer Abnahme der für diese Marker, insbesondere für Oct-3/4, positiven Zellen und somit zu einer Abnahme des Anteils pluripotenter Zellen (siehe Abbildung 13). Hieraus schlussfolgern wir, dass die Verwendung früher Passagen $(<35)$ vorteilhaft sein sollte.

Im Rahmen der erfolgreichen Differenzierungen $(n=19)$ konnte ein Kardiomyozytenanteil von durchschnittlich $51 \pm 3 \%$ bei einem Output von $148 \pm 12 \%$ lebender Kardiomyozyten (n = 48), bezogen auf die Anzahl initial eingesetzter Stammzellen erreicht werden. Diese Werte liegen zwar über denen, die in anderen Arbeiten durch eine spontane Differenzierung erreicht werden konnten, erreichen jedoch bei Weitem nicht den auf Grund vorheriger Publikationen zu erwartenden Bereich, insbesondere, da hierbei eine Aufreinigung mittels Laktatselektion einbezogen ist (vgl. siehe oben, Lian et al. 2012; Tohyama et al. 2013). Insbesondere im Vergleich mit späteren Arbeiten von Shiba et al. (2016) und Zhang et al. (2017), fiel der erreichte Kardiomyozytenanteil niedrig aus. Dennoch genügte die Reinheit der Kardiomyozyten, um spontan kontrahierende EHM zu generieren, erklärt aber auch teilweise deren, weiter unten beschriebenes, niedriges Kraftniveau. 
Die Untersuchung in Bezug auf die weiter oben geforderte, möglichst umfangreiche Übereinstimmung morphologischer und funktioneller Charakteristika mit nativem Myokard ergab folgende Ergebnisse:

Nach zuvor bewiesener Verwendbarkeit etablierter kardialer Antikörper mittels Immunfluoreszenzfärbung von nativem kardialem Gewebe des Rhesusaffen, konnte gezeigt werden, dass die Sarkomere der differenzierten Kardiomyozyten eine klassische Morphologie aufwiesen. So zeigten diese eine charakteristische Querstreifung und die Zellen exprimierten typische Bausteine des kardialen Sarkomers, darunter $\alpha$-Aktinin, kardiales Troponin I, Tropomyosin und schwere Myosinketten sowie den für die kardiale Differenzierung bedeutsamen Transkriptionsfaktor Nkx2.5. Anti-Connexin-43-Antikörper zeigten jedoch nur ein unspezifisches Signal, sodass eine Expression von Connexin-43 als essentiellem Bestandteil der gap junctions nicht sicher nachgewiesen werden konnte. Diese interzellulären Membrankanäle sind für eine elektrische Kopplung von Kardiomyozyten essenziell. In 2D-Kultur wiesen Herzmuskelzellen mit 1,66 $\pm 0,03 \mu \mathrm{m}$ eine im Vergleich zu adultem Herzmuskel kürzere Sarkomerlänge auf ( $\mathrm{n}=50$ Sarkomere).

Unter funktionellen Gesichtspunkten konnte, zusätzlich zu einem rein visuellen Nachweis von Kontraktionen, durch die Analyse von Kalzium-Transienten gezeigt werden, dass die differenzierten Kardiomyozyten zur Ausbildung rhythmischer Kalziumfreisetzung in der Lage waren. Dabei lag die durchschnittliche Kalzium-Freisetzungsfrequenz bei $34 \pm 5,31 / \min (\mathrm{n}=3)$. Zudem zeigten diese Untersuchungen, dass sie untereinander eine elektrische Kopplung ausbilden und somit synchronisiert kontrahieren konnten, da benachbarte Zellen synchronisierte Kalzium-Transienten aufwiesen (siehe Abbildung 22 B und C). Dies ist eine wichtige Voraussetzung, um funktionstüchtige EHM generieren zu können beziehungsweise damit diese sich im Rahmen einer Implantation in infarziertes Gewebe integrieren können.

Zusammengenommen wiesen die im Rahmen dieser Arbeit differenzierten Kardiomyozyten also grundlegende morphologische und funktionelle Eigenschaften nativer Kardiomyozyten auf, befanden sich im Anschluss an die Differenzierung jedoch vermutlich noch in einem fetalen Entwicklungszustand und entwickelten erst in den EHM eine weitere Differenzierung (s. u.). Dies entspricht zuvor durchgeführten Untersuchungen (Tiburcy et al. 2017). Zudem sind für eine effiziente Nutzung des hier dargestellten Verfahrens weitere Optimierungen nötig. Eventuell ist eine Anpassung der verwendeten Konzentrationen von 
Activin A, BMP-4 und FGF-2 oder die Verwendung zusätzlicher Stimuli nötig. So beschrieben Kattmann et al. (2011) die Notwendigkeit einer Anpassung obiger Konzentrationen an verschiedene Zelllinien und mutmaßten, dass dies sogar für verschiedene Passagen derselben Zelllinie erforderlich sein könnte.

\section{$\underline{4.2 \text { Herstellung und morphologische Charakterisierung von EHM }}$}

Die Herstellung von EHM ist bereits für eine Reihe von Spezies und Zellarten etabliert, darunter neonatale Kardiomyozyten der Ratte (Zimmermann et al. 2000; Zimmermann et al. 2006) und differenzierte Kardiomyozyten aus parthenogenetischen Stammzellen der Maus (Didié et al. 2013), humanen embryonalen Stammzellen (Soong et al. 2012) und humanen induzierten pluripotenten Stammzellen (Streckfuss-Bömeke et al. 2013; Tiburcy et al. 2017). Als Vorbereitung auf eine klinische Translation ist jedoch die Entwicklung eines dem Menschen ähnlichen Großtiermodells nötig. Während es keine Protokolle für die zuverlässige Generierung von pluripotenten Stammzellen aus Schwein, Hund oder Schaf gibt, legen Berichte anderer Arbeitsgruppen das Makkakenmodell als wichtiges präklinisches Modell nahe (Chong et al. 2014; Chong und Murry 2014; Shiba et al. 2016; Ichimura und Shiba 2017; Zhang et al. 2017; Liu et al. 2018), um mögliche Risiken, wie die Induktion von Arrhythmien und das Wachstum von Teratomen zu untersuchen (Karikkineth und Zimmermann 2013). Zudem wäre mit dem Großtiermodell die langfristige Evaluation der Funktion implantierter Gewebe grundsätzlich auch über Jahre möglich, was im Nagetiermodell auf Grund der kurzen Lebensspanne dieser Tiere nicht umsetzbar ist.

In der vorliegenden Forschungsarbeit wurde versucht, die etablierten Methoden zur EHMGenerierung auf die oben beschriebenen differenzierten Kardiomyozyten aus induzierten pluripotenten Stammzellen des Rhesusaffen anzupassen, um erste Schritte für ein solches Großtiermodell zu entwickeln.

Damit EHM zur Gewebeersatztherapie eingesetzt werden können, müssen sie in möglichst vielen morphologischen und funktionellen Charakteristika mit nativem Gewebe übereinstimmen. Diese wurden in der vorliegenden Arbeit untersucht, um sie im Anschluss daran mit nativem Herzmuskelgewebe vergleichen zu können. In der Zusammenschau ergaben sich diesbezüglich die nachfolgenden Ergebnisse: 
Die Morphologie der EHM wurde wie die der differenzierten Kardiomyozyten mit Hilfe von Immunfluoreszenzfärbungen untersucht. Dabei ging es jedoch nicht mehr um die differenzierte Untersuchung des sarkomerischen Aufbaus, sondern um die Frage, wie sich die Kardiomyozyten innerhalb der EHM verteilen. Es konnte gezeigt werden, dass diese sich im oberen, mittleren und unteren Bereich (Schnittführung entsprechend Abbildung 28) eines EHM nahezu gleichmäßig verteilen und dabei Muskelfibrillen mit charakteristischer Querstreifung ausbilden. Des Weiteren sind diese zu einem großen Teil entlang der Längsrichtung der EHM-Arme und damit längs der durch die Silikonhalter entwickelten Zugkraft ausgerichtet. Diese übernehmen bei der Ausreifung der künstlichen Gewebe eine wichtige Rolle, da sie eine, den physiologischen Bedingungen im Herzen entsprechende, auxotone Belastung des Muskelgewebes ermöglichen. Andere Verfahren, die die EHM unter isometrischen oder isotonen Stress setzen, scheinen unterlegen und sind zudem unphysiologisch (Liaw und Zimmermann 2016). Die mechanische Zugspannung induziert hypertrophes Wachstum und verstärkt die morphologische und funktionelle Reifung der Kardiomyozyten in den EHM. So führt sie zu einer vermehrt longitudinalen, parallelen Ausrichtung der Zellen und verbessert die kontraktilen Eigenschaften der EHM (Fink et al. 2000; Zimmermann und Eschenhagen 2003). Die oben beschriebene weitere Reifung der Kardiomyozyten in den EHM ließ sich an der Länge der Sarkomere nachvollziehen: waren diese in 2D-Kultur noch kürzer als in nativem Myokard, zeigten sie in EHM eine mit nativem Myokard vergleichbare Länge (siehe Tabelle 29). Dabei zeigten die Zellen in EHM lediglich einen durchschnittlichen Durchmesser von $15,2 \pm 0,4 \mu \mathrm{m}$ und ein durchschnittliches Volumen von 2478 \pm 191 fl. Dies entspricht am ehesten dem Volumen fetaler Kardiomyozyten gemessen im Schaf (Bensley et al. 2016). Herzmuskelzellen aus unter serumfreier Kultur entwickelten EHM aus hiPSC wiesen ein fast fünffaches Volumen von 12.101 $\pm 1.240 \mathrm{fl}$ auf (Tiburcy et al. 2017).

Um zu untersuchen, ob es innerhalb der EHM zu einer weiteren Proliferation der Kardiomyozyten kam, wurden die EHM dissoziiert und ihr Kardiomyozytengehalt konnte prozentual und absolut bestimmt werden und ins Verhältnis zu den initial verwendeten Zellzahlen gesetzt werden. Unter Einbeziehung der EHM der Differenzierungen 16-18 konnte ein Kardiomyozytenanteil von durchschnittlich $23 \pm 5 \%$, bei einer gemittelten

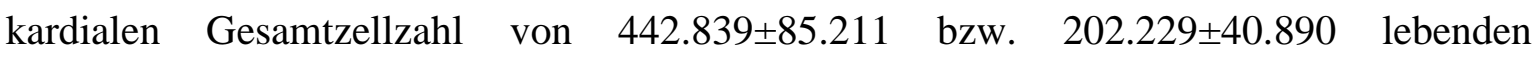
Kardiomyozyten pro EHM erreicht werden. Durch die geringe Reinheit der bei der Differenzierung gewonnenen Kardiomyozyten wurden schlussendlich nur 488.958 \pm 51.750 Herzmuskelzellen pro EHM eingesetzt. In der Folge kam es dadurch in EHM zu einer 
Abnahme des Kardiomyozytenanteils auf 13 $\pm 4 \%$. Dies entspricht Analysen von Tiburcy et al. (2011), nach denen es zwischen Tag null und Tag zwölf der EHM-Kultur aus neonatalen Herzmuskelzellen der Ratte zu einer Abnahme der Zellzahl um 70\% kommt, vornehmlich durch eine hohe Apoptoserate der Kardiomyozyten zu Beginn der Kultur. Vergleichbare Arbeiten zeigten dies auch für humane Herzmuskelzellen in EHM (Tiburcy et al. 2017). Diese neonatalen Herzmuskelzellen befinden sich in einem postnatalen Status, während die in dieser Arbeit verwendeten Zellen mutmaßlich einem embryonalen oder fetalen Entwicklungszustand entsprechen. In EHM, die mit aus humanen ESC differenzierten Kardiomyozyten generiert wurden, konnte deren Proliferation, insbesondere unter zyklischem mechanischem Stress jedoch nachgewiesen werden (Tiburcy et al. 2011; Tiburcy und Zimmermann 2013). Tulloch et al. (2011) zeigten anhand von EHM, die mittels aus hiPSC beziehungsweise ESC differenzierten Kardiomyozyten hergestellt wurden, eine durchschnittliche Proliferationsrate der Kardiomyozyten innerhalb der EHM von 33\% innerhalb von fünf Tagen, gemessen anhand der DNASynthese. Des Weiteren konnten sie nachweisen, dass eine uniaxiale periodische Dehnung sogar zu einer um 7,4\% höheren Proliferation im Vergleich zu statischem Stress führte. Die hier gezeigte Abnahme der Kardiomyozytenzahl widerspricht also der Erwartung einer weiteren Zellvermehrung. Sie weist entweder auf eine terminale Differenzierung hin oder ist das Ergebnis einer initial hohen, eine hypothetische Proliferation übersteigenden, Apoptoserate. Da die differenzierten Zellen bereits initial nach der Zellvereinzelung, also vor dem Generieren der EHM, eine Lebendzellrate von lediglich $41 \pm 2 \%$ aufwiesen, ist Letzteres naheliegend. Ein weiteres Zellsterben zu Beginn der EHM-Kultur, ausgelöst durch den im Rahmen ihrer Herstellung auftretenden Stress, ist durchaus denkbar.

\section{$\underline{4.3 \text { Funktionelle Charakterisierung von EHM mittels Kontraktionsanalysen }}$}

Um zu evaluieren, ob die generierten EHM eine ausreichende Kraft entwickeln können, um sie in der Gewebeersatztherapie einsetzbar $\mathrm{zu}$ machen, wurde ihre Kraft unter verschiedenen Bedingungen gemessen. Zuerst wurde dabei untersucht, ob sie einen positiven Frank-Starling-Mechanismus aufwiesen, welcher die Beziehung zwischen Vorspannung und entwickelter Kraft beschreibt. Herzmuskulatur reagiert innerhalb eines physiologischen Bereiches auf eine Erhöhung der Vordehnung des Gewebes mit einer Zunahme der Kontraktionskraft. Es wird vermutet, dass dies unter anderem auf einer besseren Überlappung von Aktin- und Myosinfilamenten sowie einer steigenden Kalziumsensitivität des kardialen Troponin C infolge der Sarkomerdehnung beruht. Zudem scheint 
das elastische Protein Titin unter steigender Vorlast als eine Art Mediator die Anzahl der Myosin-Querbrücken zu erhöhen. Da diese auf molekularer Ebene für die Kraftentwicklung verantwortlich sind, würde dies in einer stärkeren Kontraktion münden. Mit zunehmender Vordehnung, ausgedrückt in einer Zunahme der Sarkomerlänge, nimmt die entwickelte Kraft zwischen 1,7 $\mu \mathrm{m}$ und 2,2 $\mu \mathrm{m}$ Länge (im humanen Herzen) derselben rasch zu, um dann bei einer weiteren Dehnung ebenso rapide wieder abzunehmen (Sequeira und van der Velden 2015). Da die EHM unter steigender Vordehnung einen signifikanten Anstieg der Kontraktionskraft von $0,14 \pm 0,01 \mathrm{mN}$ auf $0,18 \pm 0,02 \mathrm{mN}-$ dies entspricht einer Veränderung um $+28,6 \%$ - zeigten und somit einen positiven FrankStarling-Mechanismus aufwiesen, erfüllen sie diese Forderung und damit ein wichtiges Kriterium nativen Myokards. Dabei stieg die RT jedoch prozentual mit 83\% deutlicher an, es ist somit eine starke Erhöhung der Vorspannung nötig, um einen im Verhältnis deutlich geringeren Anstieg der systolischen Kraft zu generieren. Das Verhältnis TT zu RT sank dabei von 0,3 auf 0,2 ab. In gesundem Myokard sollte dieses Verhältnis jedoch grundsätzlich größer als 1 sein und bei Vorlasterhöhung ansteigen. Zimmermann et al. (2002b; 2004) konnten zudem anhand von EHM aus neonatalen Kardiomyozyten der Ratte zeigen, dass diese - mit einer Ratio von 1,33 - ein solches Kriterium erfüllen können. Ursache des obigen ungünstigen Verhältnisses von TT zu RT könnte der hohe Anteil an Nichtkardiomyozyten in Rhesus-EHM sein.

Natives Myokard reagiert auf steigende extrazelluläre Kalziumkonzentrationen mit einer Zunahme der Kontraktionskraft. Die intrazelluläre Kalziumkonzentration wird durch einen Kalziumeinwärtsstrom und eine dadurch getriggerte Kalziumfreisetzung aus dem sarkoplasmatischen Retikulum reguliert. Über Bindung von Kalziumionen an Troponin C wird die Anzahl an möglichen Querbrückenbindungen zwischen Aktin und Myosin und somit die entwickelte Kontraktionskraft moduliert (Sun und Irving 2010). Die in dieser Arbeit produzierten EHM zeigten eine positiv inotrope Reaktion auf eine Erhöhung der extrazellulären Kalziumkonzentration, mit einer maximal entwickelten durchschnittlichen Kraftamplitude von $0,23 \pm 0,02 \mathrm{mN}$ bei einer extrazellulären Kalziumkonzentration von im Mittel 2,9 $\pm 0,2 \mathrm{mmol} / \mathrm{l}$. Die halbmaximale Kraft wurde bei einer Kalziumkonzentration von durchschnittlich 0,6 $\pm 0,2 \mathrm{mmol} / 1$ entwickelt $(\mathrm{n}=19)$. Dabei nahm ihre Grundspannung jedoch wider Erwarten um 19,1\% ab. Dadurch bedingt stieg das Verhältnis von Kraftamplitude zu Grundspannung von 0,13 auf 0,4. Unter Einbeziehung der durchschnittlichen Kardiomyozytenzahl konnte eine durchschnittliche maximale Kraft pro Kardiomyozyt von 2,4 $\pm 0,5 \mathrm{nN}$ ermittelt werden. Die EHM der Differenzierungen 12 und 17 wurden zudem 
getrennt von denen der Differenzierungen 16 und 18 betrachtet, da sie unter anderen Kulturbedingungen differenziert wurden: ihre Differenzierung wurde um einen Tag verlängert und die Behandlung mit IWP-4 dauerte zwei Tage länger an. Interessanterweise wiesen sie sowohl eine größere maximale Kraft pro Kardiomyozyt als auch eine, vermutlich diesem Umstand geschuldete, größere maximale Kontraktionskraft pro EHM auf. Daraus könnte eine weitere Ausreifung der Kardiomyozyten in der verlängerten Zellkultur und eine mögliche Optimierung des Differenzierungsprotokolls abgeleitet werden. Insgesamt entwickelten die EHM ein im Vergleich $\mathrm{zu}$ anderen Arbeiten eher niedriges Kontraktionskraftniveau. Pro EHM wurde eine durchschnittliche Kontraktionskraft entwickelt, welche mit EHM vergleichbar ist, die auf aus humanen iPSC differenzierten Kardiomyozyten beruhen. Diese entwickelten eine durchschnittliche Kontraktionskraft von 0,24 mN (Streckfuss-Bömeke et al. 2013). EHM aus Kardiomyozyten, die von Tiburcy et al. (2017) aus humanen ESC oder iPSC unter serumfreien Bedingungen differenziert wurden, entwickelten im Schnitt eine 6,5-fach (hESC) bzw. 11-fach (hiPSC) größere Kraft. Das niedrigere Kontraktionskraftniveau lässt sich zumindest teilweise durch die geringe Reinheit der verwendeten Zellen erklären. Denn gleichzeitig erreichte die in der vorliegenden Arbeit entwickelte durchschnittliche Kraft pro Kardiomyozyt einen annähernd 2,2-fachen Wert im Vergleich zu dem von Riegler et al. (2015) publizierten Kraftniveau. Zudem wurde die Kraft pro Querschnitt betrachtet, hierbei zeigte sich ein Durchschnittswert von $0,07 \pm 0,01 \mathrm{mN} / \mathrm{mm}^{2}(\mathrm{n}=19)$. Dies liegt weit unter dem Niveau von etwa $3 \mathrm{mN} / \mathrm{mm}^{2}$, welches Zimmermann et al. (2004) an EHM aus neonatalen Kardiomyozyten der Ratte zeigen konnten, und erreicht nicht annähernd die $20 \mathrm{mN} / \mathrm{mm}^{2}$, die die von ihnen isolierten Ventrikelstreifen aus dem Herzen der Ratte aufbrachten. Tiburcy et al. (2017) zeigten für EHM aus hiPSC nach acht Wochen Kultur eine Kontraktionskraft von $6,2 \pm 0,8 \mathrm{mN} / \mathrm{mm}^{2}$. Zum Vergleich entwickelt der Herzmuskel eines menschlichen Säuglings eine Kraft von etwa $1 \mathrm{mN} / \mathrm{mm}^{2}$ (Wiegerinck et al. 2009).

Zudem zeigten die hier generierten EHM bei Erhöhung der Frequenz einen kontinuierlichen und signifikanten Abfall der Kontraktionskraft. Diese negative Frequenztreppe widerspricht dem Bowditch-Phänomen und wird in unreifem Herzgewebe im Tiermodell sowie in Patienten mit Herzinsuffizienz beobachtet (Zimmermann et al. 2000; Alpert et al. 2002). Die negative Frequenztreppe deutet auf eine unreife bzw. defekte Kalziumhomöostase hin. 
Neben einer Erhöhung von Vorspannung, extrazellulärer Kalziumkonzentration und Herzfrequenz kommt es auch unter adrenerger Stimulation zu einem positiv inotropen Effekt in nativem Myokard. Dieser Effekt wird über Beta1-Rezeptoren vermittelt, die darüber hinaus auch positiv chronotrop und lusitrop wirken, sie bewirken also auch eine Verkürzung der Kontraktionsamplitude. Im Rahmen der Stimulation mit steigender Isoprenalin-Konzentration zeigten die Rhesus-EHM einen minimalen, nicht signifikanten Anstieg der entwickelten Kraft von $0,12 \pm 0,01 \mathrm{mN}$ auf $0,14 \pm 0,02 \mathrm{mN}$. Zudem zeigte sich eine deutliche Verkürzung der Anspannungs- und Entspannungszeiten. Zusammengenommen zeigte sich ein teilweise erwarteter Effekt nach adrenerger Stimulation.

Eine die Katecholamineffekte antagonisierende, parasympathische Wirkung vermittelt Acetylcholin am Herzen über muskarinerge M2-Rezeptoren. Nach Zugabe von Carbachol unter maximaler Isoprenalinstimulation zeigte sich ein negativ inotroper Effekt mit einem Abfall der entwickelten Kraft um 53\%. Die Anspannungs- (T1) und Relaxationszeit (T2) verlängerten sich jedoch nicht wie erwartet, sondern verkürzten sich sogar. In Zusammenschau mit den gezeigten betaadrenergen Befunden liegt die Vermutung nahe, dass die adrenerge und muskarinerge Signaltransduktion in den hier entwickelten EHM noch keinen adulten Entwicklungszustand aufweist. Bezugnehmend auf bisherige Arbeiten in diesem Forschungsbereich wäre ein positiv inotroper Effekt unter Isoprenalin jedoch zu erwarten gewesen. So zeigten Zimmermann et al. (2000) bei der Arbeit mit EHM aus neonatalen Kardiomyozyten der Ratte einen Anstieg der Kontraktionsamplitude um 45\% bei einer Konzentration von 0,1 mM Isoprenalin und eine Abnahme der Kontraktionsdauer um 21\%, gleichzeitig führte eine Konzentration von $1 \mathrm{mM}$ Carbachol zu einer Antagonisierung der Isoprenalineffekte. In späteren Arbeiten mit neonatalen Kardiomyozyten aus „Fischer-344-Ratten“ zeigten sie 2002 sogar einen Anstieg der Kontraktionsamplitude um $185 \pm 10 \%$ bei $1 \mathrm{mM}$ Isoprenalin (Zimmermann et al. 2002a). Streckfuss-Bömeke et al. (2013) wiesen auch für EHM aus kardial differenzierten hiPSC einen deutlichen Anstieg der Kontraktionskraft unter Stimulation mit Isoprenalin nach. 
Tabelle 31: Vergleich der maximalen Kontraktionskraft pro EHM und pro aus EHM isoliertem Kardiomyozyt.

\begin{tabular}{|c|c|c|}
\hline & $\begin{array}{c}\text { Maximale } \\
\text { Kontraktionskraft / } \\
\text { EHM (mN) }\end{array}$ & $\begin{array}{c}\text { Maximale } \\
\text { Kontraktionskraft / } \\
\text { Kardiomyozyt (nN) }\end{array}$ \\
\hline EHM Diff. 12/17 $(\mathrm{n}=12)$ & $0,26 \pm 0,03$ & $3,19 \pm 0,70$ \\
\hline EHM Diff. 16/18 $(n=7)$ & $0,17 \pm 0,02$ & $0,90 \pm 0,28$ \\
\hline EHM Diff. 12, 16, 17, $18(\mathrm{n}=19)$ & $0,23 \pm 0,02$ & $2,35 \pm 0,52$ \\
\hline $\begin{array}{c}\text { EHM aus differenzierten hESC } \\
\text { /hiPSC unter serumfreien } \\
\text { Bedingungen (Tiburcy et al. 2017) }\end{array}$ & $\begin{array}{l}\text { ca.1,5 (hESC), } \\
\text { ca. } 2,5 \text { (hiPSC) }\end{array}$ & ca. 10 \\
\hline $\begin{array}{c}\text { EHM aus differenzierten hESC } \\
\text { (Riegler et al. 2015) }\end{array}$ & $0,35 \pm 0,11$ & $1,07 \pm 0,84$ \\
\hline $\begin{array}{c}\text { EHM aus differenzierten PSC der } \\
\text { Maus (Didié et al. 2013) }\end{array}$ & $0,82 \pm 0,03$ & Keine Daten vorliegend. \\
\hline $\begin{array}{c}\text { EHM aus differenzierten hiPSC } \\
\text { (Streckfuss-Bömeke et al. 2013) }\end{array}$ & 0,24 & Keine Daten vorliegend. \\
\hline $\begin{array}{c}\text { EHM aus neonatalen } \\
\text { Kardiomyozyten der Ratte } \\
\text { (Zimmermann et al. } 2002 \mathrm{~b} \text { ) }\end{array}$ & $0,75 \pm 0,11$ & Keine Daten vorliegend. \\
\hline
\end{tabular}

Daten für verschiedene Kulturbedingungen: EHM der Differenzierungen 12,17 (n = 12) vs. EHM der Differenzierungen 16,18 ( $\mathrm{n}=7$ ) vs. EHM der Differenzierungen 12, $16-18(\mathrm{n}=19)$, beziehungsweise EHM beruhend auf verschiedenen Herkunftszelllinien. Zur Berechnung der Kraft pro Kardiomyozyt wurde die Gesamtzahl an Herzmuskelzellen pro EHM verwendet.

Die in dieser Arbeit generierten EHM erfüllten zusammenfassend drei von vier untersuchten Kriterien, die von Soong et al. (2012) für „humane EHM hoher Qualität“ aufgestellt wurden:

Erstens entwickelten sie sichtbare, spontane Kontraktionen mit einer Frequenz von über 60 Schlägen pro Minute, zweitens erzeugten sie eine isometrische Kraft von über 0,2 $\mathrm{mN}$ bei einer Kalziumkonzentration von $2 \mathrm{mmol} / \mathrm{l}$ und drittens wiesen sie organisierte Muskelbündel eindeutiger Querstreifung auf. Sie zeigten allerdings keine signifikant positiv inotrope Reaktion auf die Stimulation mit Isoprenalin. 
Zusammenfassend lässt sich sagen, dass die erzeugten EHM in vielen Punkten nativem Myokard ähnelten, jedoch auf Grund der geringen Reinheit der mit diesem Protokoll differenzierten Kardiomyozyten eine relativ geringe Kraft entwickelten. Wie die Kraft pro Kardiomyozyt zeigt, besitzen die Zellen jedoch prinzipiell das Potential, kräftigere EHM zu formieren. Grundsätzlich scheint das hier entwickelte Protokoll eine solide Grundlage für eine Anwendung im Großtiermodell zur Überprüfung des Potentials von EHM zur Herzreparatur zu sein.

\section{$\underline{4.4 \text { Ausblick }}$}

In der Vergangenheit konnte gezeigt werden, dass sich EHM aus neonatalen Kardiomyozyten der Ratte im immunsupprimierten infarzierten Nagermodell integrieren, überleben, sich mit dem Empfängergewebe elektrisch koppeln und die systolische und diastolische Funktion verbessern können. Dabei kam es zu einem Einsprießen von Gefäßen und somit zu einem Anschluss der EHM an das Gefäßnetz des Empfängerorganismus. Erstaunlicherweise induzierten die spontan kontrahierenden EHM in diesen Modellen keine Arrhythmien, möglicherweise, da ihre langsamere Schlagfrequenz von der des Empfängers überspielt wurde (Zimmermann et al. 2002a; Zimmermann et al. 2006). Spätere Arbeiten zeigten, dass sich EHM aus Kardiomyozyten, die aus humanen ESC differenziert worden waren, ebenfalls im Nagermodell implantieren lassen, inklusive der Ausbildung eines Gefäßnetzes. Die Transplantate waren 220 Tage nach Implantation weiterhin nachweisbar, was eine langfristige Nutzung des EHM-Modells in der Gewebeersatztherapie möglich erscheinen lässt. Zudem zeigten die transplantierten Kardiomyozyten eine weitere Ausreifung und es wurde keine Tumorbildung beobachtet. Allerdings zeigte sich keine Verbesserung der kontraktilen Funktion der infarzierten Nagerherzen. Dies überrascht jedoch nicht, da in einem solchen xenogenen Modell eine elektrische Kopplung humaner Kardiomyozyten mit denen der Ratte notwendig wäre. Eine solche konnte bisher nicht gezeigt werden, vermutlich bedingt durch die großen Unterschiede in der Herzfrequenz dieser Spezies (Riegler et al. 2015). Allerdings konnte eine derartige elektrische Kopplung humaner Kardiomyozyten mit dem Empfängergewebe im Guinea-Schwein gezeigt werden. Dazu verwendeten Shiba et al. (2012) aus hESC differenzierte Herzmuskelzellen und implantierten diese in infarzierte Schweineherzen. Sie konnten über die elektrische Kopplung hinaus nachweisen, dass diese Kardiomyozyten sowohl die ventrikuläre Funktion im Vergleich zu transplantierten Nicht-Myozyten verbesserten als auch vor induzierten Arrhythmien schützten. Zudem zeigten sie einen 
Gefäßanschluss des Transplantats, und es kam nicht zur Ausbildung von Teratomen. Romagnuolo et al. (2019) wiesen jedoch in einem analogen Modell das Auftreten von induzierter ventrikulärer Tachykardie innerhalb der ersten vier Wochen nach Transplantation nach. Wie oben bereits erwähnt, gelang Shiba et al (2016) der Nachweis einer Kopplung von aus riPSC differenzierten Kardiomyozyten im allogenen haploidentischen Infarktmodell. Sie zeigten zudem eine Verbesserung der kardialen Funktion. Sollte dies ebenso für die Implantation von EHM im Großtiermodell gelten diese positiven Effekte wurden nur anhand von Einzelzellverbänden gezeigt -, verspricht dies eine potenzielle Verbesserung funktioneller Parameter infarzierten kardialen Gewebes. Die in dieser Arbeit generierten EHM bilden die Grundlage, um die Integration von EHM in das Empfängergewebe inklusive einer erhofften elektrischen Kopplung und Verbesserung funktioneller Parameter des Herzens in einem allogenen oder gar autologen Modell weiter zu evaluieren. In einer autologen Studie könnte auf eine Immunsuppression des Empfängers verzichtet werden. Sollten Studien im Großtiermodell eine Verbesserung funktioneller kardialer Parameter zeigen und sich Risiken wie Kanzerogenität und Arrhythmogenität der Implantate ausschließen lassen, wäre ein klinischer Einsatz denkbar. Darüber hinaus müsste dann auch ein therapeutischer Vorteil im Vergleich mit etablierten Behandlungsweisen belegt werden. Der nächste Schritt wäre somit, die hier entwickelten EHM in einem Infarktmodell des Rhesusaffen einzusetzen und hinsichtlich der genannten Parameter zu evaluieren. Zuvor müsste jedoch das verwendete Differenzierungsprotokoll hinsichtlich seiner Effektivität und Robustheit optimiert werden, um eine Population von Kardiomyozyten mit höherer Reinheit zu erhalten. 


\section{Zusammenfassung}

Herzkreislauf-Erkrankungen nehmen in den westlichen Industrieländern bezüglich Mortalität, Morbidität und volkswirtschaftlichen Kosten eine führende Rolle ein. Gleichzeitig ist die Herztransplantation die einzige kausale und ultimative Therapie der Herzmuskelschwäche. Im Rahmen dieser Arbeit wurde das bereits etablierte Modell des engineered heart muscle (EHM) verwendet und für die Anwendung als Allotransplantat in einem Großtiermodell (Rhesusaffe) vorbereitet. Dazu mussten Differenzierungsprotokolle zur Herstellung von Herzmuskelzellen aus induzierten pluripotenten Stammzellen des Rhesusaffen (riPSC) entwickelt werden. Hauptziel dieser Arbeit war somit zu untersuchen, ob funktionelle EHM aus von riPSC abgeleiteten Herzmuskelzellen hergestellt werden können und dabei typische kontraktile Eigenschaften des Herzens aufweisen.

Kardiomyozyten wurden durch gerichtete Differenzierung - über pharmako-logische Modulation des Wnt-Signalweges - aus riPSC gewonnen, durch metabolische Selektion aufgereinigt und bezüglich ihrer morphologischen und funktionellen Charakteristika mittels Immunfluoreszenzfärbungen und Aufzeichnung von Kalzium-Transienten analysiert. In einem zweiten Schritt wurden diese Kardiomyozyten genutzt, um nach einem bereits für Herzmuskelzellen anderer Abstammung etablierten Protokoll EHM durch Vermischung mit Kollagen Typ I Hydrogel herzustellen (Zimmermann et al. 2000). Deren funktionelle und morphologische Eigenschaften wurden durch Kontraktionskraftmessungen unter pharmakologischer Stimulation, Aktionspotentialanalysen und Immunfluoreszenzfärbungen untersucht.

Die durch Differenzierung gewonnenen Kardiomyozyten zeigten spontane Kontraktionen und über Immunfluoreszenzfärbungen konnten typische Proteine kardialer Sarkomere und deren charakteristische anisotrope Anordnung nachgewiesen werden. Eine elektrische Kopplung konnte durch synchronisierte Kalzium-Transienten verifiziert werden. Allerdings war die Differenzierung nur in 58\% der Durchläufe erfolgreich und erreichte mit einem Kardiomyozytenanteil von etwa 51\% eine eher geringe Reinheit. Die in dieser Arbeit generierten EHM zeigten eine positiv inotrope Reaktion bei einer Erhöhung der extrazellulären Kalziumkonzentration, jedoch auf einem im Vergleich $\mathrm{zu}$ anderen Publikationen relativ niedrigen Kraftniveau, mit einer maximalen durchschnittlichen Kontraktionskraftentwicklung von $0,23 \pm 0,02 \mathrm{mN}$ bei einer durch-schnittlichen

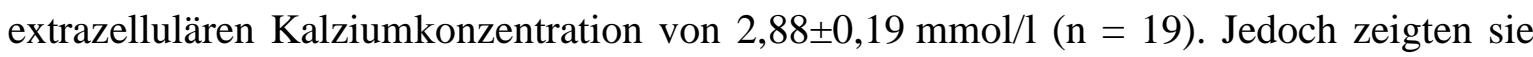


keine statistisch signifikante positiv inotrope Reaktion auf beta-adrenerge Stimulation mit Isoprenalin und kein Bowditch-Phänomen. Mittels Aktionspotential-analysen konnten typisch kardiale Aktionspotentiale nachgewiesen werden $(n=3)$. Zudem zeigten sich in den EHM kräftige, entlang ihrer Längsachse ausgerichtete Muskelbündel mit charakteristischer Querstreifung und einer weiteren Ausreifung der Sarkomere.

Die kardiale Differenzierung von hiPSC konnte bereits vielfach gezeigt werden (Paige et al. 2010; Lian et al. 2012; Streckfuss-Bömeke et al. 2013; Kadari et al. 2015), wohingegen Stammzellen nicht-humaner Primaten bisher wenig Beachtung auf diesem Feld fanden (Leschik et al. 2008; Blin et al. 2010; Wunderlich et al. 2012; Zhao et al. 2018). Die vorliegende Arbeit konnte zeigen, dass riPSC zu Kardiomyozyten differenziert und in der Herstellung von funktionellen EHM verwendet werden können. Diese wurden bereits aus einer Reihe von Zellen hergestellt, darunter neonatale Kardiomyozyten der Ratte (Zimmermann et al. 2000; Zimmermann et al. 2006) und differenzierte Kardiomyozyten aus parthenogenetischen Stammzellen (PSC) der Maus (Didié et al. 2013), humanen embryonalen Stammzellen (Soong et al. 2012) und hiPSC (Streckfuss-Bömeke et al. 2013, Tiburcy et al. 2017). Die hier produzierten EHM erfüllten drei von vier Kriterien, die Soong et al. (2012) für „humane EHM hoher Qualität“ aufstellten: Sie zeigten sichtbare, spontane Kontraktionen mit einer Frequenz von über 60 Schlägen pro Minute und erzeugten eine isometrische Kraft von über $0,2 \mathrm{mN}$ bei einer Kalziumkonzentration von $2 \mathrm{mmol} / \mathrm{l}$. Dabei blieben sie allerdings unter dem Kraftniveau anderer Arbeiten. Die Kraft pro Kardiomyozyt erreichte hingegen einen 2,2-fachen Wert von Kardiomyozyten, die von Riegler et al. (2015) aus hESC differenziert wurden. Zudem beinhalteten sie organisierte Muskelbündel aus anisotrop organisierten Sarkomeren. Sie zeigten allerdings keine positiv inotrope Reaktion auf die Stimulation mit Isoprenalin und erfüllten dieses Kriterium somit nicht. Über eine Anwendung in der Herzreparatur im Affenmodell soll in Zukunft geforscht werden. 


\section{Anhang}

Tabelle A1: Daten zur Beziehung zwischen extrazellulärer Kalziumkonzentration und entwickelter Kontraktionskraft.

\begin{tabular}{|c|c|c|}
\hline Kalziumkonzentration & Kontraktionskraft (mN) & Anzahl EHM (n) \\
\hline 0,2 & $0,09 \pm 0,02$ & 19 \\
\hline 0,4 & $0,10 \pm 0,01$ & 19 \\
\hline 0,8 & $0,14 \pm 0,02$ & 19 \\
\hline 1,2 & $0,16 \pm 0,02$ & 19 \\
\hline 1,6 & $0,20 \pm 0,02$ & 19 \\
\hline 2 & $0,20 \pm 0,03$ & 19 \\
\hline 2,4 & $0,21 \pm 0,02$ & 15 \\
\hline 2,8 & $0,21 \pm 0,03$ & 15 \\
\hline 3,2 & $0,22 \pm 0,03$ & 15 \\
\hline 3,6 & $0,22 \pm 0,03$ & 19 \\
\hline
\end{tabular}

EHM der Differenzierungen 12, 16-18 bei einer Kalziumkonzentration von 0,2 bis 2,4 mmol/l (EHM der Differenzierung 16, $\mathrm{n}=4$ ) bzw. bis 3,6 mmol/l (EHM der Differenzierungen 12, 17 und 18, $\mathrm{n}=15$ ). Messungen erfolgten unter isometrischen Bedingungen bei $37^{\circ} \mathrm{C}$ unter kontinuierlicher Begasung mit Carbogen $\left(95 \% \mathrm{O}_{2}, 5 \% \mathrm{CO}_{2}\right)$ für die Einstellung eines $\mathrm{pH}$-Wertes von 7,4 bei einer Stimulationsfrequenz von 1,5 Hz (beziehungsweise $2 \mathrm{~Hz}$ bei EHM aus der Kardiomyozyten Differenzierung 16). 
Tabelle A2: Ergebnisse der erfolgreichen Differenzierungsrunden.

\begin{tabular}{|c|c|c|c|c|c|c|c|}
\hline & $\begin{array}{l}\text { riPSC } \\
\text { (Mio.) }\end{array}$ & $\begin{array}{l}\text { Zellzahl } \\
\text { gesamt }\end{array}$ & Zellzahl lebend & $\begin{array}{c}\text { Anteil lebende } \\
\text { Zellen (\%) }\end{array}$ & $\begin{array}{c}\text { Kardiomyozyten } \\
\text { gesamt }\end{array}$ & $\begin{array}{l}\text { Anteil Kardio- } \\
\text { myozyten (\%) }\end{array}$ & $\begin{array}{l}\text { Output Kardio- } \\
\text { myozyten (\%) }\end{array}$ \\
\hline Diff.1 & 4 & 27.914 .286 & 9.770 .000 & 35 & 24.285 .429 & 87 & 607 \\
\hline Diff.7 & 4 & 20.781 .250 & 13.300 .000 & 64 & 10.432 .188 & 50 & 26 \\
\hline Diff.7 (T75) & 6 & 29.545 .455 & 9.750 .000 & 33 & 11.700 .000 & 40 & 195 \\
\hline Diff.9 & 4 & 25.686 .591 & 15.900 .000 & 62 & 15.900 .000 & 51 & 329 \\
\hline Diff.10 & 2 & 23.175 .000 & 9.270 .000 & 40 & 9.015 .075 & 39 & 451 \\
\hline Diff.16 & 6 & 62.037 .037 & 33.500 .000 & 54 & 30.073 .500 & 49 & 501 \\
\hline Diff.17 & 7 & 37.668 .161 & 16.800 .000 & 45 & 19.157 .200 & 51 & 274 \\
\hline
\end{tabular}

Dargestellt sind die Ergebnisse der Differenzierungsrunden 1, 2, 7, 7 (T75), 8, 9, 10, 16, 17, 17-3 und 18 (für Differenzierungsrunde 7 erfolgte eine getrennte Analyse für Standardkultur in T25-Kulturflaschen (Diff.7) und für Kultur in T75-Kulturflaschen (Diff.7 (T75)). Angegeben ist die Anzahl der eingesetzten riPSC (Mio.), die Gesamtanzahl der differenzierten Zellen, die Anzahl der lebenden differenzierten Zellen, die Gesamtanzahl der Kardiomyozyten sowie der Anteil lebender Zellen, der Kardiomyozytenanteil und der prozentuale Output an Kardiomyozyten bezogen auf die Anzahl eingesetzter riPSC der jeweiligen Differenzierungsrunde. 


\section{Literaturverzeichnis}

Alpert NR, Mulieri LA, Warshaw D (2002): The failing human heart. Cardiovasc Res $\underline{54}$, $1-10$

Brandt R, Chatterjee T, Dill T, Ernst S, Hamm C W, Kähler J, Köster R, Kuck K-H, Nienaber CA, Petzsch T et al.: Kardiologie. In: Bob A, Bob K (Hrsg.): Duale Reihe Innere Medizin. 3. Auflage; Thieme, Stuttgart 2013, 23-237

Bai XP, Zheng HX, Fang R, Wang TR, Hou XL, Li Y, Chen XB, Tian WM (2011): Fabrication of engineered heart tissue grafts from alginate/collagen barium composite microbeads. Biomed Mater $\underline{6}, 045002$

Ban K, Wile B, Kim S, Park H-J, Byun J, Cho K-W, Saafir T, Song M-K, Yu SP, Wagner M et al. (2013): Purification of Cardiomyocytes From Differentiating Pluripotent Stem Cells Using Molecular Beacons That Target Cardiomyocyte-Specific mRNA. Circulation $\underline{128}, 1897-1909$

Barresi MJ, D’Angelo JA, Hernández LP, Devoto SH (2001): Distinct mechanisms regulate slow-muscle development. Curr Biol 11, 1432-1438

Bensley JG, De Matteo R, Harding R, Black MJ (2016): Three-dimensional direct measurement of cardiomyocyte volume, nuclearity, and ploidy in thick histological sections. Sci Rep $\underline{6}, 23756$

Bergmann O, Bhardwaj RD, Bernard S, Zdunek S, Barnabe-Heider F, Walsh S, Zupicich J, Alkass K, Buchholz BA, Druid H et al. (2009): Evidence for Cardiomyocyte Renewal in Humans. Science 324, 98-102

Blin G, Nury D, Stefanovic S, Neri T, Guillevic O, Brinon B, Bellamy V, Rücker-Martin C, Barbry P, Bel A et al. (2010): A purified population of multipotent cardiovascular progenitors derived from primate pluripotent stem cells engrafts in postmyocardial infarcted nonhuman primates. J Clin Invest 120, 1125-1139

Baba HA, Kirkpatrick CJ, Wohlschläger J: Herz. In: Böcker W, Denk H, Heitz PU, Höfler G, Kreipe H, Moch H (Hrsg.): Pathologie. 5. Auflage; Urban \& Fischer/Elsevier, München 2012, 357-394

Bursac N, Papadaki M, Cohen RJ, Schoen FJ, Eisenberg SR, Carrier R, Vunjak-Novakovic G, Freed LE (1999): Cardiac muscle tissue engineering: toward an in vitro model for electrophysiological studies. Am J Physiol 277, H433-H444 
Chong JJH, Murry CE (2014): Cardiac regeneration using pluripotent stem cellsProgression to large animal models. Stem Cell Res $\underline{13}, 654-665$

Chong JJH, Yang X, Don CW, Minami E, Liu Y-W, Weyers JJ, Mahoney WM, Van Biber B, Cook SM, Palpant NJ et al. (2014): Human embryonic-stem-cell-derived cardiomyocytes regenerate non-human primate hearts. Nature 510, 273-277

Destatis (2017a): Diagnosedaten der Patienten und Patientinnen in Krankenhäusern (einschl. Sterbe- und Stundenfälle) 2016. Fachserie 12 Gesundheit; Reihe 6.2.1, 1-82. https://www.destatis.de/DE/Themen/Gesellschaft-Umwelt/Gesundheit/Krankenhaeuser/Pu blikationen/Downloads-Krankenhaeuser/diagnosedaten-krankenhaus-2120621167005.html ; abgerufen am 07.05.2020

Destatis (2017b): Krankheitskosten 2015. Fachserie 12 Gesundheit; Reihe 7.2.1, 1-31. https://www.destatis.de/GPStatistik/servlets/MCRFileNodeServlet/DEHeft_derivate_0003 3175/2120721159004.pdf\%3Bjsessionid\%3DB19129ECF3A61F8DB331D847FC4E599C; abgerufen am 07.05.2020

Destatis (2017c): Todesursachen in Deutschland 2015. Fachserie 12 Gesundheit; Reihe 4, 1-51. https://www.destatis.de/DE/Themen/Gesellschaft-Umwelt/Gesundheit/Todesursache n/Publikationen/Downloads-Todesursachen/todesursachen-2120400157004.pdf?_blob=p ublicationFile; abgerufen am 07.05.2020

Didié M, Christalla P, Rubart M, Muppala V, Döker S, Unsöld B, El-Armouche A, Rau T, Eschenhagen T, Schwoerer AP et al. (2013): Parthenogenetic stem cells for tissueengineered heart repair. J Clin Invest $\underline{123}, 1285-1298$

Dubois NC, Craft AM, Sharma P, Elliott DA, Stanley EG, Elefanty AG, Gramolini A, Keller G (2011): SIRPA is a specific cell-surface marker for isolating cardiomyocytes derived from human pluripotent stem cells. Nat Biotechnol 29, 1011-1018

Eschenhagen T, Fink C, Remmers U, Scholz H, Wattchow J, Weil J, Zimmermann W-H, Dohmen HH, Schäfer H, Bishopric N et al. (1997): Three-dimensional reconstitution of embryonic cardiomyocytes in a collagen matrix: a new heart muscle model system. FASEB J $\underline{11}, 683-694$

Eurotransplant International Foundation: Annual Report 2018 Eurotransplant International Foundation. Eurotransplant International Foundation, Den Haag 2018

Fink C, Ergün S, Kralisch D, Weil J, Eschenhagen T (2000): Chronic stretch of engineered heart tissue induces hypertrophy and functional improvement. FASEB J $\underline{14}$, 669-679 
Germanguz I, Sedan O, Zeevi-Levin N, Shtrichman R, Barak E, Ziskind A, Eliyahu S, Meiry G, Amit M, Itskovitz-Eldor J et al. (2011): Molecular characterization and functional properties of cardiomyocytes derived from human inducible pluripotent stem cells. J Cell Mol Med $\underline{15}, 38-51$

Glauner B (2006): Standardisierung der Vitalitätsbestimmung. BIOspektrum (Heidelb.) 15, 394-395

Hattori F, Chen H, Yamashita H, Tohyama S, Satoh Y, Yuasa S, Li W, Yamakawa H, Tanaka T, Onitsuka T et al. (2010): Nongenetic method for purifying stem cell-derived cardiomyocytes. Nat Methods $\underline{7}, 61-66$

Herold G (Hrsg.): Innere Medizin 2018. Gerd Herold, Köln 2018

Ichimura H, Shiba Y (2017): Recent Progress Using Pluripotent Stem Cells for Cardiac Regenerative Therapy. Circ J $\underline{81}$, 929-935

Kadari A, Mekala S, Wagner N, Malan D, Köth J, Doll K, Stappert L, Eckert D, Peitz M, Matthes J et al. (2015): Robust Generation of Cardiomyocytes from Human iPS Cells Requires Precise Modulation of BMP and WNT Signaling. Stem Cell Rev Rep $\underline{11}, 560$ 569

Karikkineth BC, Zimmermann W-H (2013): Myocardial tissue engineering and heart muscle repair. Curr Pharm Biotechnol $\underline{14}, 4-11$

Kattman SJ, Witty AD, Gagliardi M, Dubois NC, Niapour M, Hotta A, Ellis J, Keller G (2011): Stage-Specific Optimization of Activin/Nodal and BMP Signaling Promotes Cardiac Differentiation of Mouse and Human Pluripotent Stem Cell Lines. Cell Stem Cell $\underline{8}, 228-240$

Kehat I, Kenyagin-Karsenti D, Snir M, Segev H, Amit M, Gepstein A, Livne E, Binah O, Itskovitz-Eldor J, Gepstein L (2001): Human embryonic stem cells can differentiate into myocytes with structural and functional properties of cardiomyocytes. J Clin Invest $\underline{108}$, $407-414$

Kofidis T, Akhyari P, Boublik J, Theodorou P, Martin U, Ruhparwar A, Fischer S, Eschenhagen T, Kubis HP, Kraft T et al. (2002): In vitro engineering of heart muscle: Artificial myocardial tissue. J Thorac Cardiovasc Surg 124, 63-69

Korcarz CE, Padrid PA, Shroff SG, Weinert L, Lang RM (1997): Doppler echocardiographic reference values for healthy rhesus monkeys under ketamine hydrochloride sedation. J Med Primatol 26, 287-298 
Koyanagi M, Takahashi J, Arakawa Y, Doi D, Fukuda H, Hayashi H, Narumiya S, Hashimoto N (2008): Inhibition of the Rho/ROCK pathway reduces apoptosis during transplantation of embryonic stem cell-derived neural precursors. J Neurosci Res $\underline{86}, 270$ 280

Leor J, Aboulafia-Etzion S, Dar A, Shapiro L, Barbash IM, Battler A, Granot Y, Cohen S (2000): Bioengineered cardiac grafts a new approach to repair the infarcted myocardium? Circulation $\underline{102}$, III56-III61

Leschik J, Stefanovic S, Brinon B, Pucéat M (2008): Cardiac commitment of primate embryonic stem cells. Nat Protoc $\underline{3}, 1381-1387$

Li R-K, Jia Z-Q, Weisel RD, Mickle DA, Choi A, Yau TM (1999): Survival and function of bioengineered cardiac grafts. Circulation $\underline{100}$, II63-II69

Lian X, Hsiao C, Wilson G, Zhu K, Hazeltine LB, Azarin SM, Raval KK, Zhang J, Kamp TJ, Palecek SP (2012): Robust cardiomyocyte differentiation from human pluripotent stem cells via temporal modulation of canonical Wnt signaling. Proc Natl Acad Sci USA $\underline{109}$, E1848-E1857

Liaw NY, Zimmermann W-H (2016): Mechanical stimulation in the engineering of heart muscle. Adv Drug Deliv Rev $\underline{96}, 156-160$

Liu H, Zhu F, Yong J, Zhang P, Hou P, Li H, Jiang W, Cai J, Liu M, Cui K et al. (2008): Generation of Induced Pluripotent Stem Cells from Adult Rhesus Monkey Fibroblasts. Cell Stem Cell $\underline{3}, 587-590$

Liu Y-W, Chen B, Yang X, Fugate JA, Kalucki FA, Futakuchi-Tsuchida A, Couture L, Vogel KW, Astley CA, Baldessari A et al. (2018): Human embryonic stem cell-derived cardiomyocytes restore function in infarcted hearts of non-human primates. Nat Biotechnol $\underline{36}, 597-605$

Lu T-Y, Lin B, Kim J, Sullivan M, Tobita K, Salama G, Yang L (2013): Repopulation of decellularized mouse heart with human induced pluripotent stem cell-derived cardiovascular progenitor cells. Nat Commun $\underline{4}, 2307$

Lundy SD, Zhu W-Z, Regnier M, Laflamme MA (2013): Structural and Functional Maturation of Cardiomyocytes Derived from Human Pluripotent Stem Cells. Stem Cells Dev 22, 1991-2002

Meinertz T, Trappe H-J, Anders G, Andresen D, Gohlke H, Gummert J, Müller G, Oswalt I, Voigtländer T, Vestweber M et al.: Deutscher Herzbericht 201729. 
Bericht/Sektorenübergreifende Versorgungsanalyse zur Kardiologie, Herzchirurgie und Kinderherzmedizin in Deutschland. Deutsche Herzstiftung e.V., Frankfurt am Main 2018

Müller W, Gautier F (1975): Interactions of Heteroaromatic Compounds with Nucleic Acids A - T-Specific Non-Intercalating DNA Ligands. Eur J Biochem 54, 385-394

Noguchi R, Nakayama K, Itoh M, Kamohara K, Furukawa K, Oyama J, Node K, Morita S (2016): Development of a three-dimensional pre-vascularized scaffold-free contractile cardiac patch for treating heart disease. J Heart Lung Transplant $\underline{35}$, 137-145

Norol F, Merlet P, Isnard R, Sebillon P, Bonnet N, Cailliot C, Carrion C, Ribeiro M, Charlotte F, Pradeau P et al. (2003): Influence of mobilized stem cells on myocardial infarct repair in a nonhuman primate model. Blood 102, 4361-4368

Okahara-Narita J, Umeda R, Nakamura S, Mori T, Noce T, Torii R (2012): Induction of pluripotent stem cells from fetal and adult cynomolgus monkey fibroblasts using four human transcription factors. Primates $\underline{53}, 205-213$

Ott HC, Matthiesen TS, Goh S-K, Black LD, Kren SM, Netoff TI, Taylor DA (2008): Perfusion-decellularized matrix: using nature's platform to engineer a bioartificial heart. Nat Med 14, 213-221

Paige SL, Osugi T, Afanasiev OK, Pabon L, Reinecke H, Murry CE (2010): Endogenous Wnt/ $\beta$-Catenin Signaling Is Required for Cardiac Differentiation in Human Embryonic Stem Cells. PLoS One $\underline{5}$, e11134

Riegler J, Tiburcy M, Ebert A, Tzatzalos E, Raaz U, Abilez OJ, Shen Q, Kooreman NG, Neofytou E, Chen VC et al. (2015): Human engineered heart muscles engraft and survive long term in a rodent myocardial infarction model. Circ Res $\underline{117}, 720-730$

Romagnuolo R, Masoudpour H, Porta-Sánchez A, Qiang B, Barry J, Laskary A, Qi X, Massé S, Magtibay K, Kawajiri H, et al. (2019): Human Embryonic Stem Cell-Derived Cardiomyocytes Regenerate the Infarcted Pig Heart but Induce Ventricular Tachyarrhythmias. Stem Cell Rep $\underline{12}, 967-981$

Schrader J, Gödecke A, Kelm M: Das Herz. In: Klinke R, Pape H-C, Kurtz A, Silbernagl S (Hrsg.): Physiologie. 6. Auflage; Georg Thieme Verlag, Stuttgart 2010, 134-171

Sequeira V, van der Velden J (2015): Historical perspective on heart function: the FrankStarling Law. Biophys Rev $\underline{7}, 421-447$ 
Shiba Y, Fernandes S, Zhu W-Z, Filice D, Muskheli V, Kim J, Palpant NJ, Gantz J, Moyes KW, Reinecke H et al. (2012): Human ES-cell-derived cardiomyocytes electrically couple and suppress arrhythmias in injured hearts. Nature $\underline{489}, 322-325$

Shiba Y, Gomibuchi T, Seto T, Wada Y, Ichimura H, Tanaka Y, Ogasawara T, Okada K, Shiba N, Sakamoto K, et al. (2016): Allogeneic transplantation of iPS cell-derived cardiomyocytes regenerates primate hearts. Nature $\underline{538}, 388-391$

Shimizu T, Yamato M, Isoi Y, Akutsu T, Setomaru T, Abe K, Kibuchi A, Umezu M, Okano T (2002): Fabrication of Pulsatile Cardiac Tissue Grafts Using a Novel 3Dimensional Cell Sheet Manipulation Technique and Temperature-Responsive Cell Culture Surfaces. Circ Res $\underline{90}$, e40-e48

Sidhu K, Kim J, Chayosumrit M, Dean S, Sachdev P (2012): Alginate Microcapsule as a 3D Platform for Propagation and Differentiation of Human Embryonic Stem Cells (hESC) to Different Lineages. J Vis Exp 1ㅜ, 3608

Soong PL, Tiburcy M, Zimmermann W-H (2012): Cardiac Differentiation of Human Embryonic Stem Cells and their Assembly into Engineered Heart Muscle. Curr Protoc Cell Biol 55, 23.8.1-23.8.21

Streckfuß-Bömeke K, Wolf F, Azizian A, Stauske M, Tiburcy M, Wagner S, Hübscher D, Dressel R, Chen S, Jende J et al. (2013): Comparative study of human-induced pluripotent stem cells derived from bone marrow cells, hair keratinocytes, and skin fibroblasts. Eur Heart J 34, 2618-2629

Sun Y-B, Irving M (2010): The molecular basis of the steep force-calcium relation in heart muscle. J Mol Cell Cardiol $\underline{48}$, 859-865

Takahashi K, Yamanaka S (2006): Induction of Pluripotent Stem Cells from Mouse Embryonic and Adult Fibroblast Cultures by Defined Factors. Cell 126, 663-676

Takahashi K, Tanabe K, Ohnuki M, Narita M, Ichisaka T, Tomoda K, Yamanaka S (2007): Induction of Pluripotent Stem Cells from Adult Human Fibroblasts by Defined Factors. Cell $\underline{131}, 861-872$

Tanaka M, Chen Z, Bartunkova S, Yamasaki N, Izumo S (1999): The cardiac homeobox gene Csx/Nkx2. 5 lies genetically upstream of multiple genes essential for heart development. Development $\underline{126}, 1269-1280$

Taylor DA, Sampaio LC, Gobin A (2014): Building New Hearts: A Review of Trends in Cardiac Tissue Engineering. Am J Transplant 14, 2448-2459 
Tiburcy M, Zimmermann W-H (2013): Modeling myocardial growth and hypertrophy in engineered heart muscle. Trends Cardiovasc Med 24, 7-13

Tiburcy M, Didie M, Boy O, Christalla P, Doker S, Naito H, Karikkineth BC, ElArmouche A, Grimm M, Nose M et al. (2011): Terminal Differentiation, Advanced Organotypic Maturation, and Modeling of Hypertrophic Growth in Engineered Heart Tissue. Circ Res $\underline{109}, 1105-1114$

Tiburcy M, Hudson JE, Balfanz P, Schlick S, Meyer T, Chang Liao M-L, Levent E, Raad F, Zeidler S, Wingender E et al. (2017): Defined Engineered Human Myocardium With Advanced Maturation for Applications in Heart Failure Modeling and Repair. Circulation $\underline{135}, 1832-1847$

Tohyama S, Hattori F, Sano M, Hishiki T, Nagahata Y, Matsuura T, Hashimoto H, Suzuki T, Yamashita H, Satoh Y et al. (2013): Distinct Metabolic Flow Enables Large-Scale Purification of Mouse and Human Pluripotent Stem Cell-Derived Cardiomyocytes. Cell Stem Cell $\underline{12}, 127-137$

Tulloch NL, Muskheli V, Razumova MV, Korte FS, Regnier M, Hauch KD, Pabon L, Reinecke H, Murry CE (2011): Growth of Engineered Human Myocardium With Mechanical Loading and Vascular Coculture. Circ Res 109, 47-59

Uosaki H, Fukushima H, Takeuchi A, Matsuoka S, Nakatsuji N, Yamanaka S, Yamashita JK (2011): Efficient and Scalable Purification of Cardiomyocytes from Human Embryonic and Induced Pluripotent Stem Cells by VCAM1 Surface Expression. PLoS One $\underline{6}$, e23657 Watanabe K, Ueno M, Kamiya D, Nishiyama A, Matsumura M, Wataya T, Takahashi JB, Nishikawa S, Nishikawa S, Muguruma K et al. (2007): A ROCK inhibitor permits survival of dissociated human embryonic stem cells. Nat Biotechnol $\underline{25}, 681-686$

Wiegerinck RF, Cojoc A, Zeidenweber CM, Ding G, Shen M, Joyner RW, Fernandez JD, Kanter KR, Kirshbom PM, Kogon BE et al. (2009): Force Frequency Relationship of the Human Ventricle Increases During Early Postnatal Development. Pediatr Res $\underline{65}$, 414-419 Wunderlich S, Haase A, Merkert S, Beier J, Schwanke K, Schambach A, Glage S, Göhring G, Curnow EC, Martin U (2012): Induction of Pluripotent Stem Cells from a Cynomolgus Monkey Using a Polycistronic Simian Immunodeficiency Virus-Based Vector, Differentiation Toward Functional Cardiomyocytes, and Generation of Stably Expressing Reporter Lines. Cellular Reprogram 14, 471-484 
Wunderlich S, Kircher M, Vieth B, Haase A, Merkert S, Beier J, Göhring G, Glage S, Schambach A, Curnow EC et al. (2014): Primate iPS cells as tools for evolutionary analyses. Stem Cell Res 12, 622-629

Xu XQ, Zweigerdt R, Soo SY, Ngoh ZX, Tham SC, Wang ST, Graichen R, Davidson B, Colman A, Sun W (2008): Highly enriched cardiomyocytes from human embryonic stem cells. Cytotherapy $\underline{10}, 376-389$

Yanagawa B, Rao V, Yau TM, Cusimano RJ (2014): Potential myocardial regeneration with CorMatrix ECM: A case report. J Thorac Cardiovasc Surg 147, e41-e43

Zhao X, Chen H, Xiao D, Yang H, Itzhaki I, Qin X, Chour T, Aguirre A, Lehmann K, Kim $Y$ et al. (2018): Comparison of Non-human Primate versus Human Induced Pluripotent Stem Cell-Derived Cardiomyocytes for Treatment of Myocardial Infarction. Stem Cell Reports $\underline{10}, 422-435$

Zhang X, Cao H, Bai S, Huo W, Ma Y (2017): Differentiation and characterization of rhesus monkey atrial and ventricular cardiomyocytes from induced pluripotent stem cells. Stem Cell Res 20, 21-29

Zhong B, Trobridge GD, Zhang X, Watts KL, Ramakrishnan A, Wohlfahrt M, Adair JE, Kiem H-P (2010): Efficient generation of nonhuman primate induced pluripotent stem cells. Stem Cells Dev 20, 795-807

Zimmermann ME, Fuerstenau-Sharp M, Stark K, Jentsch N, Klingenstein M, Drzymalski M, Wagner S, Maier LS, Baessler A, Fischer M et al. (2015): Generation of Highly Purified Human Cardiomyocytes from Peripheral Blood Mononuclear Cell-Derived Induced Pluripotent Stem Cells. PLoS One 10, e0126596

Zimmermann WH (2009): Remuscularizing Failing Hearts with Tissue Engineered Myocardium. Antioxid Redox Signal 11, 2011-2023

Zimmermann WH, Eschenhagen T (2003): Cardiac tissue engineering for replacement therapy. Heart Fail Rev $\underline{8}, 259-269$

Zimmermann WH, Fink C, Kralisch D, Remmers U, Weil J, Eschenhagen T (2000): Threedimensional engineered heart tissue from neonatal rat cardiac myocytes. Biotechnol Bioeng $\underline{68}, 106-114$

Zimmermann WH, Didié M, Wasmeier GH, Nixdorff U, Hess A, Melnychenko I, Boy O, Neuhuber WL, Weyand M, Eschenhagen T (2002a): Cardiac grafting of engineered heart tissue in syngenic rats. Circulation $\underline{106}, \mathrm{I} 151-\mathrm{I} 157$ 
Zimmermann WH, Schneiderbanger K, Schubert P, Didié M, Münzel F, Heubach J, Kostin S, Neuhuber WL, Eschenhagen T (2002b): Tissue Engineering of a Differentiated Cardiac Muscle Construct. Circ Res $\underline{90}$, 223-230

Zimmermann WH, Melnychenko I, Eschenhagen T (2004): Engineered heart tissue for regeneration of diseased hearts. Biomaterials $\underline{25}, 1639-1647$

Zimmermann WH, Melnychenko I, Wasmeier G, Didié M, Naito H, Nixdorff U, Hess A, Budinsky L, Brune K, Michaelis B et al. (2006): Engineered heart tissue grafts improve systolic and diastolic function in infarcted rat hearts. Nat Med $\underline{12}, 452-458$ 


\section{Danksagung}

Meinen besonderen Dank möchte ich Herrn Prof. Dr. med. Wolfram-Hubertus Zimmermann für die Vergabe der Promotionsarbeit und die herausragende fachliche Anleitung und geduldige, zuverlässige und freundliche Unterstützung bei der Ausarbeitung der Promotion aussprechen.

Des Weiteren danke ich allen Mitarbeitern des Instituts für Pharmakologie und Toxikologie der Medizinischen Fakultät der Universität Göttingen, die mich in meiner Arbeit unterstützt und mit Rat und Tat zur Seite standen, insbesondere PD Dr. Michael Didié, der mir zu Beginn der Arbeit als Betreuer zur Seite stand. Zudem möchte ich hier explizit Dr. Brian Golat, Dr. Satish Galla und Dr. M.L. Chang Liao nennen, die mich ebenfalls in besonderer Weise unterstützten.

Zudem bedanke ich mich für die finanzielle Förderung im Rahmen eines Promotionsstipendiums durch das German Centre for Cardiovascular Research. Zudem möchte ich mich für die langjährige finanzielle und ideelle Förderung durch die Studienstiftung des Deutschen Volkes bedanken. 